INSTITUTO DE PESQUISAS ENERGÉTICAS E NUCLEARES

Autarquia associada à Universidade de São Paulo

ESTUDO DOS EFEITOS DA RADIAÇÃO GAMA NO POLIETILENO LINEAR DE BAIXA DENSIDADE (PELBD) INJETADO

ANA CLAUDIA FEITOZA DE OLIVEIRA

Dissertação apresentada como parte dos requisitos para obtenção do grau de Mestre em Ciências na Área de Tecnologia Nuclear - Materiais

Orientador: Dr ${ }^{\mathrm{a}}$ Duclerc Fernandes Parra

São Paulo 
Aos meus pais Maria José e José Feitosa, pela compreensão e amor incondicional.

A minhas irmãs Aline e Andreia, pelo carinho e incentivo.

A meus parentes Maria da Guia, Marcos Antônio, avó Maria do Carmo, por estarem sempre presentes na minha vida.

A meus avós Quitéria, Cícero e Geraldo (in memorian). 


\section{AGRADECIMENTOS}

A Deus pelas inúmeras bênçãos que recebo a cada instante de minha vida, dentre elas a oportunidade de ter acesso aos conhecimentos acadêmicos.

A Dra. Duclerc Fernandes Parra e ao Dr. Hélio Fernando Rodrigues Ferreto pela orientação e paciência em compartilharem seus conhecimentos.

Ao Instituto de Pesquisas Energéticas e Nucleares (IPEN) pela oportunidade de realização dos experimentos.

A Comissão Nacional de Energia Nuclear (CNEN) pela bolsa BMT concedida.

A BRASKEM pelo fornecimento das amostras de polietileno linear de baixa densidade (PELBD).

A professora Dra. Ticiane Sanches Valera e o Técnico Kleber Vaccioli do laboratório de processos de materiais poliméricos (Departamento de Engenharia de Materiais e Metalurgia - Poli-USP) pela injeção dos corpos de prova.

A CBE/EMBRARAD pela irradiação das amostras.

A Heloísa Zen, pelo auxílio no manuseio do equipamento de reologia.

Ao Eleosmar Gasparin, pelos ensaios de análise térmica.

A Dra. Maria Claudia, Telma Carolina, Dr. Washington Oliani pelo auxílio no manuseio do aparelho de Difração de Raios-X.

Ao Rodrigo do laboratório de célula combustível pela análise no infravermelho. 
Ao Dr. Rodolfo Politano do laboratório CCTM pelos ensaios de análise termodinâmico-mecânica.

Ao Edson Takeshi, Henrique Ferreira, Ludmila Pozzo, pela amizade.

Aos colegas do Centro de Química e Meio Ambiente pelo apoio e amizade.

Aos professores do Ensino e da Escola Politécnica por contribuir com minha formação.

A Comissão de Pós Graduação pelo esclarecimento de dúvidas durante o curso de mestrado.

Ao Dr. José Seneda pelas sugestões de apresentação da dissertação.

A Banca Examinadora Dra. Ticiane Sanches Valera e ao Dr. Filipe Carvalho Pedroso de Lima pelas sugestões para esta dissertação. Aos suplentes Dra. Sandra Regina Scagliusi Martin, Dr. Washington Luiz Oliani e a Dra. Harumi Otaguro pelo aceite do convite. 


\title{
ESTUDO DOS EFEITOS DA RADIAÇÃO GAMA NO POLIETILENO LINEAR DE BAIXA DENSIDADE (PELBD) INJETADO
}

\author{
ANA CLAUDIA FEITOZA DE OLIVEIRA
}

\begin{abstract}
RESUMO
O uso do método de esterilização por radiação gama ajuda na redução da contaminação microbiológica. O polietileno linear de baixa densidade (PELBD) é um polímero de cadeias lineares e ramificações curtas. Neste trabalho o PELBD injetado foi irradiado por uma fonte de ${ }^{60} \mathrm{Co}$ com $2000 \mathrm{kCi}$ de atividade, na presença de ar, em doses de 5, 10, 20, 50 ou 100 kGy e taxas de dose de cerca de $5 \mathrm{kGy} \cdot \mathrm{h}^{-1}$ em temperatura ambiente $\left(25^{\circ} \mathrm{C}\right)$. Após a irradiação, foi necessário submeter as amostras a um tratamento térmico em uma estufa por 60 min a $100{ }^{\circ} \mathrm{C}$ para a recombinação e aniquilação dos radicais residuais. Na sequência as amostras injetadas foram irradiadas e caracterizadas para identificar os efeitos de degradação térmica, cisão e reticulação em cada dose. Verificou-se uma degradação térmica da resina ao passar pelo processo de modelagem por injeção confirmada pela análise de FTIR. Os PELBD injetados irradiados nas doses de 5 , 10 ou 20 kGy tiveram maior tendência a cisão do que aqueles nas doses de 50 ou 100 kGy, nos quais predominou a reticulação. Desta forma determinaram-se os efeitos da irradiação e do processo nos PELBD moldados por injeção.
\end{abstract}




\title{
STUDY OF EFFECTS GAMMA RADIATION LINEAR LOW DENSITY POLYETHYLENE (LLDPE) INJECTED
}

ANA CLAUDIA FEITOZA DE OLIVEIRA

\begin{abstract}
The use of the method of sterilization by gamma radiation helps in reducing microbiological contamination. The linear low density polyethylene (LLDPE) is a linear polymer chain with short chain branching. In this work, the LLDPE were irradiated in ${ }^{60} \mathrm{Co}$ gamma source with $2000 \mathrm{kCi}$ of activity, in presence of air, with doses of $5,10,20,50$ or $100 \mathrm{kGy}$, at about $5 \mathrm{kGy} \cdot \mathrm{h}^{-1}$ dose rate, at room temperature. After irradiation, the samples were heated for $60 \mathrm{~min}$ at $100{ }^{\circ} \mathrm{C}$ to promote recombination and annihilation of residual radicals. In the sequence LLDPE injected samples were irradiated and characterized to identity the effects of terminal degradation, scission end crosslinking occurred in each dose. There was a thermal degradation of the resin through the process of injection molding confirmed by FTIR analysis. And LLDPE injected irradiated at doses of 5, 10 or $20 \mathrm{kGy}$ has a greater tendency to scission than those at doses of 50 or $100 \mathrm{kGy}$, where predominated crosslinking consequently the effects of irradiation and injection molding were investigated in LLDPE processed.
\end{abstract}




\section{SUMÁRIO}

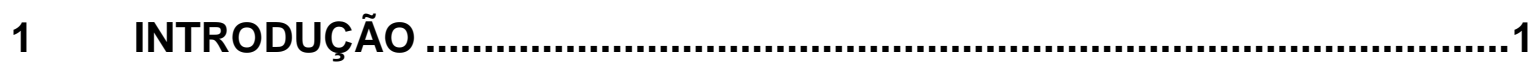

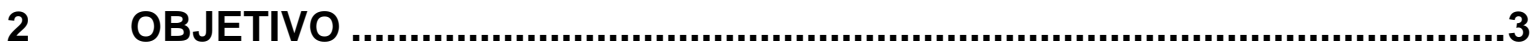

3 REVISÃO BIBLIOGRÁFICA ............................................................4

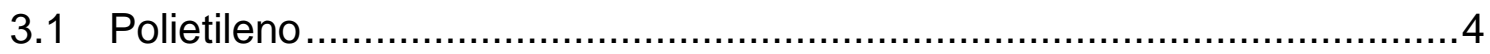

3.1.1 Polietileno linear de baixa densidade (PELBD) ...........................

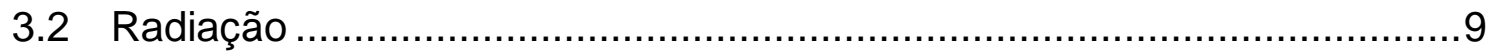

3.3 Modificação na estrutura do polietileno. ...................................... 12

3.4 Interação da radiação com o polímero ................................................ 14

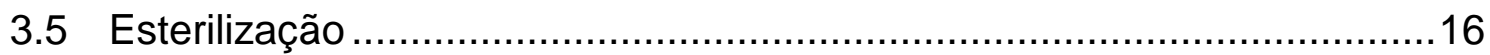

4 MATERIAIS E MÉTODOS ...................................................................24

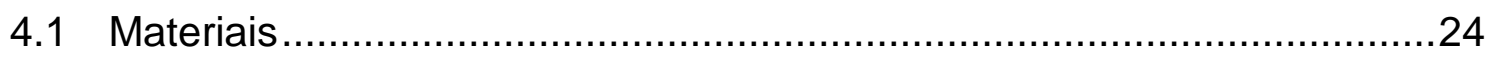

4.1.1 Polietileno linear de baixa densidade (PELBD) ...........................24

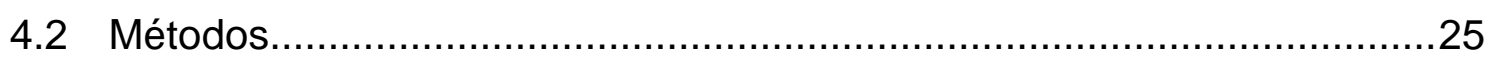

4.2.1 Procedimento da preparação das amostras................................. 25

4.2.2 Preparação do material para irradiação e o tratamento pós-irradiação26

4.2.3 Caracterização dos materiais ................................................ 26

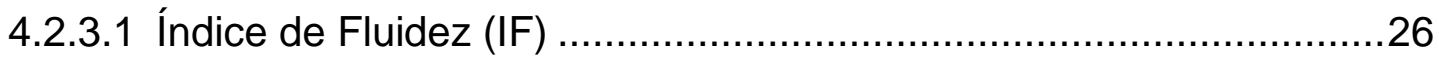

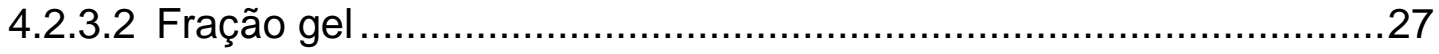

4.2.3.3 Espectroscopia na região do Infravermelho por Transformada de

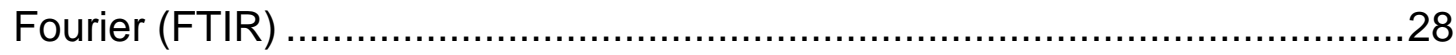

4.2.3.4 Análises por Calorimetria exploratória diferencial (DSC) ................29

4.2.3.5 Difração de Raios X (DRX) ............................................... 31

4.2.3.6 Análise de termogravimetria (TG) ........................................ 32

4.2.3.7 Análise termodinâmico-mecânica (DMA) .................................33

4.2.3.8 Reometria de placas paralelas............................................. 34 
4.2.3.9 Ensaios mecânicos .37

$5 \quad$ RESULTADOS E DISCUSSÕES 38

5.1 PELBD processado antes da irradiação...................................... 38

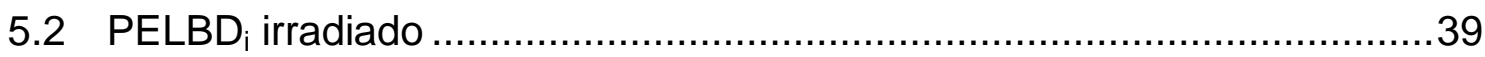

5.3 PELBD $_{\mathrm{i}}$ irradiado após tratamento térmico ....................................40

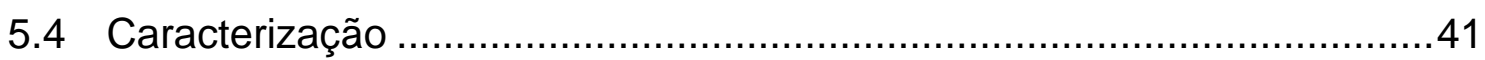

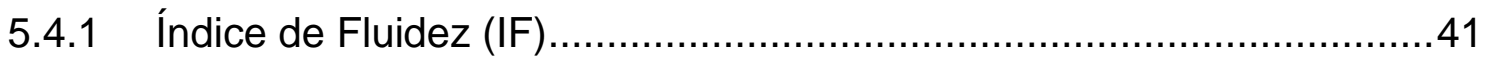

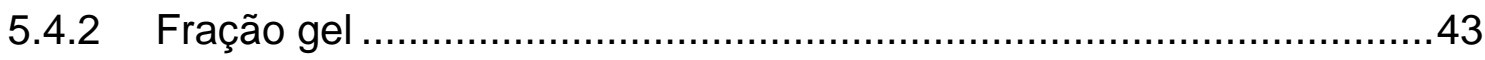

5.4.3 Análise no Infravermelho por Transformada de Fourier (FTIR)..........45

5.4.4 Análises por Calorimetria exploratória diferencial (DSC) ................48

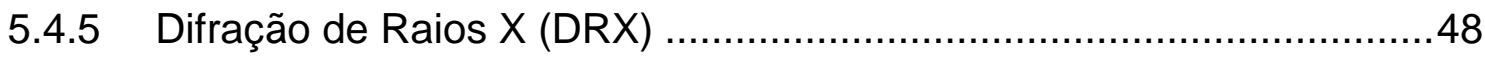

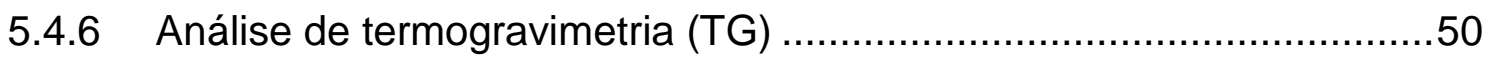

5.4.7 Análise termodinâmico-mecânica (DMA) ................................... 53

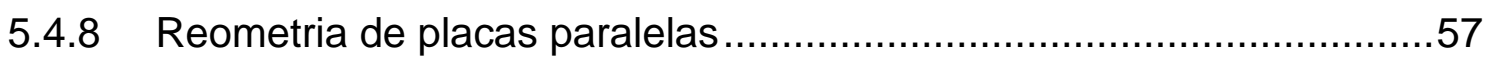

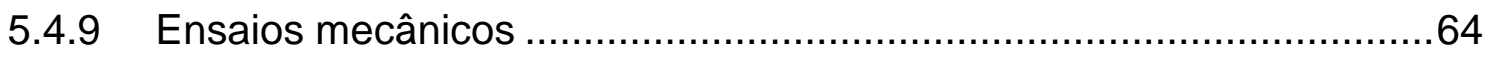

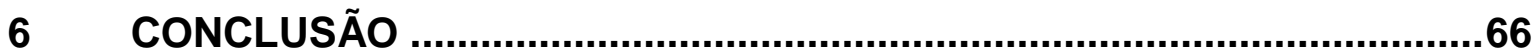

APÊNDICE A - $1^{\circ}$ ANÁLISE DE DRX DO PELBD, NAS DOSES DE 0, 5, 10, 20 , 50 OU 100 KGY......................................................................................68

APÊNDICE B - $2^{\circ}$ ANÁLISE DE DRX DO PELBD, NAS DOSES DE 0, 5, 10, 20, 50 OU 100 KGY. ....................................................................................69

APÊNDICE C - $3^{\circ}$ ANÁLISE DE DRX DO PELBD, NAS DOSES DE 0, 5, 10, 20,

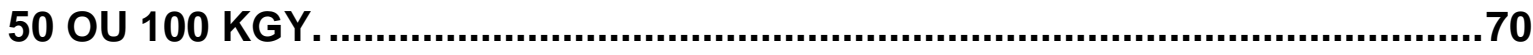

REFERÊNCIAS BIBLIOGRÁFICAS..............................................................78 


\section{ÍNDICE DE FIGURAS}

FIGURA 1- Modelo de morfologia "Cadeias dobradas". 5

FIGURA 2- Modelo de morfologia "Miscela Franjada". .7

FIGURA 3 - Representação da estrutura molecular do polietileno. (a) Modelo da cadeia polimérica. (b) Modelo da célula unitária. 7

FIGURA 4 - Transferência de energia de fonte radioativa para o elétron: ionização (a) e excitação (b). 10

FIGURA 5 - Decaimento do isótopo radioativo cobalto-60 (34).

FIGURA 6 - Formação de ligações cruzadas pela formação de pontes silano (38).

FIGURA 7 - Classificação dos polímeros de acordo com a sua tendência em interagir com a radiação ionizante: reticular (a) degradar (b) ${ }^{(32)}$

FIGURA 8 - Possíveis reações das interações do polímero com a radiação ionizante ${ }^{(9)(30)}$.

FIGURA 9 - Formas de ligações cruzadas. Tipo H (a) e Tipo T (b) ${ }^{(9)}$. 15

FIGURA 10 - Aspecto da resina de PELBD. .24

FIGURA 11 - Máquina Injetora 25

FIGURA 12 - PELBD ${ }_{i}$ no saco de nylon para irradiação (a) e PELBD ${ }_{i}$ após irradiação para tratamento térmico na estufa (b).

FIGURA 13 - Aparelho CEAST IFM.

FIGURA 14 - Determinação de fração gel. Sistema em refluxo (a) e amostras de PELBD $_{i}$ embaladas para a extração (b). 
FIGURA 15 - Espectrômetro no infravermelho, marca da Thermo Nicolet, modelo Nexus 6700 FTIR.

FIGURA 16 - Equipamento Mettler Toledo DSC 822 (a). Prensa para fechamento da cápsula (b). 30

FIGURA 17 - Representação esquemática do fenômeno de difração ${ }^{(69)}$. 31

FIGURA 18 - Aparelho de Difração de Raios X (DRX), marca Rigaku, modelo Miniflex II. .32

FIGURA 19 - Mettler Toledo, Modelo TGA 851e SDTGA. Vista externa (a) Vista interna com a haste de sustentação do conjunto formado por estribo e cadinho (b). .33

FIGURA 20 - Vista do equipamento analisador DMA da marca Netzsch (a) Montagem da amostra para flexão em 3 pontos (b).

FIGURA 21 - Vista do equipamento reômetro oscilatório modelo MCR 300, da Physica (a). Montagem da amostra no equipamento (b) (c). .35

FIGURA 22 - Ensaio controle de varredura de deformação do $P E L B D_{i}$ não irradiado.

FIGURA 23 - Máquina universal de ensaios EMIC (a). Corpo de prova montado no equipamento (b). Rompimento do corpo de prova (c).

FIGURA 24 - Amostras de PELBD ${ }_{i}$ antes da irradiação em forma de discos e gravatas.

FIGURA 25 - PELBD i irradiado. (a) 5 kGy. (b) 10 kGy. (c) 20 kGy. (d) 50 kGy. (e) 100 kGy. (f) Comparação do PELBDi (0, 5, 10, 20, 50 ou 100 kGy).

FIGURA 26 - PELBD i após ser colocado na estufa. (a) 5 kGy. (b) 10 kGy. (c) 20 kGy. (d) 50 kGy. (e) 100 kGy. (f) PELBD não irradiado e irradiado.

FIGURA 27 - Amostras obtidas no processo de análise de índice de fluidez do PELBD. (a) 0 kGy. (b) 5 kGy. (c) 10 kGy. 
FIGURA 28 - Índice de fluidez do PELBD, resina, injetado e irradiado em função da dose de radiação

FIGURA 29 - Porcentagem de inchamento do PELBD, resina, injetado e irradiado em função da dose de radiação.

FIGURA 30 - Aspecto do gel da análise de fração gel do PELBD . (a) 50 kGy (b) 100 kGy.

FIGURA 31 - Fração gel do PELBD, resina, injetado e irradiado em função da dose de radiação.

FIGURA 32 - Espectros FT-IR da resina PELBD entre 500 e $4000 \mathrm{~cm}^{-1}$. .45

FIGURA 33- Espectros FTIR do PELBD ${ }_{i}$ irradiado com doses de 0, 5, 10, 20, 50 ou $100 \mathrm{kGy}$ entre 500 e $4000 \mathrm{~cm}^{-1}$. 46

FIGURA 34 - Detalhe no intervalo de 1250 a $1750 \mathrm{~cm}^{-1}$ dos Espectros FT-IR do PELBD $_{i}$ (a) e da resina (b).

FIGURA 35 - Ensaio controle do $P E L B D_{i}$ não irradiado na análise de DRX. 49

FIGURA 36 - Porcentagem de cristalinidade por DRX e DSC do $P E L B D_{i}$ não irradiado e irradiado com diferentes doses.

FIGURA 37 - TG-DTG em função da temperatura do PELBD ${ }_{i}$ obtido com doses de 0 kGy e resina (R) (a), 5 kGy (b), 10 kGy (c), 20 kGy (d), 50 kGy (e) e 100 kGy (f).

FIGURA 38 - Porcentagem de decomposição do PELBD resina, injetado e irradiado em função da temperatura.

FIGURA 39 - Curvas de módulo de perda (E”) em função da temperatura. .54

FIGURA 40 - Dissipação de energia (Tan $\delta$ ) em função da temperatura. 54

FIGURA 41 - Análise termodinâmico-mecânica (DMA) do PELBD ${ }_{i}$ não irradiado e irradiado. 
FIGURA 42 - Altura do pico (Tan $\delta$ - fundo exponencial) em função da dose de irradiação. .56

FIGURA 43 - Temperatura do pico (Tan $\delta$ - fundo exponencial) em função da dose de irradiação. 56

FIGURA 44 - Módulos de cisalhamento (G 'e G") em função da frequência........59

FIGURA 45 - Gráficos da Razão entre as curvas G" e G'. 60

FIGURA 46 - Variação da frequência angular em função da dose de radiação....61

FIGURA 47 - PELBD 50 kGy na análise de reologia. .57

FIGURA 48 - Resultado obtido do PELBD i irradiado com doses (a) 50 kGy (b) 100 kGy após término da análise de reologia.

FIGURA 49 - Análise de reologia do PELBD i obtido com dose de 100 kGy. .58

FIGURA 50 - Viscosidade complexa em função da taxa de cisalhamento. .62

FIGURA 51 - Viscosidade complexa em função da frequência das amostras irradiadas. 63

FIGURA 52- Resultado de teste de tração, força em função do tempo para $P E L B D_{i}$ não irradiado e irradiado.

FIGURA 53 - Tensão de ruptura e Deformação do PELBD i não irradiado e irradiado em função das doses de radiação. .65 


\section{ÍNDICE DE TABELAS}

TABELA 1 - Características de operação e propriedades dos polietilenos obtidos pelo processo em solução ${ }^{(4)}$

TABELA 2 - Características de operação e propriedades dos polietilenos obtidos pelo processo em lama ${ }^{(4)}$

TABELA 3 - Características de operação e propriedades dos polietilenos obtidos pelo processo em fase gasosa ${ }^{(4)}$

TABELA 4 - Doses de radiação gama que resultam em danos nas estruturas microbiológicas ${ }^{(46)}$ :

TABELA 5 - Embalagens de produtos farmacêuticos e alimentícios utilizadas nos processos de esterilização.

TABELA 6 - Embalagens de produtos ortopédicos submetidas a processos de esterilização.

TABELA 7 - Embalagens de produtos farmacêuticos submetidas a processos de esterilização.

TABELA 8 - Embalagens de produtos médico-hospitalares submetidas a processos de esterilização.

TABELA 9 - Especificações do PELBD tipo LH-820/30AF, fornecido pela BRASKEM

TABELA 10 - Especificações do processo de injeção das amostras. 25

TABELA 11 - Valores de temperatura de fusão, entalpia de fusão e cristalinidade obtidos por (DSC). 


\title{
LISTA DE ABREVIAÇÕES, ACRÔNIMOS E SÍMBOLOS.
}

\author{
Á -Angstrom
}

ABNT.NBR- Associação Brasileira de Normas Técnicas

ABS- Acrilonitrila butadieno estireno

Al- alumínio

ASTM- American Society for Testing and Materials

a.C.- antes de Cristo

a- alfa

$\beta$ - beta

BRASKEM- Empresa petroquímica

${ }^{\circ} \mathrm{C}$ - graus Celsius

${ }^{\circ} \mathrm{C} \cdot \mathrm{min}^{-1}$ - graus Celsius por minuto

CBE/Embrarad - Empresa Brasileira de Radiação

CCTM- Centro de Ciência e Tecnologia dos Materiais

CFR- Code of Federal Regulations

$-\mathrm{CH}_{2}$ - grupo metileno

$\mathrm{CH}_{3}$ - butila

$\mathrm{CO}_{2}$ - gás carbônico

$-\mathrm{C}=\mathrm{O}-$ carbonila

-C=C- ligação dupla entre carbonos

${ }^{59}$ Co- cobalto 59

${ }^{60} \mathrm{Co}$ - cobalto 60

${ }^{137} \mathrm{Cs}$ - Césio

CQMA- Centro de Química e Meio Ambiente

d - distância interplanar

$D_{p}$ - diâmetro da amostra após o teste de IF

DMA- Análise termodinâmico-mecânica

DNA- ácido desoxirribonucleico

DPM- distribuição do peso molecular

DSC - Calorimetria Exploratória Diferencial

DRX- Difração de Raios X 
DTG- Termogravimetria derivativa

E'- módulo de armazenamento

E" - módulo de perda

EMIC - Equipamentos e Sistemas de Ensaios Ltda.

FAO- Organização das Nações Unidas para a Agricultura e Alimentação

FDA- food and drug administration

FTIR- Espectroscopia na região do infravermelho por transformada de Fourier $\gamma$-gama

G' - módulo de armazenamento de cisalhamento

G" - módulo de perda de cisalhamento

g. $\min ^{-1}$ - gramas por minuto

g.cm ${ }^{-3}$ - grama por centímetro cúbico

g.mol ${ }^{-1}$ - grama por mol

$\Delta \mathrm{H}_{0}$ - variação de entalpia de fusão do polietileno $100 \%$ cristalino

$\Delta \mathrm{H}_{\mathrm{f}}$ - variação de entalpia de fusão da amostra

Hz- Hertz

${ }_{2}^{4} \mathrm{He}^{+2}-$ núcleos de hélio

IF- índice de fluidez

IPEN- Instituto de Pesquisas Energéticas e Nucleares

IR- região do infravermelho

J.g $\mathrm{g}^{-1}$ - Joule por grama

kCi- desintegrações por segundo

kg- quilograma

kGy- quilo Gray

Kv- quilo volt

mA- miliampere

mg- miligrama

$\mathrm{mg} \cdot \mathrm{min}^{-1}$ - miligrama por minuto

$\mathrm{mL} \cdot \mathrm{min}^{-1}$ - mililitro por minuto

min- minuto

mm- milímetro

MAO- co-catalisador metilaluminoxano 
MeV- mega elétron volt

$M_{f}$ - massa final

$\mathrm{M}_{\mathrm{i}}$ - massa inicial de cada amostra

$\mathrm{MPa}$ - mega Pascal

$\left|\eta^{*}\right|$ - módulo de viscosidade complexa

$\mu \mathrm{m}$ - micrometro

$\mathrm{Ni}$ (II)- níquel (II)

${ }^{60} \mathrm{Ni}$ - isótopo níquel 60

$\mathrm{N}$ - Newton

nm- nanômetros

$\mathrm{O}_{2}$ - oxigênio

PC- policarbonato

Pd (II)- paládio

PE- polietileno

PEAD - polietileno de alta densidade

PEBD - polietileno de baixa densidade

PELBD - polietileno linear de baixa densidade

$P E L B D_{i}$ - polietileno linear de baixa densidade injetado

PEUAPM- polietileno de ultra alto peso molecular

PM- peso molecular

PP- polipropileno

PS- poliestireno

\%- porcentagem

$\mathrm{R}$ - resina de polietileno linear de baixa densidade

S- segundo

${ }^{90} \mathrm{Sr}$ - Estrôncio

SAL- sterility assurance level

TG - Análise de Termogravimetria

$\mathrm{T}_{\mathrm{f}}$ - temperatura de fusão

$\mathrm{T}_{\mathrm{g}}$ - temperatura de transição vítrea

$\mathrm{T}_{\mathrm{m}}$ - temperatura de fusão cristalina de polímeros semicristalinos

Tan $\delta$ - dissipação de energia 
UV- ultravioleta

$\mathrm{X}_{\mathrm{C}}(\%)$ - porcentagem de cristalinidade por DSC

W (\%)- porcentagem de cristalinidade por DRX

$\omega$ - frequência angular

$\mu \mathrm{L}$-microlitro 


\section{INTRODUÇÃO}

Os polímeros podem ser de origem natural ou sintética, sendo formados a partir de um ou mais tipos de monômeros, por reações de adição ou condensação. Os polímeros parcialmente cristalinos são constituídos por duas fases distintas: cristalitos pequenos, de aproximadamente $100 \AA$, e dispersos numa matriz amorfa ${ }^{(1),-(2)}$. O alto peso molecular e a estrutura química dos materiais poliméricos são os principais responsáveis pelas suas boas propriedades e pela sua utilização em inúmeras aplicações ${ }^{(3)}$. São materiais que podem ser degradados biologicamente.

No caso do polietileno, dependendo das condições reacionais e do sistema catalítico empregado na polimerização, tipos diferentes podem ser produzidos, sendo os mais comuns, polietileno de baixa densidade (PEBD), polietileno de alta densidade (PEAD) e polietileno linear de baixa densidade (PELBD) ${ }^{(4),}{ }^{(5)}$. O polietileno é utilizado em diferentes segmentos da indústria de transformação de plásticos, abrangendo os processamentos de prensagem, moldagem por injeção e por sopro.

O polietileno linear de baixa densidade (PELBD) é um termoplástico com elevada capacidade de selagem a quente, sendo muito utilizado em embalagens de gêneros de primeira necessidade ${ }^{(4)}$. Esse polímero é parcialmente cristalino, flexível e sintetizado a partir do etileno por um processo de polimerização por coordenação aniônica em condições de baixa pressão e temperatura. O PELBD apresenta estrutura molecular de cadeias lineares com ramificações curtas ${ }^{\left({ }^{6}\right)}$.

O desenvolvimento das técnicas nucleares que se seguiu após a segunda guerra mundial veio renovar as aplicações dos materiais poliméricos. O conhecimento da interação da radiação com a matéria permitiu a modificação desses materiais com vantagens em relação à manipulação química tradicional ${ }^{(7)}$. 
A radiação gama apresenta uma alta penetração nos materiais poliméricos provocando o aparecimento de radicais livres. Esses radicais podem recombinar entre si, com o oxigênio do ar ou promover a reticulação entre cadeias poliméricas ${ }^{(8),(9)}$. As duas reações que causam as maiores alterações nas propriedades de um polímero são: a cisão e a reticulação ${ }^{(10)}$.

O tratamento com radiação ionizante está se tornando um processo comum para a esterilização de diversificados produtos e por isso necessita-se cada vez mais o desenvolvimento de embalagens adequadas a esse processo. Entretanto as embalagens podem ser irradiadas antes ou depois de embalar 0 produto (11) (12). Os polímeros que constituem as embalagens podem ser termoplásticos na forma de filmes ou laminados em multicamadas. Contudo, para adequar o polímero à aplicação pretendida são necessárias modificações em sua estrutura que garantam a sua integridade e a esterilidade sejam regulamentadas. 


\section{OBJETIVO}

Este trabalho tem como objetivo avaliar as alterações provocadas por processo de moldagem e irradiação na estrutura química e as propriedades do PELBD injetado, irradiado com radiação gama em diferentes doses, por meio de métodos de caracterização comerciais.

Contribuir para o entendimento da interação da radiação gama com o polietileno linear de baixa densidade para predição das propriedades do polímero enquanto utilizado nas indústrias de esterilização, transformação e reciclagem.

Para isso utilizam-se as técnicas índice de fluidez, fração gel, análise no infravermelho por transformada de Fourier, análise por calorimetria exploratória diferencial, difração de raios $x$, análise termogravimétrica, análise termodinâmicomecânica, reometria de placas paralelas e ensaios mecânicos na caracterização do PELBD injetado e irradiado. Em seguida comparam-se os resultados obtidos entre si juntamente com os dados obtidos da caracterização da resina de PELBD. Considera-se apenas a caracterização da resina por técnicas que não exigem amostras moldadas. 


\section{REVISÃO BIBLIOGRÁFICA}

A seguir serão comentados alguns tópicos relevantes sobre o polímero, a radiação e a relação entre eles, conforme encontrado na literatura. O objetivo é obter um conhecimento prévio de conceitos para uma melhor compreensão da pesquisa.

\subsection{Polietileno}

O polietileno foi sintetizado acidentalmente em 1898, quando o químico alemão Hans Von Pechmann aquecia diazometano. Obteve uma substância branca similar a cera colada nas paredes do recipiente, com grandes cadeias de $-\mathrm{CH}_{2}$-. Em 1933 Eric Fawcett e Reginald Gibson também analisaram um material similar a cera retido nas paredes de um recipiente que continha etileno e benzaldeído, quando submetidos a altas pressões. No entanto, a reação tinha sido desencadeada por vestígios de oxigênio contido no recipiente ${ }^{(13) .}$ Em 1939 iniciou-se a produção comercial do polietileno de baixa densidade (PEBD), um material polimérico altamente ramificado, produzido via radicais livres iniciados pelo oxigênio do ar em altas pressões ${ }^{(14)}$.

Por volta de 1950 pesquisadores em três diferentes laboratórios, na "Standard e Oil of Indiana" (1951-Zletz), na "Phillips Petroleum" (1953- Hogan e Banks) e no "Max Planck Institut fur Kohlenforschung" (1953- Ziegler, Breil, Martin e Holzkamp) independentemente descobriram diferentes catalisadores para a polimerização do etileno, sendo assim produzido pela primeira vez o polietileno de alta densidade (PEAD) em $1955^{\text {(15). }}$

Na década de 50 foram obtidos cristais de polietileno a partir de soluções muito diluídas. Por difração de elétrons nos cristais verificou-se que as cadeias poliméricas estavam orientadas perpendicularmente ao plano. A possibilidade de dobramento foi proposta por Robertson (1965) ao verificar que a espessura das plaquetas era da ordem de 10 a $20 \mathrm{~nm}$ e o comprimento das cadeias era da ordem de $10^{2}$ a $10^{3} \mathrm{~nm}$ que indicava realmente a conformação dobrada (FIG. 1). 
Essas plaquetas foram nomeadas como lamelas e o crescimento do cristal acontece por adição sucessiva das cadeias dobradas ${ }^{(16)(17)}$.

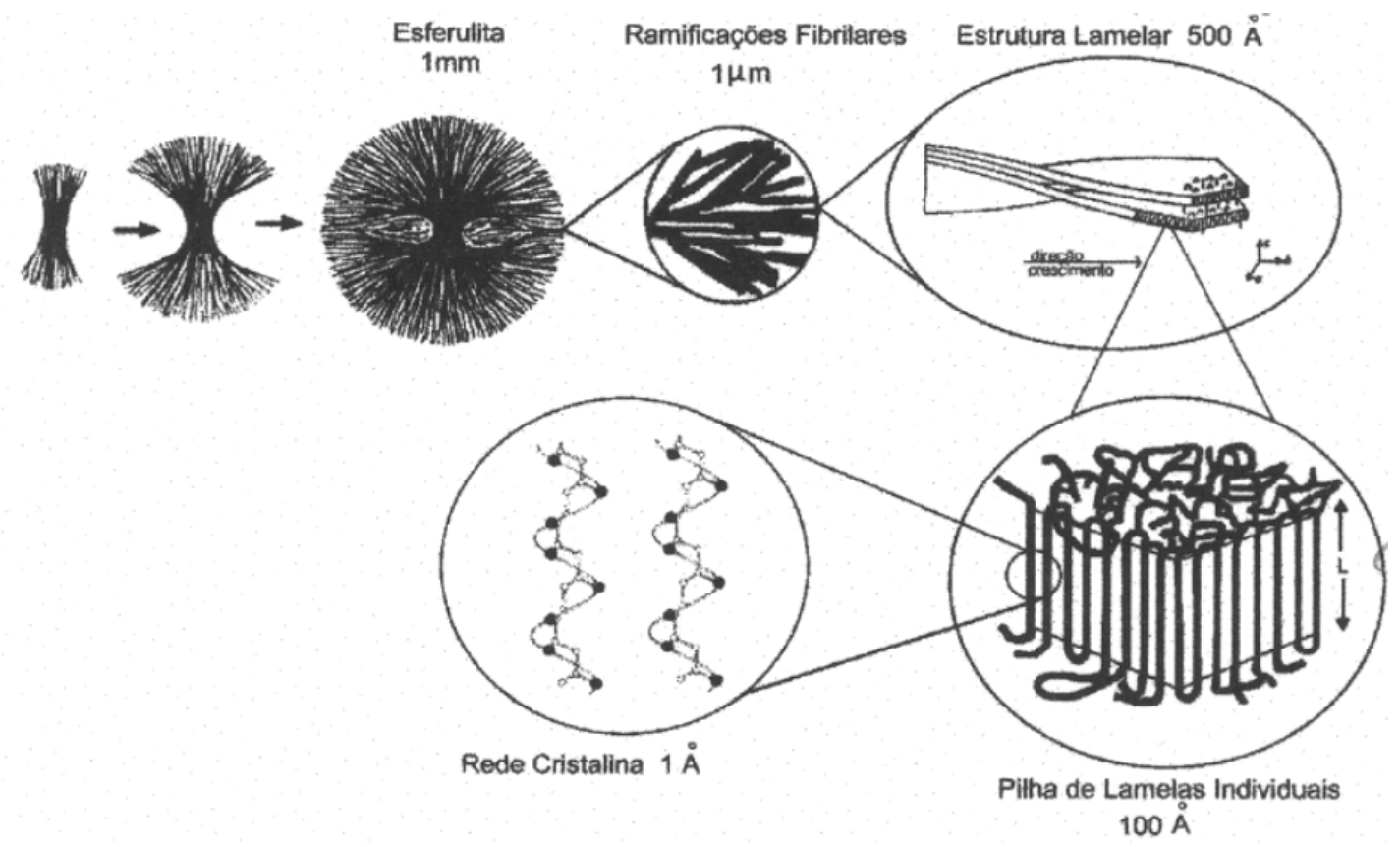

FIGURA 1- Modelo de morfologia "Cadeias dobradas".

Com o advento desses catalisadores os processos de polimerização de olefinas começaram a ser efetuados sob pressões menores sendo que os produtos apresentam menos ramificações. Em 1970 foi introduzido o PELBD através da copolimerização com a-olefinas utilizando reatores de fase gasosa, reatores com processo em solução ou reatores de fase lama ${ }^{(18)}$.

Os catalisadores homogêneos à base de metalocenos que apresentam cocatalisador metilaluminoxano (MAO) foram desenvolvidos na década de 1980 sendo mais ativos e específicos e produzindo polímeros com propriedades especiais. A função desses catalisadores é atuar no controle da microestrutura do polímero ${ }^{(19)}$.

Devido à possibilidade dos compostos MAO promoverem contaminações do produto da reação de polimerização intensificaram-se os estudos em sistemas catiônicos livres de compostos de $\mathrm{Al}^{(20)}$. 
Em 1993, a Dow Química introduziu os catalisadores homogêneos (metalocênicos) de geometria restrita para produzir polietilenos com alfa-olefina do tipo 1-octeno que permitiram criar no polietileno linear de baixa densidade uma mistura controlada de ramificações curtas e longas na cadeia principal ${ }^{(21)}$.

Em 1995, as áreas de polimerização de etileno e a-olefinas foram revigoradas com a descoberta de novos catalisadores derivados de Ni (II) e Pd (II) capazes de converter etileno e a-olefinas em polímeros com altas massas moleculares e microestruturas específicas ${ }^{(22)}$.

A partir de 2007, a Braskem começou a desenvolver e vem aprimorando a tecnologia de produção de eteno verde e polietileno verde a partir do etanol. Em 2012, a empresa foi vencedora do Prêmio FINEP - Agência Brasileira da Inovação, na categoria 'Inovação Sustentável' com o polietileno verde que é produzido no Polo Petroquímico de Triunfo, no Rio Grande do Sul (23).

A microestrutura da cadeia dos copolímeros de etileno alfa-olefinas depende do tipo e da distribuição do comonômero usado, da quantidade de ramificações e do peso molecular dos polímeros. Esses parâmetros influenciam as propriedades físicas do polímero, pois atuam diretamente na cristalinidade e na morfologia ${ }^{(24)}$.

Sabe-se que o polietileno cristaliza em uma estrutura de cadeia dobrada com célula ortorrômbica. Seu grau de cristalinidade em polímeros lineares parcialmente cristalizados varia de 5 a $95 \%$ do volume total. A cristalização completa não é atingível, devido ao seu arranjo molecular emaranhado e cruzado ${ }^{(25)}$.

Segundo o modelo da teoria Miscela Franjada os polímeros semicristalinos são constituídos por duas fases distintas: cristalitos pequenos, de aproximadamente $100 \AA$, e dispersos numa matriz amorfa formando uma série de regiões ordenadas e desordenadas ao longo do comprimento da molécula de polímero (FIG. 2). Esse modelo de morfologia considera que um polímero nunca 
poderá se tornar $100 \%$ cristalino, pois durante a cristalização os segmentos de cadeias localizados nas regiões amorfas ficam tencionados, não podendo se cristalizar posteriormente ${ }^{(1)}$.

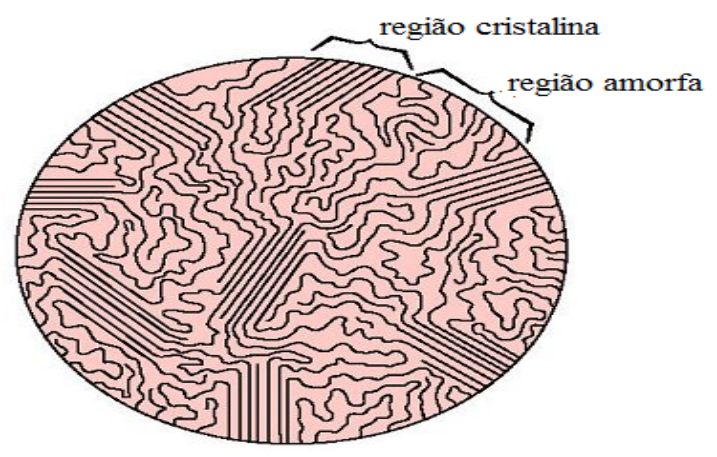

FIGURA 2- Modelo de morfologia "Miscela Franjada".

A estrutura do polietileno é constituída pela repetição do monômero - $\left(\mathrm{CH}_{2}\right)$ n- e finalizada com grupo $\mathrm{CH}_{3}$, obedecendo uma conformação planar de zig-zag (FIG. 3). O comprimento entre as ligações de carbono é aproximadamente $1,54 \times 10^{-7} \mu \mathrm{m}$ com um ângulo de ligação a cerca de $109,5^{\circ}$ (26) (27).

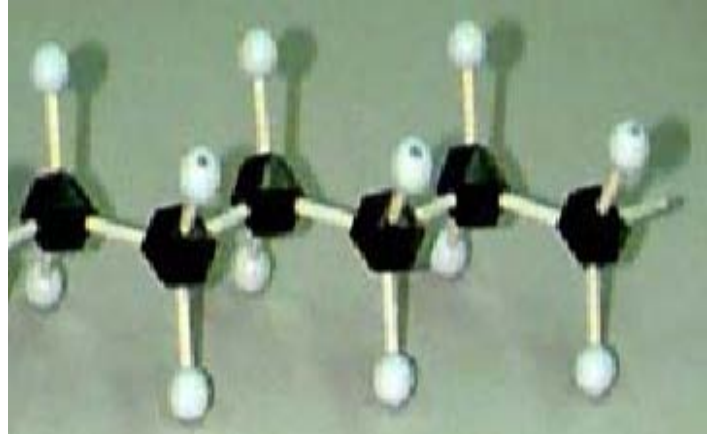

(a)

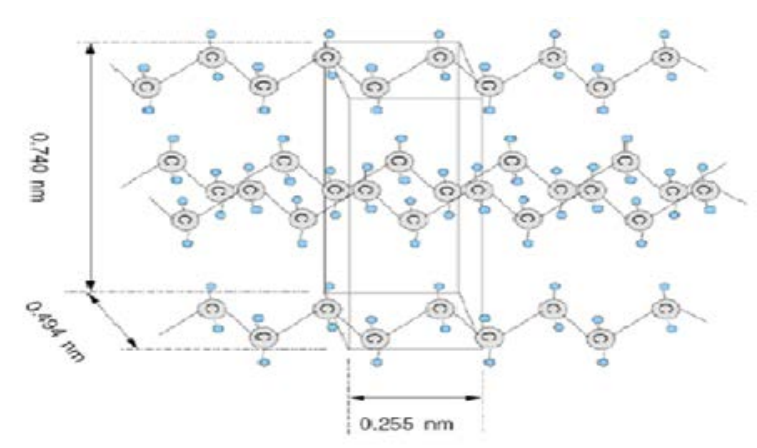

(b)

FIGURA 3 - Representação da estrutura molecular do polietileno. (a) Modelo da cadeia polimérica. (b) Modelo da célula unitária.

O grau de polimerização (número de meros na cadeia polimérica) do polietileno fica entre 3.500 e 25.000 , com uma massa molecular variando entre 100.000 e $700.000 \mathrm{~g} \cdot \mathrm{mol}^{-1(25)}$. 
O tipo de catalisador empregado na polimerização tem um efeito significativo sobre a distribuição das ramificações de cadeias curtas. Essa distribuição é função da estrutura e dos centros ativos do catalisador além das condições de polimerização ${ }^{(4)}$.

\subsubsection{Polietileno linear de baixa densidade (PELBD)}

Os PELBD constituem uma classe de polietilenos com cadeias lineares contendo somente ramificações de cadeia curta devido à inserção de uma a-olefina durante as reações de copolimerização com o eteno. As a-olefinas comumente utilizadas são o 1-buteno, o 1-hexeno e o 1-octeno ${ }^{(6)}{ }^{(18)}$. Os principais processos de polimerização do PELBD são processos em solução, dispersão ou lama e fase gasosa.

A produção de PELBD pelo processo em solução opera com as condições de processamento descritas na TAB. 1.

TABELA 1 - Características de operação e propriedades dos polietilenos obtidos pelo processo em solução ${ }^{(4)}$.

\begin{tabular}{ll}
\hline Processo & Em solução \\
Características de operação & \\
Tipo de reator & RPA \\
Matéria prima & etileno, hidrogênio, comonômero, catalisador \\
Catalisador & Ziegler-Natta ou metalocênico \\
Pressão de polimerização (MPa) & 3,5 \\
Temperatura reacional $\left({ }^{\circ} \mathrm{C}\right)$ & acima de 150 \\
Polimerização & coordenação \\
Fase da reação & solvente \\
Propriedades & \\
Densidade $\left(\mathrm{g} \cdot \mathrm{cm}^{-3}\right)$ & entre 0,89 e 0,96 \\
Distribuição de Massa Molecular & entre 3,4 e 30 \\
\hline
\end{tabular}

As condições de processamento de polimerização em dispersão ou lama apresentam-se na TAB. 2. 
TABELA 2 - Características de operação e propriedades dos polietilenos obtidos pelo processo em lama ${ }^{(4)}$.

\begin{tabular}{|c|c|}
\hline $\begin{array}{l}\text { Processo } \\
\text { Características de operação }\end{array}$ & Em lama \\
\hline Matéria prima & $\begin{array}{l}\text { etileno, hidrogênio, } \\
\text { catalisador e cocatalisador }\end{array}$ \\
\hline Catalisador & Ziegler-Natta, base cromo ou metalocênicos \\
\hline Pressão de polimerização (MPa) & abaixo de 2 \\
\hline Temperatura reacional $\left({ }^{\circ} \mathrm{C}\right)$ & abaixo de 90 \\
\hline Polimerização & dispersão ou lama \\
\hline Propriedades & \\
\hline Densidade $\left(\mathrm{g} . \mathrm{cm}^{-1}\right)$ & 0,91 e 0,96 \\
\hline Distribuição de Massa Molecular & 3,5 e 30 \\
\hline
\end{tabular}

No processo em fase gasosa as condições de polimerização estão na TAB. 3.

TABELA 3 - Características de operação e propriedades dos polietilenos obtidos pelo processo em fase gasosa ${ }^{(4)}$.

\begin{tabular}{|c|c|}
\hline $\begin{array}{l}\text { Processo } \\
\text { Características de operação }\end{array}$ & Fase gasosa \\
\hline Matéria prima & $\begin{array}{l}\text { etileno, hidrogênio, comonômero, } \\
\text { catalisador e cocatalisador }\end{array}$ \\
\hline Comonômero & 1-propeno, 1-buteno ou 1-hexeno \\
\hline Catalisador & $\begin{array}{l}\text { Ziegler-Natta, base } \quad \text { cromo } \\
\text { metalocênicos }\end{array}$ \\
\hline Pressão de polimerização (MPa) & 2,4 \\
\hline Temperatura reacional $\left({ }^{\circ} \mathrm{C}\right)$ & abaixo de 15 \\
\hline Polimerização & fase gasosa \\
\hline Propriedades & \\
\hline Densidade $\left(\mathrm{g} \cdot \mathrm{cm}^{-3}\right)$ & entre 0,91 e 0,96 \\
\hline Teor de incorporação alfa-olefinas (\%) & 9 \\
\hline
\end{tabular}

\subsection{Radiação}

A radioatividade começou a ser estudada em 1896 por Henri Becquerel com a descoberta das emissões de raios x do urânio. Anos depois, em 1919 Ernest Rutherford descobriu que átomos radioativos desintegravam emitindo 
partículas- $\alpha$ ou partículas- $\beta$ transformando-se em outro elemento químico. Em 1938 Fermi recebe o premio Nobel pela descoberta da utilização de nêutron na produção de isótopos radioativos ${ }^{(9)(28)}$. Anos antes da descoberta do nêutron, W. Bothe e $\mathrm{H}$. Becker demonstraram que o Berílio quando bombardeado por partículas- $\alpha$ do polônio emitia uma radiação muito penetrante chamada de radiação gama ${ }^{(29)}$.

As fontes de radiação podem ser naturais como os isótopos radioativos radônio e rádio ou artificiais como ${ }^{90} \mathrm{Sr},{ }^{137} \mathrm{Cs}$ e o ${ }^{60} \mathrm{Co}$ (radiação gama) e os aceleradores (feixes de elétrons). Todas essas fontes transferem energia para os átomos do material. Quando essa transferência de energia é maior que a energia do elétron, este será ejetado ionizando o átomo. Mas quando essa energia não é suficientemente alta para a ionização, o elétron é transferido para um nível superior de energia, resultando numa excitação, FIG. $4^{(9)(30)}$.

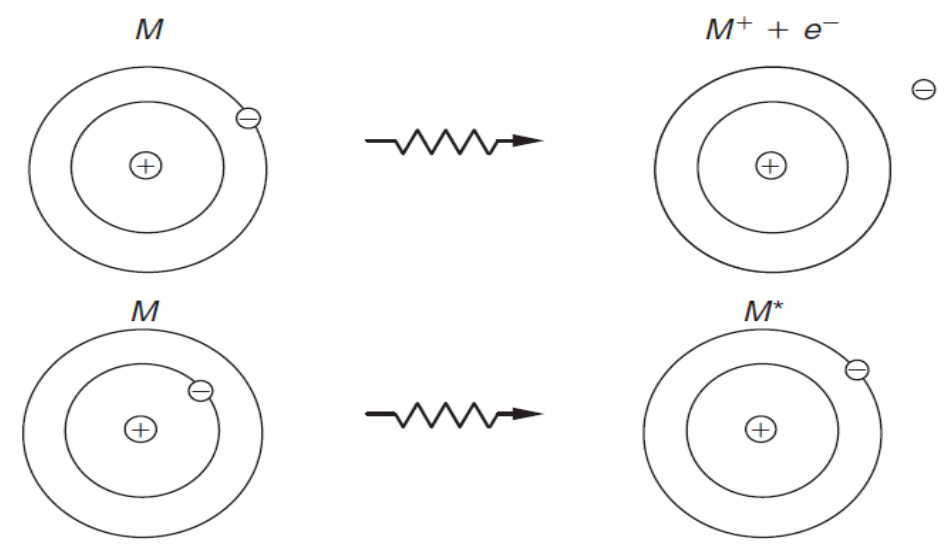

FIGURA 4 - Transferência de energia de fonte radioativa para o elétron: ionização (a) e excitação (b).

A seguir serão abordados os tipos de radiação e as interações com a matéria.

As radiações menos penetrantes como $\alpha$ (alfa), $\beta$ (beta) ou elétrons de baixa energia são utilizadas quando se pretende irradiar a camada superficial da amostra. As partículas alfa são núcleos de hélio, ${ }_{2}^{4} \mathrm{He}^{2+}$, emitidas por núcleos radioativos que são características do decaimento de radioisótopos. Essas partículas perdem energia rapidamente ao atravessar líquidos ou sólidos. Em 
gases a penetração é maior e seu alcance depende da densidade do meio e pressão ${ }^{(31)}$.

As partículas $\beta$ são emitidos por núcleos radioativos. Essas partículas $\beta$ de um mesmo elemento radioativo não são todas emitidas com a mesma energia, mas com energia diferentes que variam de zero até um valor máximo que é característico do elemento. Ao passarem através da matéria, as partículas $\beta$ perdem energia, devido a colisões inelásticas com elétrons. Entretanto como as partículas $\beta$ têm a mesma massa dos elétrons, perdem mais da metade da sua energia em uma única colisão e podem ser defletidas em grandes ângulos ${ }^{(9)}$.

Os nêutrons por não possuírem carga, não produzem ionização direta na matéria, mas interagem quase exclusivamente com o núcleo atômico. Os nêutrons podem penetrar nos materiais de espessura maior, em consequência a irradiação com nêutrons não é limitada às regiões superficiais do absorvedor ${ }^{(32)}$.

Os raios gama $(\gamma)$ são radiações eletromagnéticas de origem nuclear, sem carga e sem massa. Os raios y gerados pelo decaimento radioativo interagem com as moléculas da matéria através de elétrons secundários. Estes raios interagem com a matéria por três processos principais: o efeito fotoelétrico, espalhamento Compton e a produção de pares. Com energia de 100 a 1 MeV o espalhamento Compton é o principal mecanismo de absorção, em que um y-fóton incidente perde energia suficiente para ejetar um elétron em um átomo da matéria irradiada, e o restante de sua energia é emitida como um novo fóton com menor energia $^{(32)(31)}$.

A fonte utilizada para este trabalho é de ${ }^{60}$ Co que é produzido artificialmente pela irradiação do ${ }^{59} \mathrm{Co}$ em reator nuclear. $\mathrm{O}{ }^{60} \mathrm{Co}$ decai para $\mathrm{O}$ estado de ${ }^{60} \mathrm{Ni}$ emitindo uma partícula $\beta$ negativa com uma meia-vida de aproximadamente 5,27 anos ${ }^{(9)}$. O estado excitado do ${ }^{60} \mathrm{Ni}$ decai mais uma vez para se estabilizar emitindo dois fótons com energias de 1,173 e 1,333 MeV,

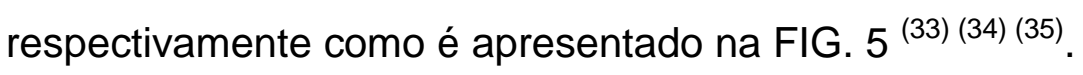




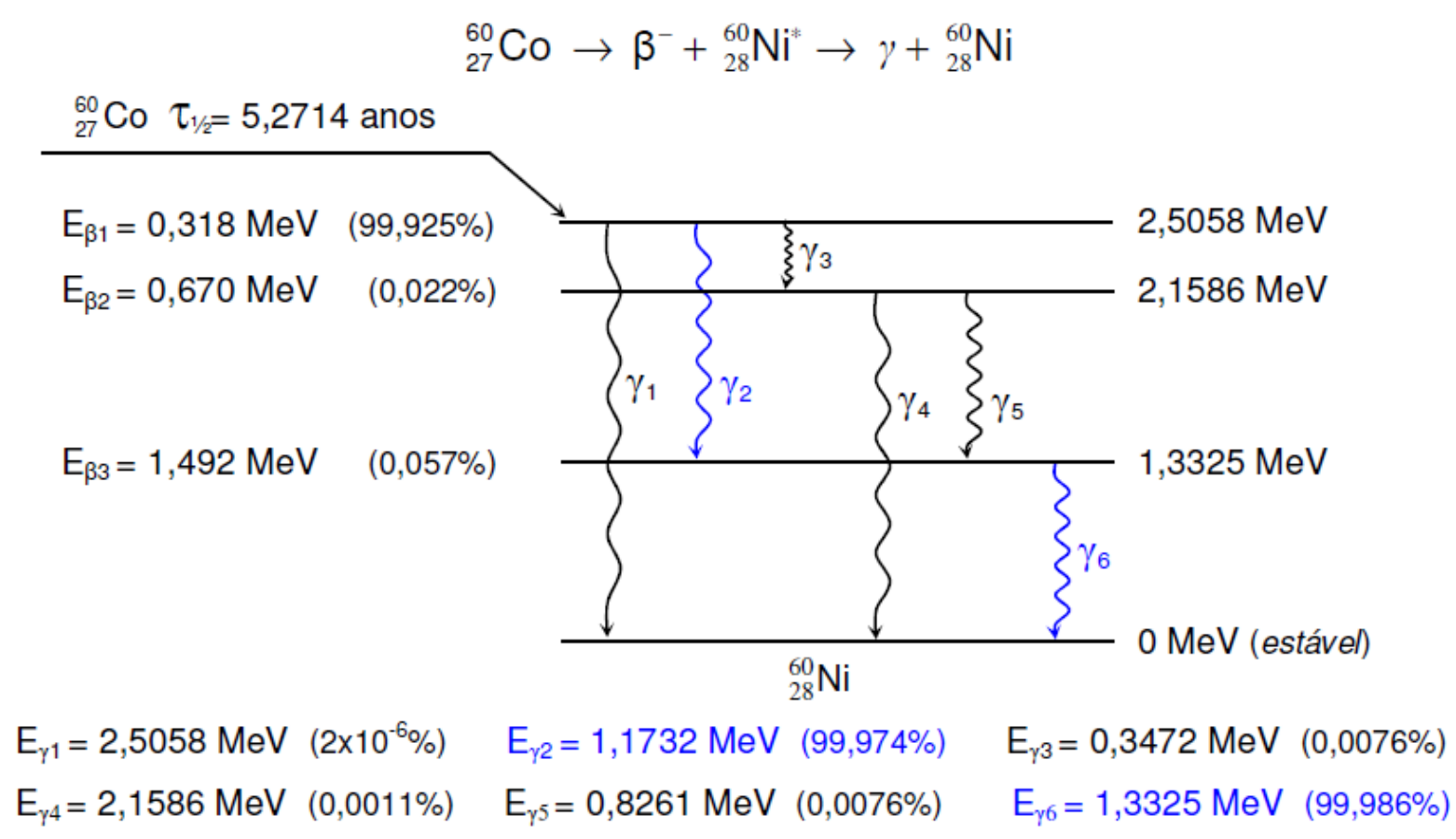

FIGURA 5 - Decaimento do isótopo radioativo cobalto-60 ${ }^{(34)}$.

\subsection{Modificação na estrutura do polietileno.}

A reticulação consiste na formação de uma rede entre as cadeias de um ou mais polímeros através de ligações covalentes ou iônicas. Para esse efeito podem existir dois tipos de reticulação na fase amorfa, um por adição de um agente reticulante sendo considerada reticulação química, e outro por meio da interação da radiação ionizante com o polímero sendo considerada reticulação física (36) (37).

A reticulação do PELBD pode ser efetuada por meio de processo de extrusão reativa, envolvendo a enxertia de silanos vinílicos na cadeia polimérica com a formação de ligações cruzadas no polímero via formação de pontes siloxano $^{(38)}$, FIG. 6. 

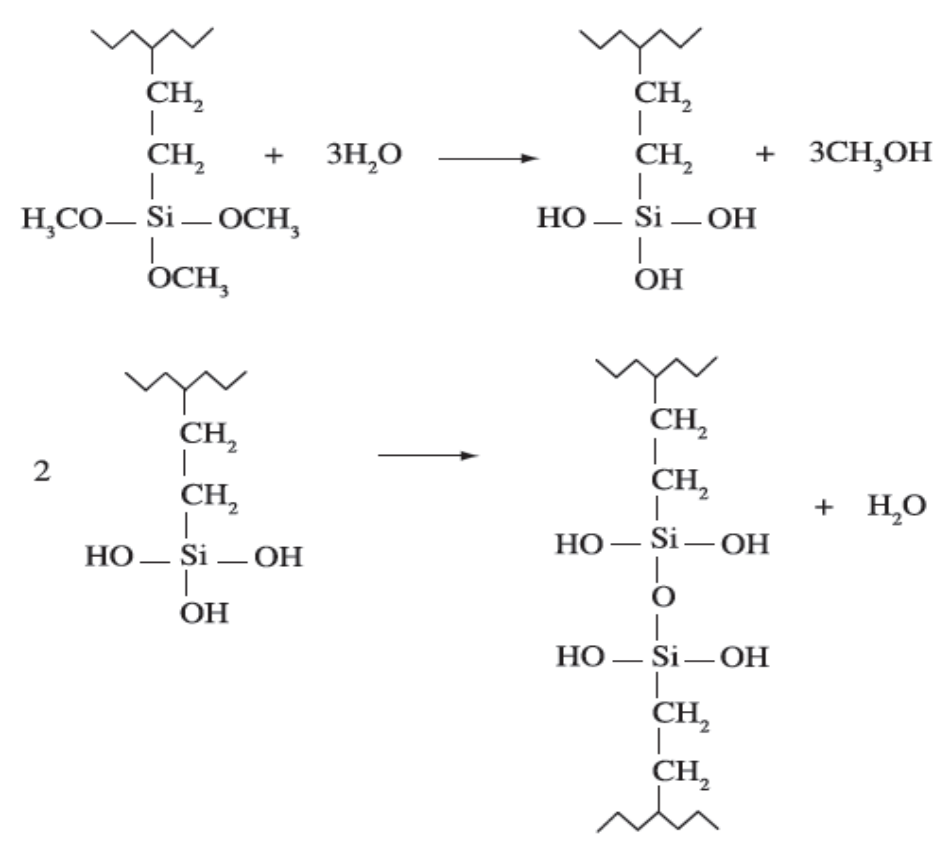

FIGURA 6 - Formação de ligações cruzadas pela formação de pontes silano ${ }^{(38) .}$

A estrutura molecular do PELBD também pode ser modificada com adição de concentração baixa de peróxido orgânico durante o processo de extrusão. Com isso criam-se ramificações, mudando o grau de insaturação devido à reação de acoplamento entre os grupos terminais vinílicos ou radicais alílicos e os radicais secundários. Ambas as reações promovem a abstração do hidrogênio no polímero ${ }^{(39)}$.

Com a reticulação nos polímeros via radiação ionizante pode surgir outra interação competitiva chamada de degradação. Desta forma os materiais poliméricos passam a ser classificados em dois grupos, sendo eles reticulativo ou degradativo. Quando um polímero com grupos vinila possui cada átomo de carbono da cadeia principal ligado a pelo menos um átomo de hidrogênio, terá maior tendência a reticular. Se o polímero apresenta carbonos quaternários irá preferencialmente ter um comportamento de degradação, FIG. $7^{(32)}$. 


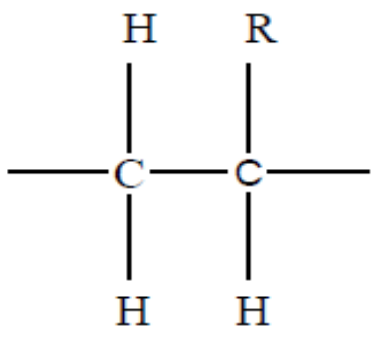

(a)

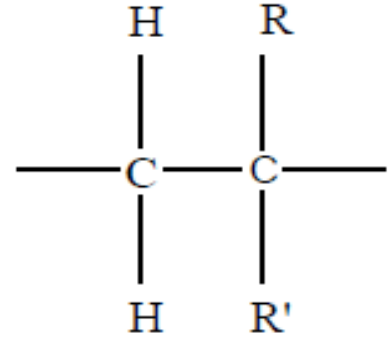

(b)

FIGURA 7 - Classificação dos polímeros de acordo com a sua tendência em interagir com a radiação ionizante: reticular (a) degradar (b) ${ }^{(32) \text {. }}$

A irradiação gama em presença de ar induz a formação de grupos carbonila devido ao oxigênio, e é acompanhada de cisão da cadeia molecular. O teor de gel e a intensidade de cor amarelada aumentam com a dose de irradiação gama $^{(40)}$.

\subsection{Interação da radiação com o polímero}

Com irradiação de materiais poliméricos podem-se obter modificações estruturais como a formação de novas ligações químicas ou ramificações melhorando suas propriedades para fins industriais. As interações primárias de radiação ionizante com polímeros incluem ionização, excitação, estabilização térmica do elétron, neutralização de íons e radicais livres. As reações secundárias após a geração de radicais livres incluem abstração de hidrogênio, ligação dupla, recombinação (reticulação ou ramificação), cisão da cadeia, oxidação, enxerto $^{(9)(30) \text {. }}$

A FIG. 8 apresenta as possíveis reações da interação da radiação ionizante com o polímero. 


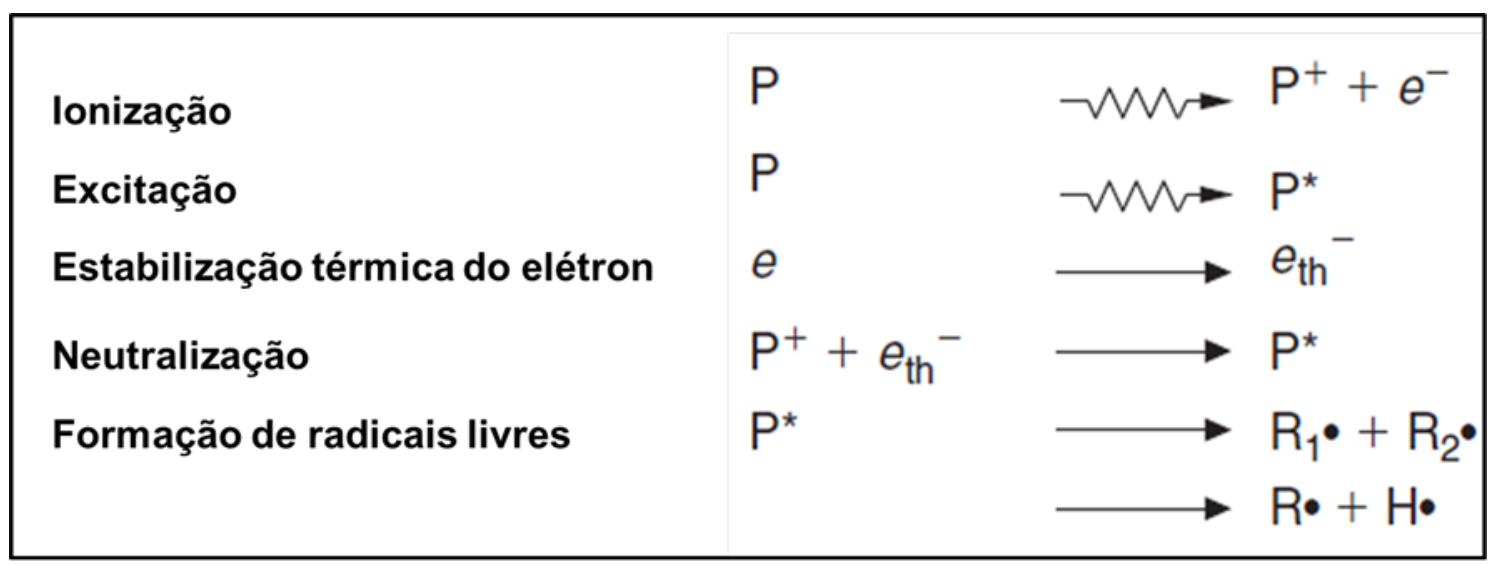

\begin{tabular}{|c|c|c|}
\hline $\begin{array}{l}\text { Abstração de hidrogênio } \\
\text { Adição de dupla ligação } \\
\text { Reticulação ou ramificação } \\
\text { Cisão de cadeia } \\
\text { Oxidação } \\
\text { Enxertia }\end{array}$ & $\begin{array}{l}\mathrm{R} \bullet+\mathrm{P} \\
\cdot \mathrm{RCH}=\mathrm{CH}_{2}+\mathrm{H} \bullet \\
\mathrm{R}_{m} \bullet+\mathrm{R}_{n} \bullet \\
\mathrm{R} \bullet \\
\mathrm{R} \bullet+\mathrm{O}_{2} \\
\mathrm{ROO} \bullet \\
\mathrm{R} \bullet+\mathrm{M} \\
\mathrm{RM} \bullet+n M\end{array}$ & $\begin{aligned} \longrightarrow & \mathrm{RH}+\mathrm{P}_{\bullet} \\
& \mathrm{RCH}_{2} \mathrm{CH}_{2} \bullet \\
& \mathrm{R}_{m}-\mathrm{R}_{n} \\
\longrightarrow & \mathrm{R}_{k} \bullet+\mathrm{R}_{l} \\
\longrightarrow & \mathrm{ROO} \bullet \\
\longrightarrow & -\mathrm{C}=\mathrm{O},-\mathrm{OH},-\mathrm{COOH} \\
& \mathrm{RM}^{\bullet} \\
& \mathrm{RM}_{n+1}\end{aligned}$ \\
\hline
\end{tabular}

FIGURA 8 - Possíveis reações das interações do polímero com a radiação ionizante $^{(9)(30)}$.

Outros resultados fundamentais destas reações incluem a reticulação, em que as cadeias poliméricas são unidas formando uma rede. Existem duas formas de ligações cruzadas, como é apresentado na FIG. 9. Os radicais de polímero envolvidos na reticulação podem ser radicais secundários que são formados pela ruptura da cadeia lateral ligada à cadeia principal (tendência dos polímeros flexíveis). Ou recombinação do radical secundário e um radical primário formado pela cisão da cadeia principal (tendência dos polímeros rígidos) ${ }^{(9)}$.

$$
\begin{aligned}
& 2-\mathrm{CH}_{2}-\dot{\mathrm{C}} \mathrm{H}-\mathrm{CH}_{2}-\longrightarrow \begin{array}{l}
-\mathrm{CH}_{2}-\mathrm{CH}-\mathrm{CH}_{2}- \\
-\mathrm{CH}_{2}-\mathrm{CH}-\mathrm{CH}_{2}-
\end{array} \quad \text { ligação cruzada tipo } \mathrm{H} \\
& \begin{array}{c}
\underset{+\mathrm{CH}_{2}-\dot{\mathrm{C}} \mathrm{H}-\mathrm{CH}_{2}-}{+} \\
-\mathrm{CH}_{2}-\dot{\mathrm{C}} \mathrm{H}_{2}
\end{array} \longrightarrow \begin{array}{l}
-\mathrm{CH}_{2}-\mathrm{CH}-\mathrm{CH}_{2}- \\
-\mathrm{CH}_{2}-\mathrm{CH}_{2}
\end{array} \quad \text { ligação cruzada tipo T }
\end{aligned}
$$

FIGURA 9 - Formas de ligações cruzadas. Tipo H (a) e Tipo T (b) ${ }^{(9}$ ). 
Algumas evidências indiretas, como o aumento da fração insolúvel, inchaço, propriedades físicas em alta temperatura, resistência à tração e curvas módulo de armazenamento em função a temperatura confirmam a existência de reticulações.

A maioria dos polímeros quando irradiados na presença de oxigênio, tem uma tendência de promover a cisão mesmo aqueles que reticulam em ambientes inertes. Nesse processo de cisão da cadeia, o peso molecular é reduzido devido ao rompimento aleatório das ligações químicas ${ }^{(30)}$.

$\mathrm{Na}$ ausência de oxigênio inicialmente acontece a cisão de cadeia e, em seguida, formam-se as ligações cruzadas, podendo ocorrer também recombinação. Na presença de oxigênio ocorrem reações em cadeia podendo formar produtos oxidados devido a difusão superficial do oxigênio no polímero ${ }^{(8)}$.

Os mecanismos de degradação também envolvem a cisão da cadeia principal ou de grupos laterais da macromolécula podendo levar à reticulação e grupos oxidados, reduzindo as propriedades do polímero. A degradação do polímero devido à radiação, na presença de oxigênio, favorece a formação de peróxidos que impedem a recombinação dos radicais livres nos extremos da cadeia $^{(9)}$.

A enxertia que se refere a um monômero incorporado na base da cadeia polimérica pode ocorrer por meio de três métodos diferentes, sendo eles: Método da irradiação simultânea (polímero é irradiado na presença do monômero), Método da pré-irradiação (polímero é irradiado sem a presença do monômero e do ar) e Método da peroxidação induzida por radiação (polímero é irradiado na presença de ar e na ausência do monômero) ${ }^{(8)}{ }^{(41)}$.

\subsection{Esterilização}

Há registros de que os egípcios utilizavam sal, piche ou alcatrão, resinas e aromáticos como anticépticos no embalsamento de corpos aproximadamente 
entre 484 e 424 a.C.. E a fumaça originada da queima de produtos químicos também era utilizada com o propósito de desodorizar e desinfetar.

Em 1860 Pasteur iniciou uma investigação microscópica do ar atmosférico, e conseguiu provar que os microorganismos presentes no ar eram responsáveis pelas mudanças ocorridas em suas soluções estéreis. O fato colocou um fim à controvérsia a respeito da geração espontânea. Outra contribuição de Pasteur para esterilização foi encontrar métodos mais efetivos com temperaturas mais elevadas que a de ebulição sendo Pasteur e Charles Chamberland responsáveis por desenvolver o primeiro esterilizador à pressão de vapor ${ }^{(42)}$.

Entre 1867 e 1888 os agentes gasosos utilizados na desinfecção eram o ácido sulfúrico, cloro, ácido hidrociânico, oxigênio, ozônio e ácido nítrico. Após 1888 iniciou-se a desinfecção por formaldeído ${ }^{(43)}$.

No início do século $X X$ o processo de esterilização por radiação ionizante começou a ser estudado e desenvolvido. Foi estabelecido como um processo comercial mundialmente desde a década de 60 tornando-se um método padrão de esterilização para a indústria ${ }^{(44)}$.

As doses de radiação interferem diretamente nas estruturas microbiológicas das células e no material genético ocasionando a ruptura das moléculas de DNA dos microrganismos ocasionando sua morte ${ }^{(45)}$. Na TAB. 4 apresentam-se as doses em relação aos aspectos microbiológicos.

TABELA 4 - Doses de radiação gama que resultam em danos nas estruturas microbiológicas ${ }^{(46)}$ :

\begin{tabular}{ll}
\hline Microorganismo & Dose letal (kGy) \\
Fungos & $1-3$ \\
Bactérias Gram-negativas & $2-5$ \\
Bactérias Gram-positivas & $5-10$ \\
Bactérias anaeróbias & $10-30$ \\
Vírus & $10-50$ \\
\hline
\end{tabular}


O procedimento selecionado para atingir o nível de esterilização estabelecido depende da natureza do material e das dificuldades impostas pelo produto. Para assegurar o êxito da esterilização necessita-se o conhecimento do método, da fonte e dos contaminantes nos produtos para minimizar a contaminação e preveni-la após o processamento ${ }^{(47)}$.

A esterilização elimina ou destrói todas as formas de microrganismos dos produtos por meio de processos físicos, químicos ou físico-químicos. Para isso necessita-se de embalagens que sejam adequadas ao produto e ao processo de esterilização. Por exemplo, a esterilização via radiação gama pode causar a formação de gases e inchar a embalagem. Caso a embalagem seja constituída por filmes poliméricos finos, o gás hidrogênio formado no tratamento por irradiação escapa pelos interstícios e culmina por não afetar a embalagem ${ }^{(48)}$.

A partir de 1960, cresceu a produção de embalagens plásticas e desde então o seu uso para embalagens de alimentos tem tomado o lugar do papel, vidro e metal ${ }^{(5)}$. Em 1969, com a crescente incidência de doenças causadas por alimentos contaminados além de perdas na produção mundial de alimentos devido a ação de pragas, insetos, fungos a Organização Mundial de Saúde (OMS), Organização das Nações Unidas para a Agricultura e Alimentação (FAO) e a Agência Internacional de Energia Nuclear (AIEA) criaram um Comitê Misto de Especialistas sobre Alimentos Irradiados (CMEAI) para avaliar as irradiações globais de alimentos. Em 1983 aprovou-se uma norma mundial para alimentos irradiados, a qual autoriza 37 países a buscar soluções de preservação de alimentos por irradiação ${ }^{(49)}$.

$\mathrm{Na}$ TAB. 5 apresentam-se as embalagens esterilizadas de produtos alimentícios sendo elas na forma de filmes de poliolefinas ou multicamadas de polietileno de acordo com o documento FDA 21 CFR 179,45 (USFDA, 2001) e norma 21 CFR $179,45 \mathrm{~d}$, respectivamente ${ }^{(50)}$. 
TABELA 5 - Embalagens de produtos farmacêuticos e alimentícios utilizadas nos processos de esterilização.

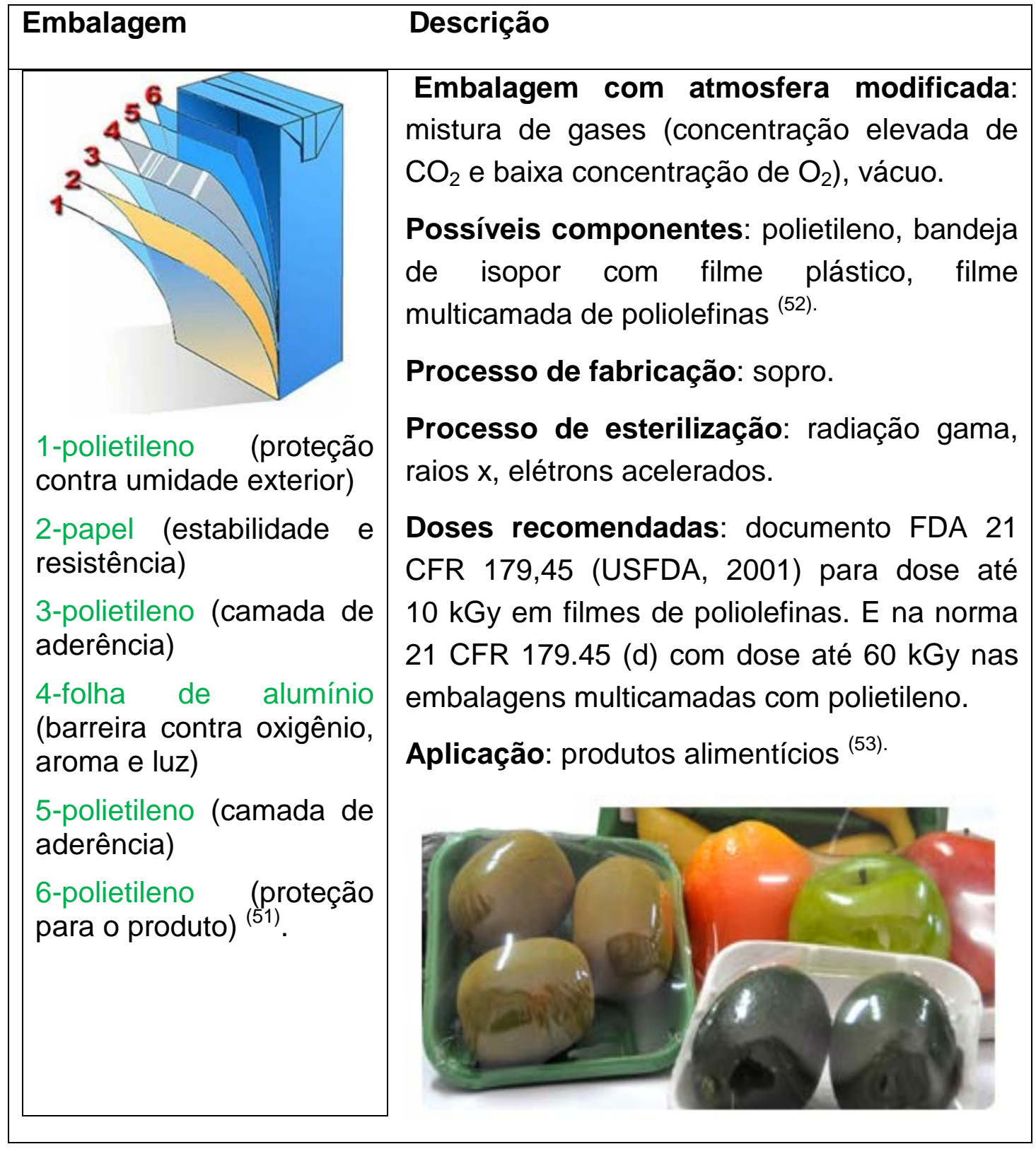

$\mathrm{Na}$ área da saúde publica o Ministério da Saúde define o Centro de Material e Esterilização (CME) como responsável pelo preparo, esterilização, estocagem e distribuição de materiais médico-hospitalares das unidades de estabelecimento de saúde para a prestação de assistência aos seus usuários ${ }^{(54)}$. O processo de esterilização estabelece uma dose mínima para atingir um nível de garantia. As normas internacionais estabelecem um nível de segurança 
microbiológica como SAL (Sterility Assurance Level) que define a probabilidade de um microrganismo estar presente numa unidade do produto individual, após a esterilização. Sendo esse nível de garantia de esterilidade de $10^{-6}$ em produtos de cuidados de saúde ${ }^{(55)}$

A partir da década de setenta os implantes ortopédicos, fabricados com polietileno de ultra-alto peso molecular (PEUAPM) começaram a ser esterilizados por meio da sua exposição a baixas doses de radiação gama, normalmente 25 kGy a 40 kGy como apresenta-se na TAB. 6.

TABELA 6 - Embalagens de produtos ortopédicos submetidas a processos de esterilização.

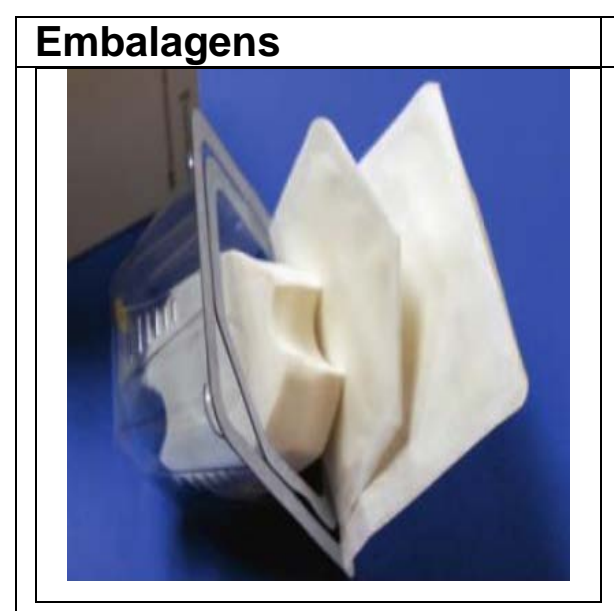

Descrição de Tyvek.

Outros componentes: espuma.

Processo de fabricação: prensagem.

Processo de esterilização: raios gama.

Doses recomendadas: dose nominal de 25 a 40 kGy de radiação gama na presença de ar.

Aplicação: produtos ortopédicos feitos de PEUAPM ${ }^{(56)}$.

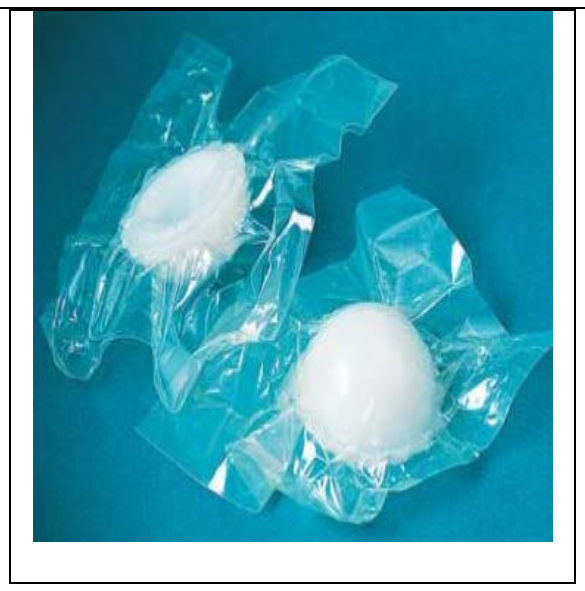

Embalagem com barreira ao ar: combinação de polímeros.

Outros possíveis componentes: alumínio. Atmosfera no interior da embalagem: nitrogênio, argônio ou vácuo.

Processo de fabricação: prensagem, sopro. Processo de esterilização: raios gama. Doses recomendadas: 25 a $40 \mathrm{kGy}$.

Aplicação: produtos ortopédicos feitos de PEUAPM ${ }^{(56)}$. 
Em 1980, o processo de esterilização por radiação foi admitido para alguns medicamentos incluindo antibióticos, esteroides e alcaloides e ervas medicinais, apresentado na TAB. 7.

TABELA 7 - Embalagens de produtos farmacêuticos submetidas a processos de esterilização.

\begin{tabular}{|c|c|}
\hline Embalagens & Descrição \\
\hline & $\begin{array}{l}\text { Frascos, tampas, tubos rígidos e outros } \\
\text { dispositivos plásticos: embalagem primária } \\
\text { (contato direto com o produto) }{ }^{(11)} \text {. } \\
\text { Possíveis componentes: PP, PE, PS, ABS, } \\
\text { PC. } \\
\text { Processo de fabricação: injeção, injeção- } \\
\text { sopro. } \\
\text { Processo de esterilização: radiação gama } \\
\text { ou E-Beans. }\end{array}$ \\
\hline $\begin{array}{l}\text { Organizaçãc } \\
\text { helth care } \\
\text { disnositivos }\end{array}$ & $\begin{array}{l}\text { Doses recomendadas: Na norma da } \\
\text { de Normalização (ISO } 11137 \text { - Sterilization of } \\
\text { tion) dose mínima de } 25 \mathrm{kGy} \text { aplicada para } \\
\text { os farmacêuticos e tecidos biológicos. } \\
\text { êuticos e médico-hospitalares }{ }^{(11)} \text {. }\end{array}$ \\
\hline
\end{tabular}

Em 1986 a Divisão Nacional de Vigilância Sanitária de Medicamentos reviu o enquadramento de produtos descartáveis como objeto de registro, sendo a normalização de registro dos produtos médico-hospitalares obrigatória, com algumas exceções como embalagens para uso em esterilização de materiais por processos físicos ${ }^{(57)}$. Somente em 2004 surgiu a norma ABNT. NBR 14990 para materiais de embalagens na forma de envelope e tubular para esterilização por radiação como apresentado na TAB. 8 . 
TABELA 8 - Embalagens de produtos médico-hospitalares submetidas a processos de esterilização.

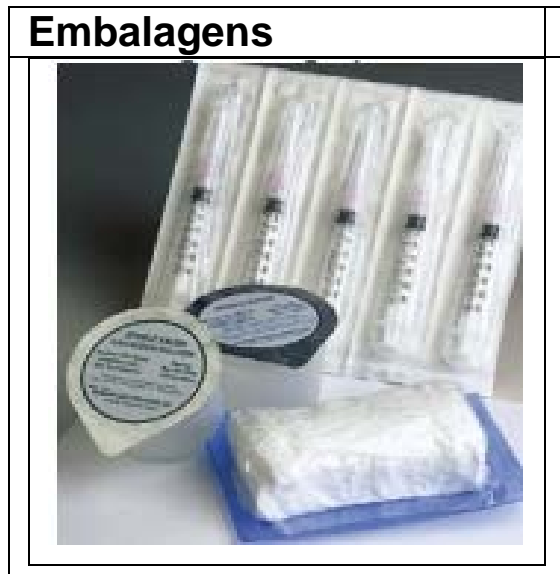

\section{Descrição}

Filme: Tyvek (composto por filamentos contínuos de PEAD) ou polietileno.

Outros possíveis componentes: filme laminado ou Blister (filme cloreto de polivinila $(P \vee C)+$ filme politereftalato de etileno (PET)), polipropileno ${ }^{(58)}$.

Processo de fabricação: método flash spun de aglutinação por pressão a quente, sopro.

Processo de esterilização: gás de óxido de etileno, plasma, radiação ionizante, calor.

Doses recomendas: ISO / TS 13004-2013 seleciona a dose de esterilização de 17.5; 20; 22.5; 27,5; 30; 32.5 ou 35 kGy.

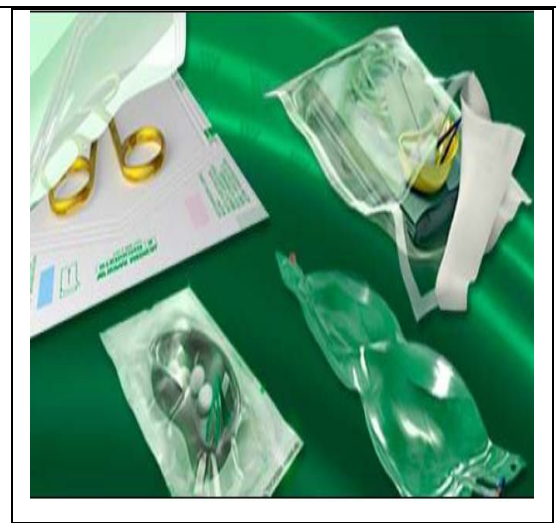

Envelopes e tubulares: constituídos de papel grau cirúrgico e filme termoplástico laminado ou pela combinação de polímeros (58).

Possíveis componentes: polietileno, poliéster, polipropileno, papel encrespado (crepado), papel plano.

Processo de fabricação: coextrusão.

Processo de esterilização: radiação.

Doses recomendadas: ISO / TS 13004-2013 seleciona a dose de esterilização de $17.5 ; 20 ; 22.5 ; 27.5 ; 30 ; 32.5$ ou 35 kGy.

Aplicação: produtos médico-hospitalares.

Norma: ABNT. NBR 14990. Sistemas e materiais de embalagem para esterilização de produtos para saúde. Parte 8: Envelope e tubular para esterilização por radiação. 2004. 
Pode-se verificar a presença dessas embalagens em diversos trabalhos da literatura sobre processos de esterilização com radiação ionizante.

De acordo com o trabalho de Bueno (2008) a dose de irradiação 3,0 kGy é suficiente para estender a vida de prateleira de 5 dias (grupos controle) para aproximadamente 30 dias do peito de frango refrigerado, diminuindo a carga bacteriana deterioradora e patogênica. Utilizou-se embalagem convencional de saco plástico feita de polietileno tipo "zip lock" da marca Ziploc, com fechamento hermético, aprovado para irradiação de alimentos e permeável ao oxigênio ou embalagem sob vácuo em saco plástico especial, aprovado pelo FDA para irradiação de alimentos ${ }^{(59)}$.

Segundo Alexandre (2008) a esterilização de superfícies de embalagens para alimentos que visa reduzir a contaminação microbiológica por meio de irradiação ultravioleta (UV) será eficaz quando o tempo de exposição do material a irradiação UV for superior a $30 \mathrm{~s}^{(60)}$. 


\section{MATERIAIS E MÉTODOS}

A seguir são descritos os materiais utilizados, o método de irradiação, a preparação das amostras e os métodos da caracterização das amostras.

\subsection{Materiais}

\subsubsection{Polietileno linear de baixa densidade (PELBD)}

Usou-se o polietileno linear de baixa densidade, produzido à base do monômero 1-hexeno a baixa pressão e com catalizador Z. Natta, FIG. 10. Neste trabalho será denominado como resina $(\mathrm{R})$.

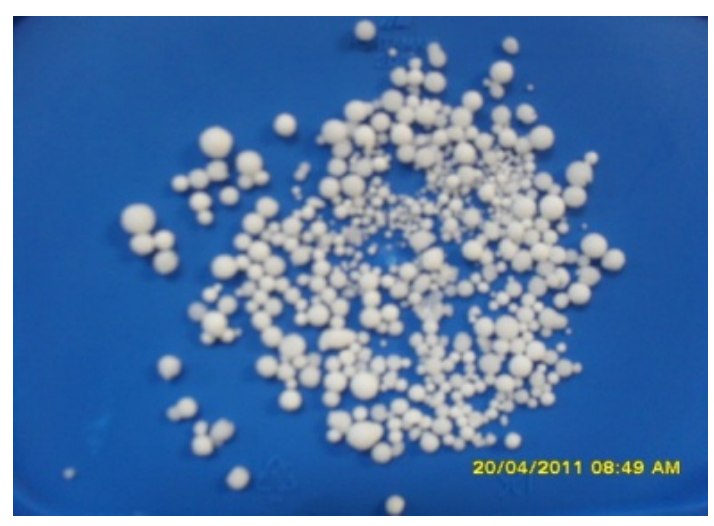

FIGURA 10 - Aspecto da resina de PELBD.

Trata-se de um polímero com ramificações curtas de butila $\left(\mathrm{CH}_{3}\right)$, sendo uma ramificação butila para 1000 átomos de carbono $\left(\mathrm{CH}_{3} / 1000 \mathrm{C}\right)$ que foi fornecido pela BRASKEM. Polímero de grão esférico com as especificações apresentadas na TAB. 9.

TABELA 9 - Especificações do PELBD tipo LH-820/30AF, fornecido pela BRASKEM.

\begin{tabular}{lll}
\hline Propriedade de Controle & Método ASTM & Valores \\
\hline Índice de Fluidez $\left(190^{\circ} \mathrm{C}, 2,160 \mathrm{~kg}\right)$ & D-1238 & $0,8 \mathrm{~g} \cdot 10 \mathrm{~min}^{-1}$ \\
Densidade & D-1505 & $0,920 \mathrm{~g} \cdot \mathrm{cm}^{-3}$ \\
\hline
\end{tabular}




\subsection{Métodos}

Amostras foram preparadas por processo de injeção e foram irradiadas conforme descrito em seguida.

\subsubsection{Procedimento da preparação das amostras}

Prepararam-se na Injetora, DEMAG ergo tech pro 35-115, corpos de provas do PELBD (FIG. 11) utilizando moldes com cavidades nas formas de discos e de gravatas no laboratório de processos de materiais poliméricos (Departamento de Engenharia de Materiais e Metalurgia - Poli-USP), seguindo as especificações descritas na TAB. 10. As amostras serão denominadas como PELBD (i indicando a injeção).

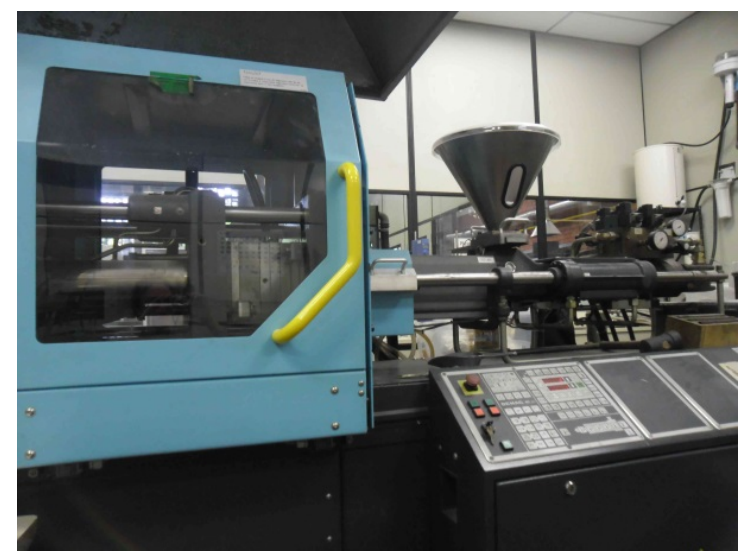

FIGURA 11 - Máquina Injetora.

TABELA 10 - Especificações do processo de injeção das amostras.

\begin{tabular}{ll}
\hline Especificações & Dados \\
\hline Perfil de temperatura $\left({ }^{\circ} \mathrm{C}\right)$ & 190 a 210 \\
Pressão de injeção 1 (bar) & 120 (pressão para preencher o molde) \\
Pressão de injeção 2 (bar) & 100 (manter o material no molde) \\
Velocidade (milímetro/segundo) & 60 \\
Contra pressão (bar) & 30 \\
Tempo de resfriamento $(\mathrm{s})$ & 15 \\
Temperatura do molde $\left({ }^{\circ} \mathrm{C}\right)$ & 35 \\
\hline
\end{tabular}




\subsubsection{Preparação do material para irradiação e o tratamento pós-irradiação}

Na FIG. 12-a, apresenta-se o PELBD ${ }_{i}$ colocado em sacos de nylon em presença de ar atmosférico. Em seguida foram encaminhados para Empresa Brasileira de Radiação (CBE/Embrarad) para irradiação em uma fonte de ${ }^{60} \mathrm{Co}$ com $2000 \mathrm{kCi}$ de atividade com doses especificadas de 5, 10, 20, 50 ou 100 kGy e taxa de dose de $5 \mathrm{kGy} \cdot \mathrm{h}^{-1}$ à temperatura ambiente.

Após a irradiação, as amostras foram submetidas a tratamento térmico em uma estufa por 60 min a temperatura de $100{ }^{\circ} \mathrm{C}$ (FIG. 12-b) para a recombinação e aniquilação dos radicais residuais.

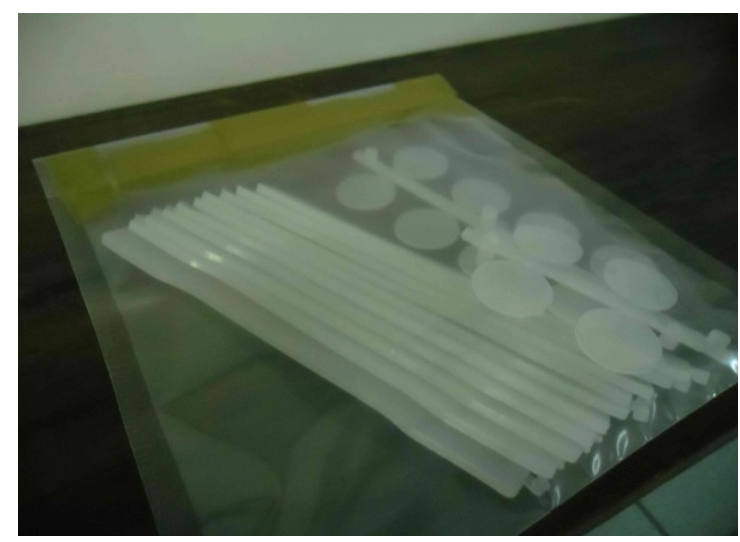

(a)

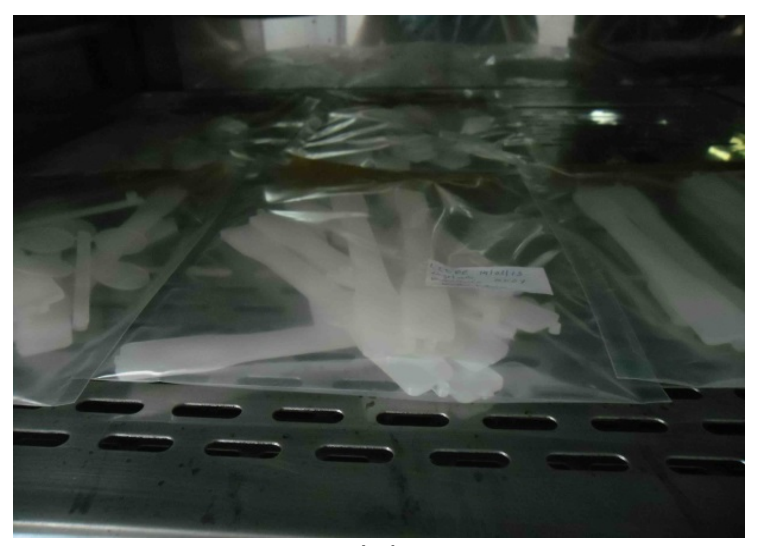

(b)

FIGURA 12 - PELBD no saco de nylon para irradiação (a) e PELBD i após irradiação para tratamento térmico na estufa (b).

\subsubsection{Caracterização dos materiais}

\subsubsection{1 Índice de Fluidez (IF)}

O índice de fluidez é um parâmetro definido empiricamente, inversamente proporcional à viscosidade, muito utilizado na indústria por caracterizar a capacidade de fluxo dos polímeros no estado fundido ${ }^{(61)}$. 
Mede-se o índice de fluidez do PELBD ${ }_{i}$, com obtenção de amostra a cada $1 \mathrm{~min}$ da passagem do polietileno através do orifício da matriz com $2 \mathrm{~mm}$ de diâmetro e $48 \mathrm{~mm}$ de comprimento. Seguem-se os parâmetros de temperatura de $190{ }^{\circ} \mathrm{C}$ e carga colocada no pistão de $2,160 \mathrm{Kg}$ de acordo com a norma ASTM D1238-04 (62), (63). Utilizou-se o aparelho CEAST IFM, localizado no Laboratório de Materiais Poliméricos no CQMA-IPEN, FIG. 13.

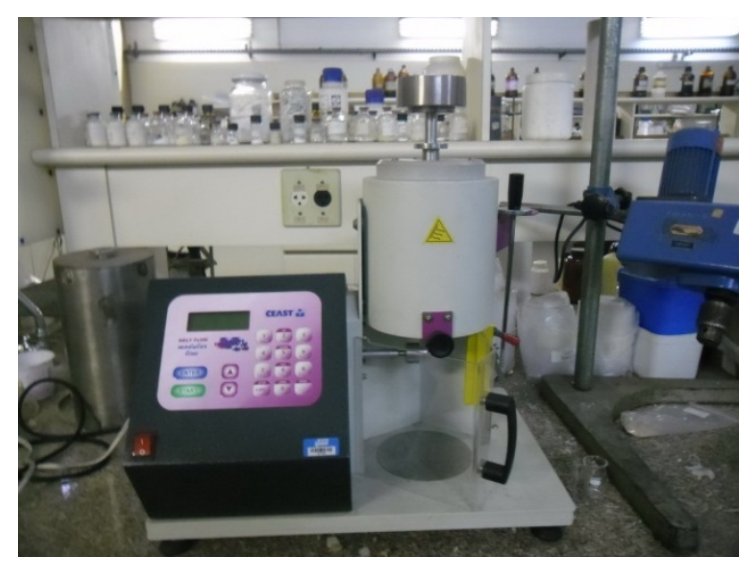

FIGURA 13 - Aparelho CEAST IFM.

Neste processo pode-se verificar também a porcentagem de inchamento das amostras extrudadas. Esse resultado é obtido pela Equação (1):

$$
\operatorname{Inchamento}(\%)=\frac{\left(D_{p}-2\right) \times 100}{2}
$$

onde o diâmetro da matriz é $2 \mathrm{~mm}$ e $\circ D_{p}$ é o diâmetro da amostra após o teste de IF.

\subsubsection{Fração gel}

As medidas de massa reticulada do $P E L B D_{i}$, foram realizados em um sistema de balões acoplados a destiladores de refluxo. As amostras foram 
embaladas em uma tela de aço inoxidável de 500 mesh e imersas em xileno sob ebulição a temperatura de $135{ }^{\circ} \mathrm{C}$ por 24 horas, conforme norma ASTM D2765-06 ${ }^{(64)}$ (FIG. 14). Para cada dose de radiação foram preparadas três embalagens.

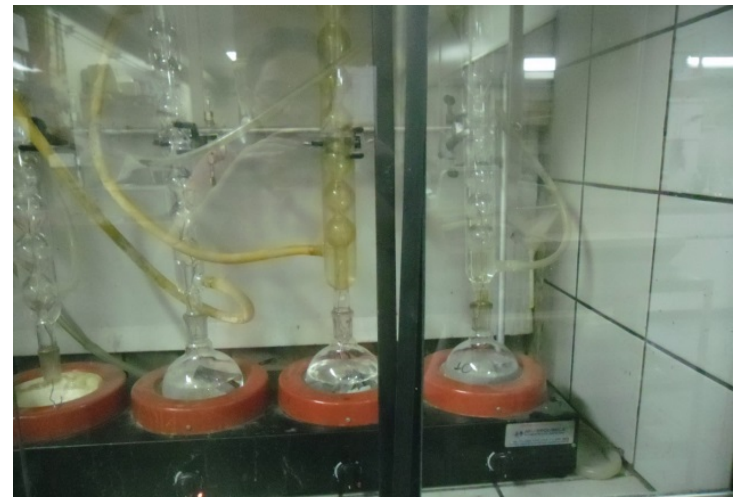

(a)

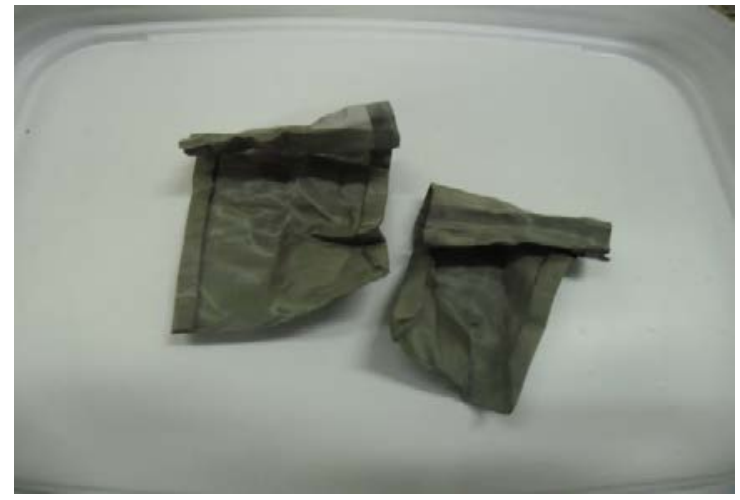

(b)

FIGURA 14 - Determinação de fração gel. Sistema em refluxo (a) e amostras de PELBD ${ }_{i}$ embaladas para a extração (b).

A fração gel foi calculada aplicando-se a Equação (2):

$$
\operatorname{gel}(\%)=\frac{M_{f} \times 100}{M_{i}}
$$

Na qual, $M_{f}$ é a massa final e $M_{i}$ é massa inicial de cada amostra.

\subsubsection{Espectroscopia na região do Infravermelho por Transformada de Fourier (FTIR)}

Por meio da espectroscopia de absorção na região do infravermelho (IR) pode-se determinar a estrutura molecular de um composto. A radiação no infravermelho corresponde à parte do espectro eletromagnético, situada entre a região do visível e das micro-ondas. A radiação irá interagir com as moléculas 
evidenciando vibrações características, o que permite determinar a presença ou ausência de grupos funcionais.

Utilizou-se um Espectrômetro, marca da Thermo Nicolet, modelo Nexus 6700 FTIR para realizar a espectroscopia de absorção na região do infravermelho com transformadas de Fourier, no intervalo de 400 a $4000 \mathrm{~cm}^{-1}{ }^{(65)}$, com resolução de $2 \mathrm{~cm}^{-1}$, localizado no Laboratório de Célula Combustível - $\mathrm{CCCH}$ no IPEN, FIG. 15.

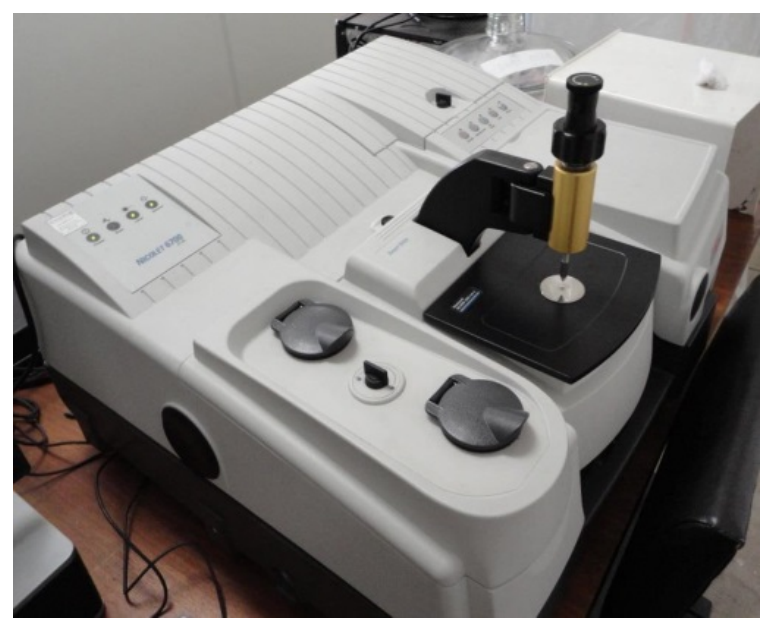

FIGURA 15 - Espectrômetro no infravermelho, marca da Thermo Nicolet, modelo Nexus 6700 FTIR.

\subsubsection{Análises por Calorimetria exploratória diferencial (DSC)}

A Calorimetria exploratória diferencial (DSC) é uma técnica de análise térmica que permite medir as mudanças das propriedades físicas ou químicas de um material em função da temperatura. A técnica de DSC mede a diferença de energia fornecida à substância e a um material de referência, ambos submetidos à mesma programação controlada de temperatura, de modo que a amostra e a referência sejam mantidas em condições isotérmicas uma em relação à outra ${ }^{(66)}$. 
Com esta técnica foram determinados o percentual de cristalinidade, temperatura de fusão e temperatura de cristalização, referentes às amostras de PELBD .

Calcula-se o grau de cristalinidade em comparação ao polímero $100 \%$ cristalino, pela Equação (3),

$$
X_{C}(\%)=\frac{\Delta H_{f} \times 100}{\Delta H_{0}}
$$

na qual $\Delta \mathrm{H}_{f}$ é a variação de entalpia da amostra e $\Delta \mathrm{H}_{0}$ é a variação de entalpia de fusão do polietileno $100 \%$ cristalino assumido como $279{\mathrm{~J} . ~ \mathrm{~g}^{-1}}^{(67)}$.

A análise foi feita utilizando-se aproximadamente $10 \mathrm{mg}$ de $P E L B D_{i}$ em uma cápsula fechada de alumínio, empregando uma programação de temperatura de 25 a $180{ }^{\circ} \mathrm{C}$ com taxa de $10{ }^{\circ} \mathrm{C} \cdot \mathrm{min}^{-1}$, mantendo-se a $180{ }^{\circ} \mathrm{C}$ por $5 \mathrm{~min}$, em seguida resfriamento até $25^{\circ} \mathrm{C}$ a taxa de $50{ }^{\circ} \mathrm{C} \cdot \mathrm{min}^{-1}$, e posterior reaquecimento seguido de resfriamento nas mesmas condições conforme a norma ASTM D3418-08 ${ }^{(68)}$. As análises foram realizadas em um equipamento da Mettler Toledo DSC 822 localizado no Laboratório de Síntese e Caracterização de Polímeros, FIG. 16.

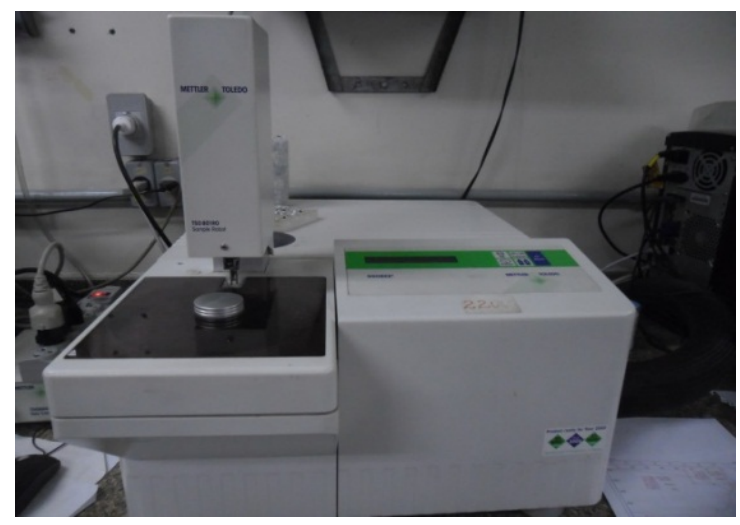

(a)

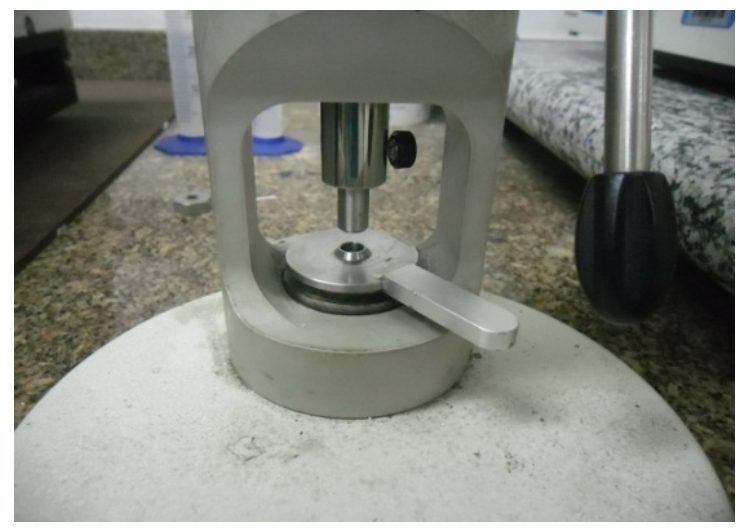

(b)

FIGURA 16 - Equipamento Mettler Toledo DSC 822 (a). Prensa para fechamento da cápsula (b). 


\subsubsection{Difração de Raios X (DRX)}

$\mathrm{Na}$ análise de DRX os feixes incidem na amostra com ângulo $\theta$ e são refletidos com ângulo de reflexão igual ao ângulo de incidência como é apresentado na FIG. 17. Os planos formados pelos átomos da amostra são paralelos entre si e estão separados por uma distância interplanar $d$ constante ${ }^{(69)}$.

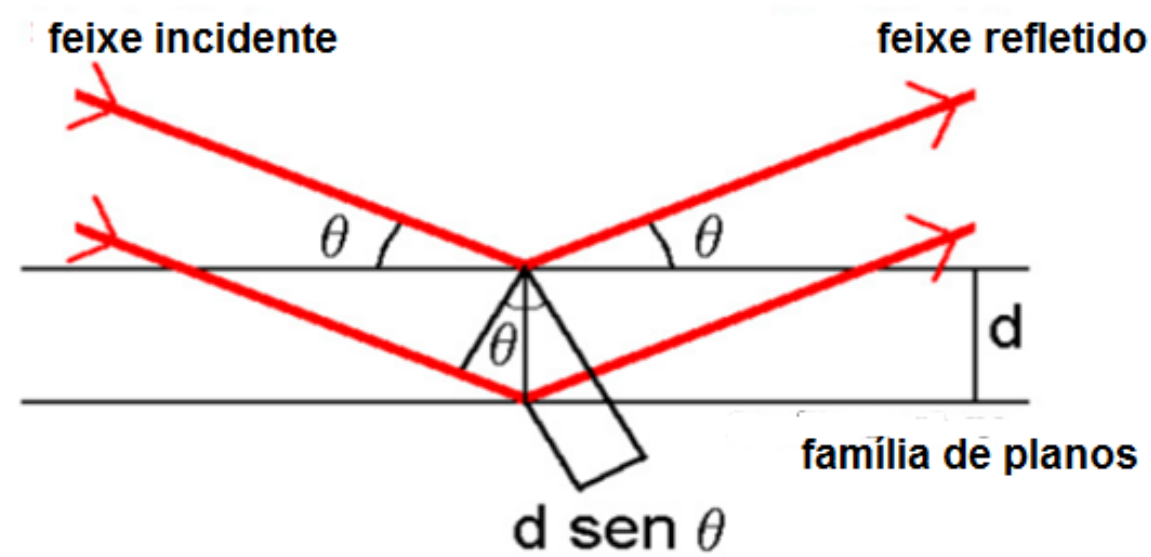

FIGURA 17 - Representação esquemática do fenômeno de difração ${ }^{(69)}$.

O cálculo da porcentagem de cristalinidade (W(\%)) utiliza a Equação (4) por meio da integração dos picos cristalinos e banda amorfa na faixa de ângulos $2 \theta$ de $15^{\circ}$ a $25^{\circ}$.

$$
W(\%)=\frac{(\text { área dos picos cristalinos })}{(\text { área de todo o espectro })}
$$

As análises foram realizadas em um aparelho de Difração de Raios $X$ (DRX), marca Rigaku, modelo Miniflex II com tubo de raios x CuKa (30 Kv/15 mA) e varredura entre os ângulos $2 \theta$ de $5^{\circ}$ a $80^{\circ}$, localizado no Laboratório de Controle Analítico de Processo no CQMA-IPEN. Utilizou-se PELBD ${ }_{i}$ com aproximadamente $20 \mathrm{~mm}$ de comprimento ; 20 mm de largura e 3 mm de espessura, FIG. 18. 


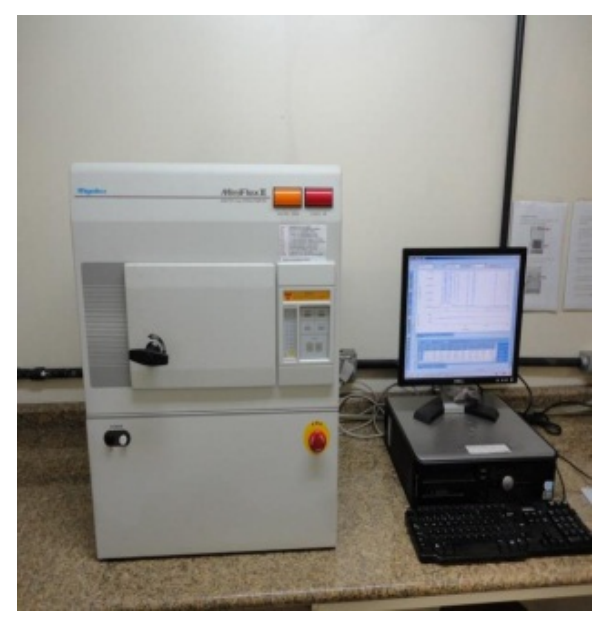

FIGURA 18 - Aparelho de Difração de Raios X (DRX), marca Rigaku, modelo Miniflex II.

\subsubsection{Análise de termogravimetria (TG)}

Com a análise de termogravimetria é possível conhecer as alterações que o aquecimento provoca no polímero em função da temperatura e/ou tempo enquanto a amostra é submetida a uma programação controlada de temperatura. Desta forma pode-se determinar a faixa de temperatura em que a amostra começa a decompor, acompanhar o andamento de reação como desidratação, oxidação, combustão e decomposição.

A amostra de $P E L B D_{i}$, cerca de $10 \mathrm{mg}$, foi colocada em um cadinho de alumina $40 \mu \mathrm{L}$, aquecida a uma taxa de $10{ }^{\circ} \mathrm{C} \cdot \mathrm{min}^{-1}$ da temperatura de 25 a $600{ }^{\circ} \mathrm{C}$, sob fluxo de oxigênio a $50 \mathrm{~mL} \cdot \mathrm{min}^{-1}$, conforme ASTM D6370-99 (70). Utilizou-se o aparelho Mettler Toledo, Modelo TGA 851e SDTGA, localizado no Laboratório de Síntese e Caracterização de Polímeros, (FIG. 19). 


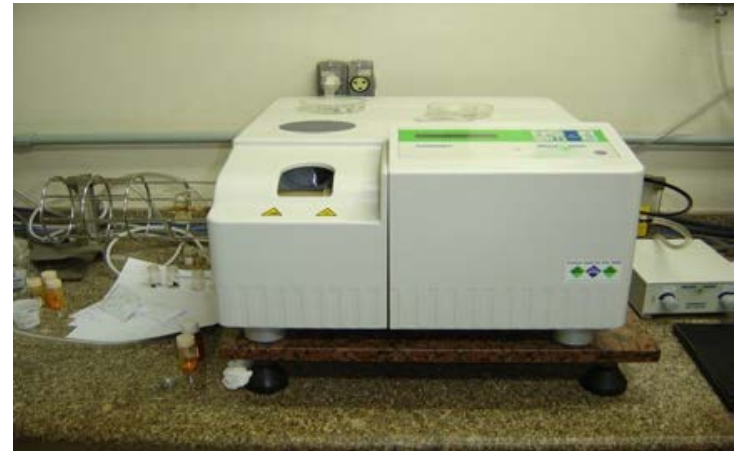

(a)

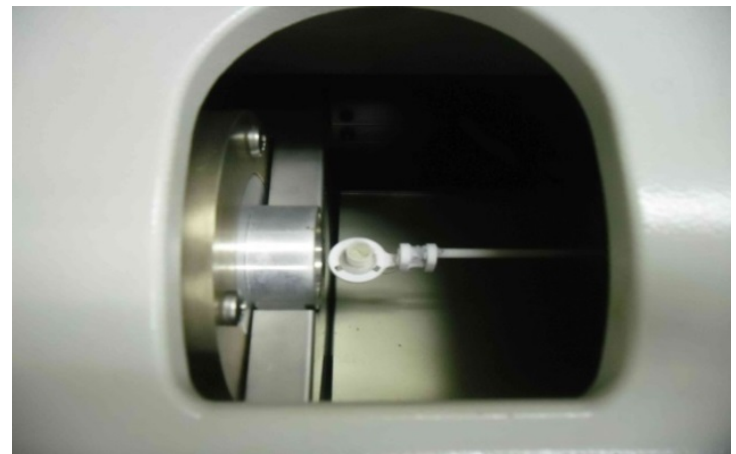

(b)

FIGURA 19 - Mettler Toledo, Modelo TGA 851e SDTGA. Vista externa (a) Vista interna com a haste de sustentação do conjunto formado por estribo e cadinho (b).

\subsubsection{Análise termodinâmico-mecânica (DMA)}

Análise termodinâmico-mecânica é um dos métodos usados para estudar o movimento molecular de polietilenos nas fases cristalina, amorfa e intermediária. Geralmente, são observados três processos de relaxação principais ( $\alpha, \beta$ e $\gamma)$. O processo a é observado na fase cristalina e os processos $\beta$ e $\gamma$ na fase amorfa, sendo a relaxação $\beta$ associada à transição vítrea.

A análise termodinâmico-mecânica é a técnica mais comum para determinar a temperatura transição vítrea $\left(T_{g}\right)$ e a temperatura de fusão cristalina de polímeros semicristalinos $\left(T_{m}\right)$, apresentando a vantagem de ser um método direto de medição ${ }^{(71)}$.

Todos os materiais poliméricos são viscoelásticos, isto é, quando deformados apresentam um comportamento característico dos materiais elásticos e plásticos. Assim, um polímero sendo solicitado por uma tensão cíclica, por exemplo, senoidal, apresentará uma deformação como resposta, também senoidal, porém atrasada (defasada) de um angulo $\delta$ com relação à solicitação. Este atraso é o resultado do tempo gasto para que ocorram rearranjos moleculares associados ao fenômeno de relaxação da cadeia polimérica ou de segmentos ${ }^{(72)(71) .}$ 
Por meio da deformação de um material, durante a aplicação das tensões oscilatórias, obtêm-se dois módulos: E' - módulo de armazenamento; E" - módulo de perda.

Quando o material é aquecido são liberadas as tensões acumuladas na amostra provenientes do processamento, tratamento ou histórico térmico. Quanto maior o tempo de permanência na temperatura, maior será o pico de relaxação e por isso a $T_{g}$ deve ser determinada no segundo aquecimento da mesma amostra.

As amostras de $P E L B D_{i}$, com corpo de prova de aproximadamente $50 \mathrm{~mm}$ de comprimento; $5 \mathrm{~mm}$ de largura e $3 \mathrm{~mm}$ de espessura, foram resfriadas a $4{ }^{\circ} \mathrm{C} \cdot \min ^{-1}$ da temperatura ambiente até $-150{ }^{\circ} \mathrm{C}$ e aquecidas até $25^{\circ} \mathrm{C}$, a $2{ }^{\circ} \mathrm{C} \cdot \min ^{-1}$ e frequência de $1 \mathrm{~Hz}, 2 \mathrm{~Hz}$ e $5 \mathrm{~Hz}$. O equipamento utilizado foi um analisador DMA da marca Netzsch utilizando um porta amostra para flexão em 3 pontos localizado no CCTM-IPEN, FIG. 20.

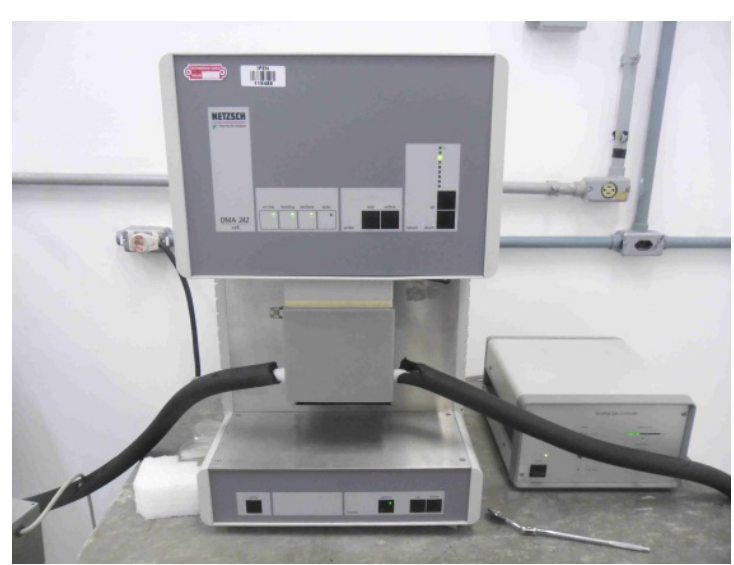

(a)

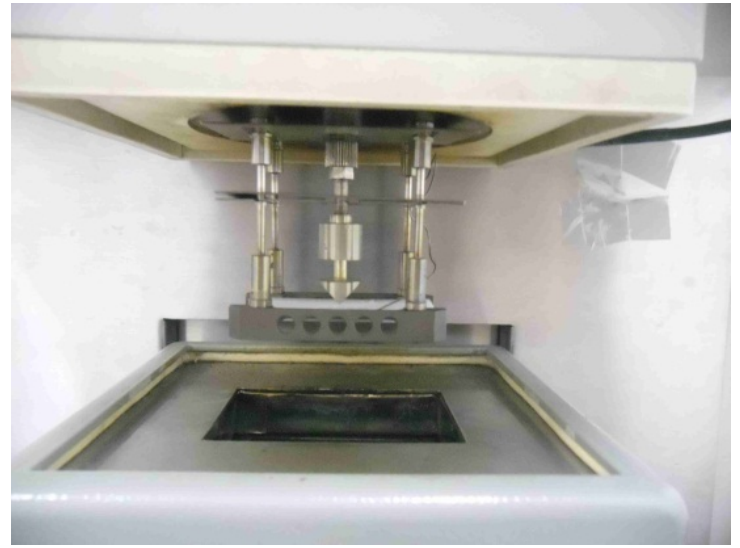

(b)

FIGURA 20 - Vista do equipamento analisador DMA da marca Netzsch (a) Montagem da amostra para flexão em 3 pontos (b).

\subsubsection{Reometria de placas paralelas}

A reologia é a ciência que estuda o fluxo e a deformação da matéria. Analisa as respostas de um material quando se aplica uma tensão ou uma deformação. 
As caracterizações reológicas foram realizadas no reômetro rotacional Anton Paar MCR 301, da Physica, Localizado no Laboratório de Síntese e Caracterização de Polímeros (FIG. 21).

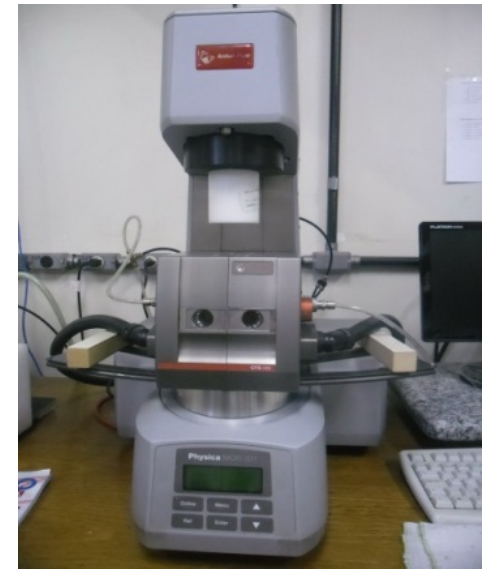

(a)

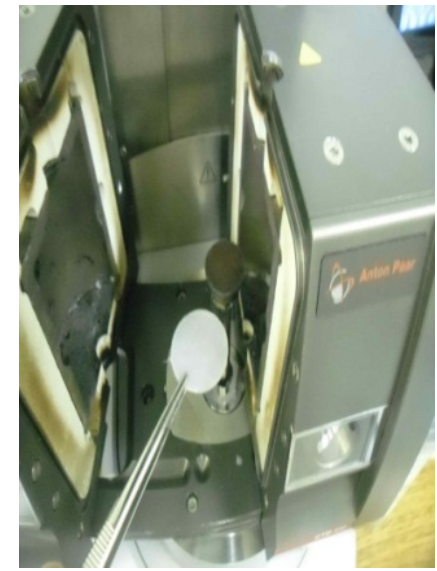

(b)

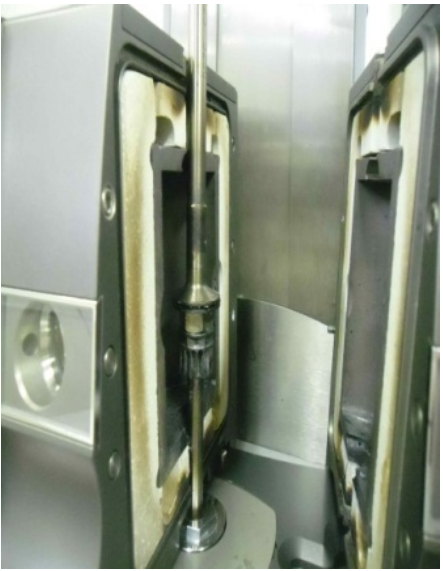

(c)

FIGURA 21 - Vista do equipamento reômetro oscilatório modelo MCR 300, da Physica (a). Montagem da amostra no equipamento (b) (c).

Nos ensaios de viscoelasticidade linear foi usada a geometria placa-placa e atmosfera de nitrogênio. As placas possuem um diâmetro de $25 \mathrm{~mm}$ e o espaço entre elas durante o ensaio foi de $1 \mathrm{~mm}$. Vários ensaios foram realizados e estão descritos a seguir:

\section{Ensaios de Varredura de deformação}

Com este ensaio determinou-se a faixa de deformação de cisalhamento numa frequência fixa, nas quais o polímero possui um comportamento correspondente ao de viscoelasticidade linear. Para isso utilizou-se duas frequências uma baixa $\left(0,1{\left.\mathrm{rad} . \mathrm{s}^{-1}\right)}\right.$ e outra alta (100 rad. $\left.\mathrm{s}^{-1}\right)$ ambas com deformação que varia de 0,1 a $20 \%$ em temperatura de $180{ }^{\circ} \mathrm{C}$. A FIG. 22 apresenta um exemplo típico de determinação de região de viscoelasticidade linear. 


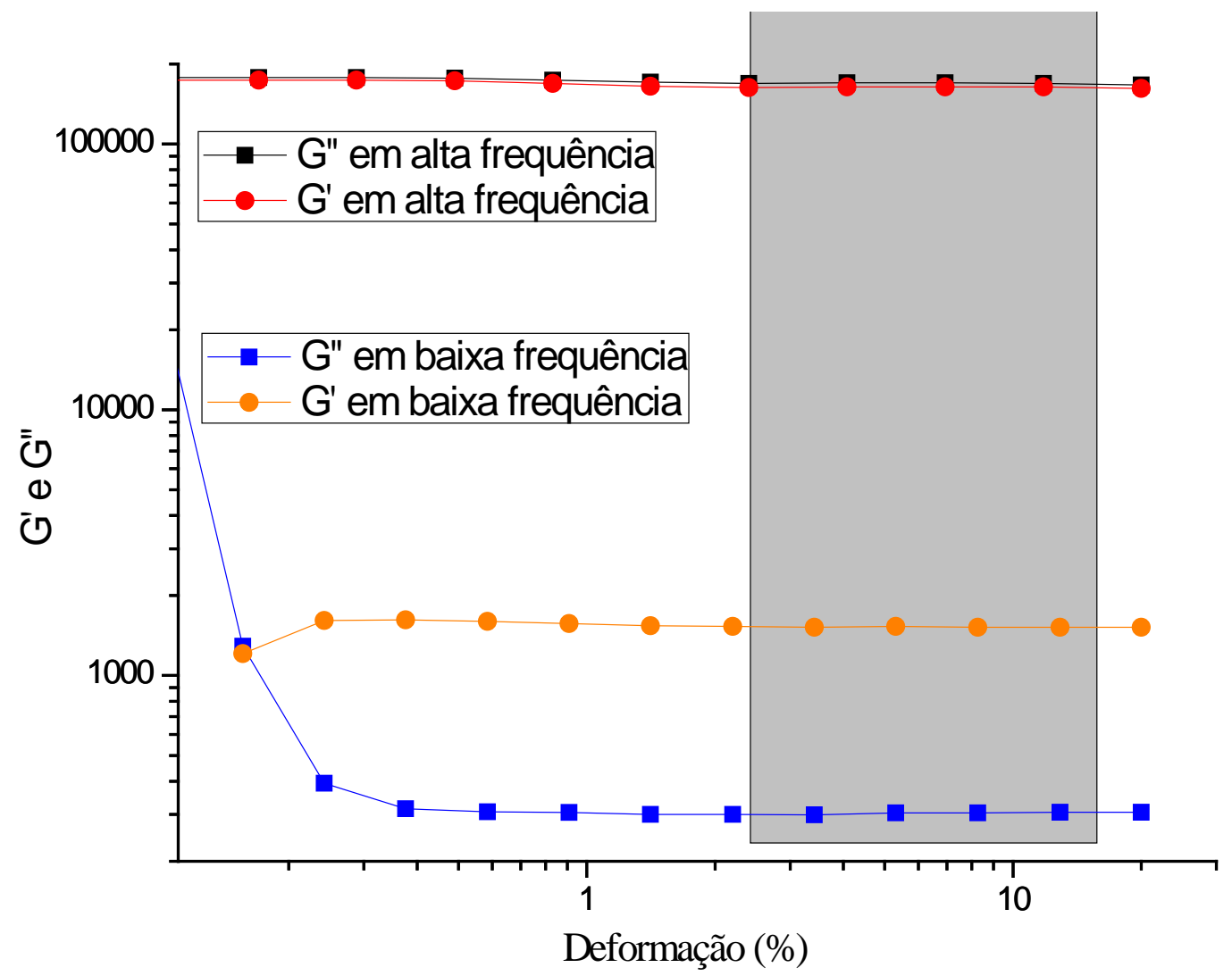

FIGURA 22 - Ensaio controle de varredura de deformação do $\operatorname{PELBD}_{\mathrm{i}}$ não irradiado.

No ensaio oscilatório de pequena amplitude é possível obter os valores de G', G" e que são sensíveis a pequenas alterações na massa molecular, à distribuição da massa molecular e às ramificações em homopolímeros (73) (74). Além disso, nas misturas poliméricas permite analisar as interações entre fases, como tensão interfacial, mudanças na morfologia, entre outras.

As amostras foram aquecidas até à temperatura de $180^{\circ} \mathrm{C}$ sob fluxo de nitrogênio, com os seguintes parâmetros: amplitude 0,01 a 100 \% com frequência angular $(\omega)$ constante de $10 . s^{-1}$ para obter os valores de $G^{\prime}, G$ e $\left|\eta^{*}\right|$ em função a frequência angular e com amplitude constante de $10 \%$, valor obtido experimentalmente, frequência angular 150 a $0,1 . \mathrm{s}^{-1}$ e temperatura $180{ }^{\circ} \mathrm{C}$ para obter os valores G' e G" em função tensão de cisalhamento $(\tau)$. 


\subsubsection{Ensaios mecânicos}

As propriedades mecânicas obtidas nestes ensaios são essenciais no processo de seleção dos materiais poliméricos. Os resultados dos ensaios de resistência mecânica sob tração são apresentados como curvas de tensão versus deformação.

Os ensaios mecânicos foram executados em máquina universal de ensaios EMIC modelo DL 3000 (FIG. 23) com velocidade de deformação de 0,02 s' ${ }^{-1}$, de acordo com norma ASTM D 638-03 ${ }^{(75)}$. Equipamento localizado no Laboratório de Síntese e Caracterização de Polímeros no CQMA-IPEN. Esse ensaio de tensão deformação é destrutivo, ou seja, o PELBD ${ }_{i}$ testado deforma-se até a fratura ${ }^{(1)}$.

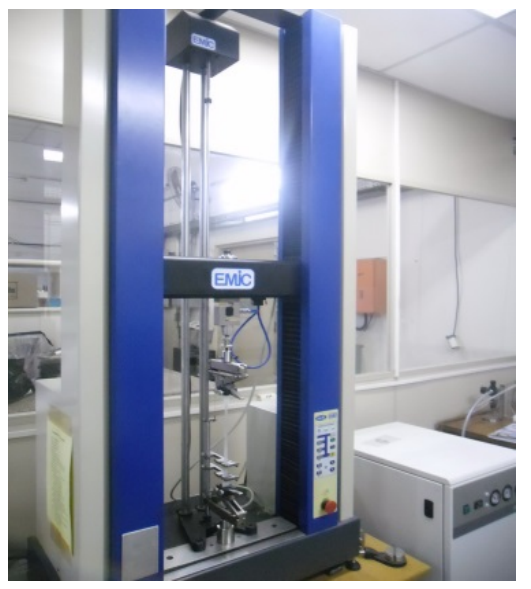

(a)

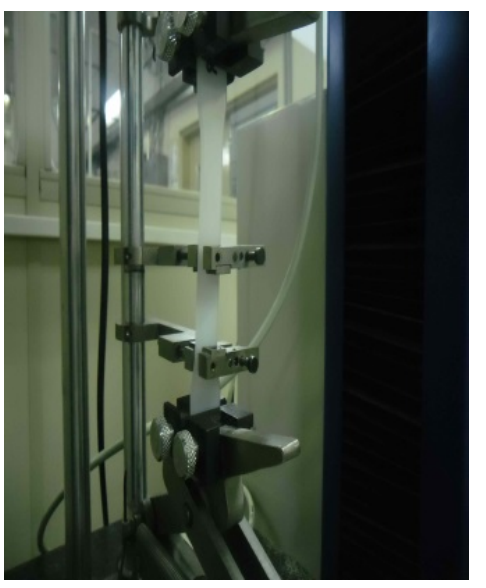

(b)

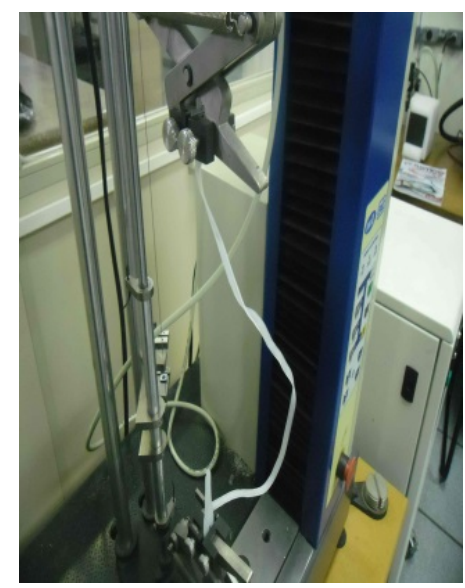

(c)

FIGURA 23 - Máquina universal de ensaios EMIC (a). Corpo de prova montado no equipamento (b). Rompimento do corpo de prova (c). 


\section{$5 \quad$ RESULTADOS E DISCUSSÕES}

$\mathrm{Na}$ sequência são apresentados os resultados obtidos do $P E L B D_{i}$ quando submetido a irradiação gama. São discutidos os aspectos visuais e as alterações estruturais por meio das diferentes técnicas de caracterização de polímeros.

\subsection{PELBD processado antes da irradiação}

Utilizou-se resina PELBD, grão esférico. No processo de moldagem por injeção geralmente, a região superficial do corpo de prova sofre resfriamento mais rápido mantendo um grau de orientação maior, enquanto a região interna da peça moldada resfria mais lentamente e sofre menos tensão. Em polímeros parcialmente cristalinos, a superfície e o interior da peça moldada diferem na cristalização e na orientação da matriz polimérica ${ }^{(76)}$.

Na FIG. 24 observa-se uma coloração leve de tom amarelo no material modificado pelo processo de injeção, corpos de prova injetados, diferente da resina de PELBD que são esferas brancas. Durante o processo de injeção forneceu-se energia suficiente para romper algumas ligações dos átomos de carbono terciário, ligações fracas originadas nos carbonos das ramificações (77) (78). Consequentemente formaram-se ligações duplas entre carbonos nessas regiões que anteriormente ao aquecimento não existiam. Desta forma apareceu-se o leve tom amarelo nas amostras moldadas.

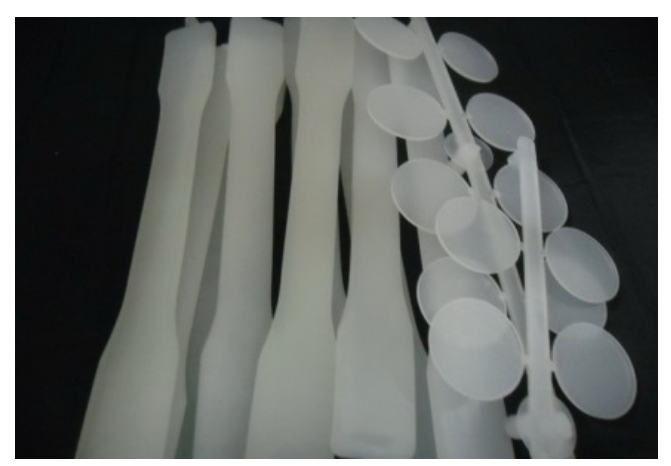

FIGURA 24 - Amostras de $\operatorname{PELBD}_{i}$ antes da irradiação em forma de discos e gravatas. 


\section{2 $\quad$ PELBD $_{\mathrm{i}}$ irradiado}

Observa-se visualmente na FIG. 25 que o processo de irradiação não influenciou a coloração se comparado ao $\mathrm{PELBD}_{\mathrm{i}}$ não irradiado ou seja, o tom levemente amarelado do corpo de prova injetado permanece o mesmo após a irradiação. Supõe-se que a radiação proporcionou cisões formando radicais livres que ficaram presos na cadeia devido a possíveis dobras na cadeia polimérica. Desta forma o oxigênio não conseguiu atacar os sítios ativos ${ }^{(77)}$.

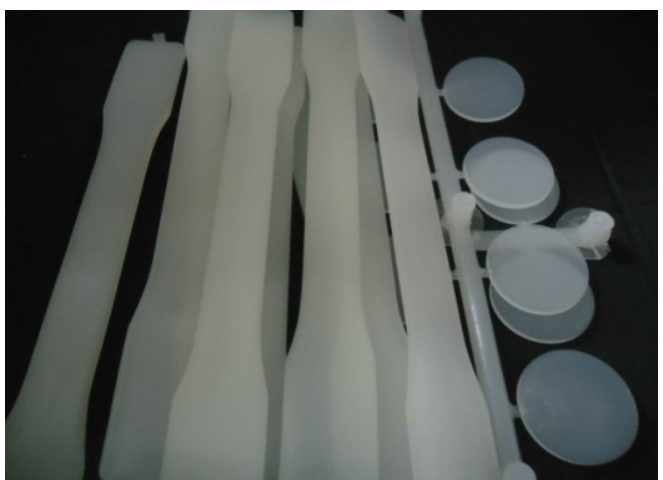

(a)

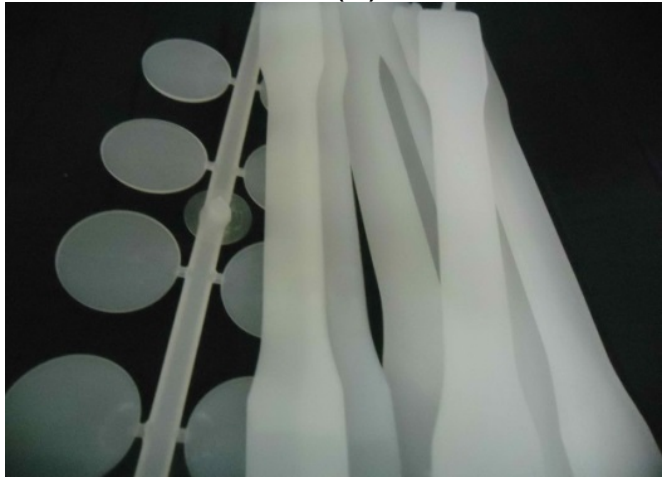

(c)

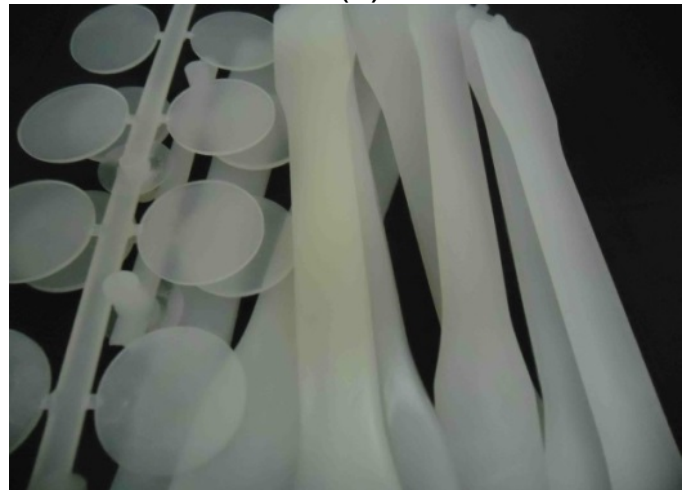

(e)

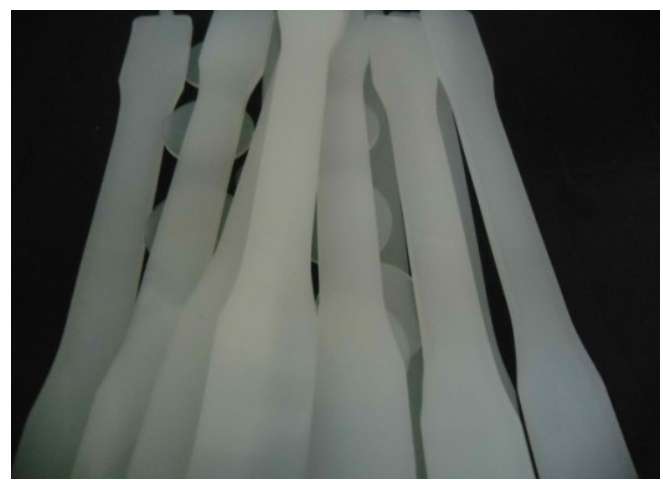

(b)

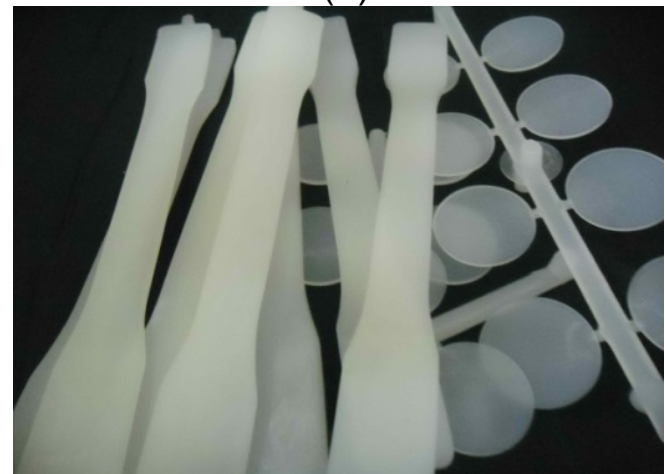

(d)

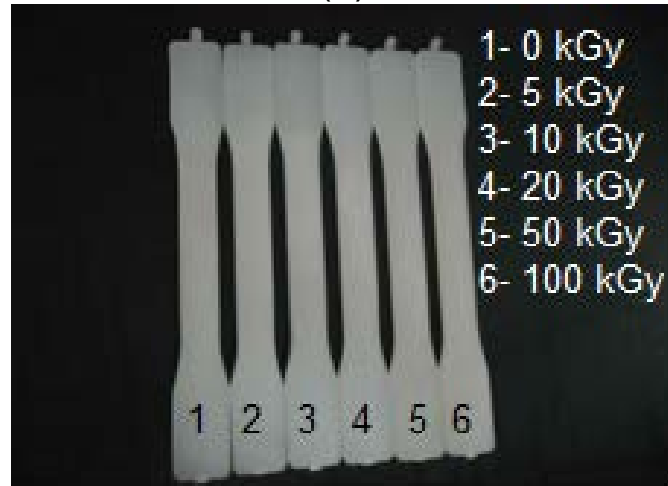

(f)

FIGURA 25 - PELBD irradiado. (a) 5 kGy. (b) 10 kGy. (c) 20 kGy. (d) 50 kGy. (e) 100 kGy. (f) Comparação do PELBDi (0, 5, 10, 20, 50 ou 100 kGy). 


\subsection{PELBD $\mathrm{P}_{\mathrm{i}}$ irradiado após tratamento térmico}

Ao submeter o PELBD i a um tratamento térmico a temperatura de $100{ }^{\circ} \mathrm{C}$ por $60 \mathrm{~min}$, aquecimento suficiente para que as cadeias moleculares se rearranjassem e ocorresse o aniquilamento dos radicais livres existentes, FIG. 26, observa-se que visualmente não ocorreu degradação térmica ${ }^{(41)}$.

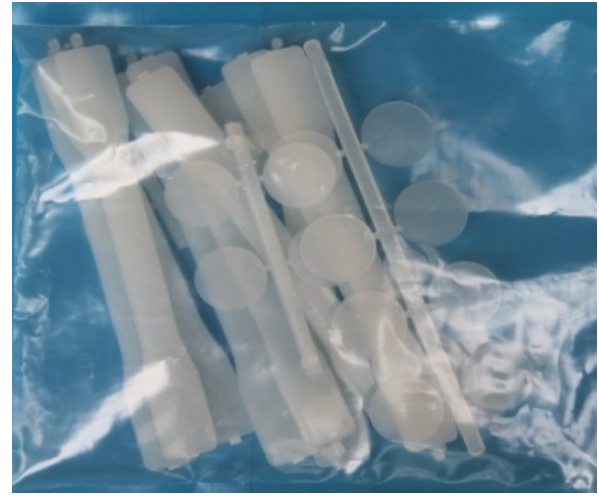

(a)

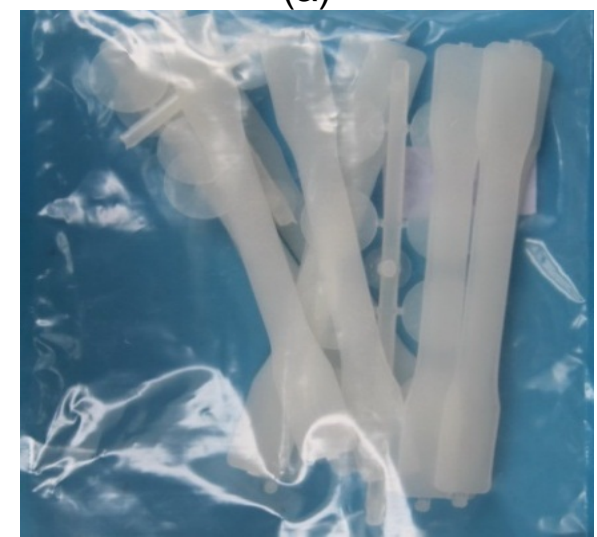

(c)

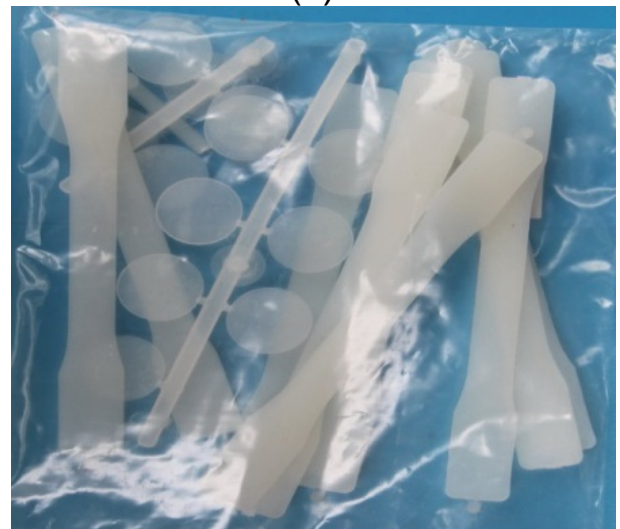

(e)

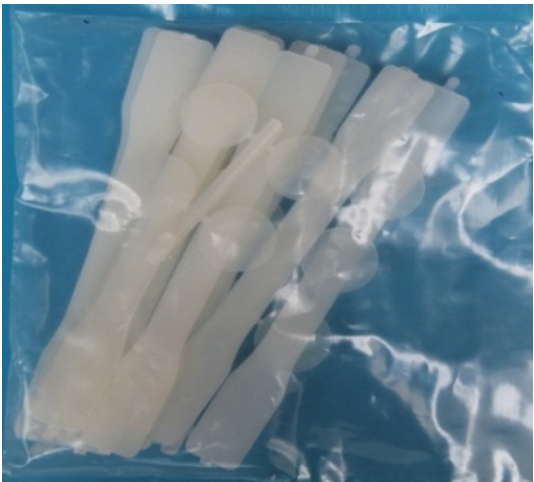

(b)

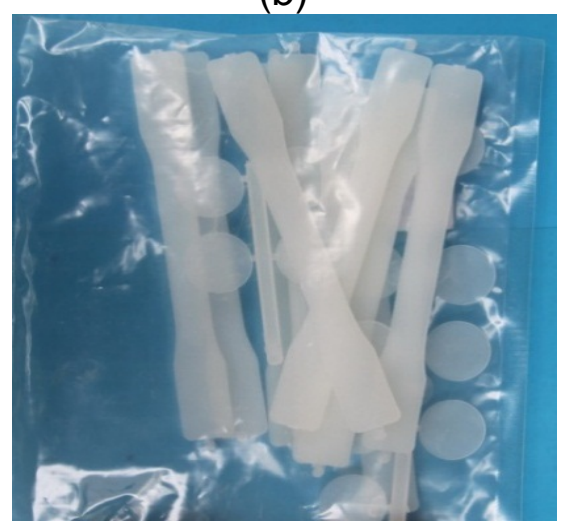

(d)

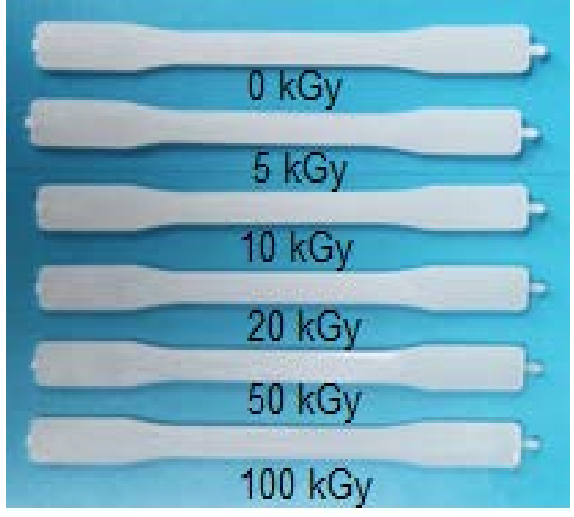

(f)

FIGURA 26 - PELBD ${ }_{i}$ após ser colocado na estufa. (a) 5 kGy. (b) 10 kGy. (c) 20 kGy. (d) 50 kGy. (e) 100 kGy. (f) PELBD não irradiado e irradiado. 


\subsection{Caracterização}

\subsection{1 Índice de Fluidez (IF)}

Na FIG. 27 apresentam-se as amostras após a medida de IF realizadas no aparelho CEAST IFM. Observa-se que as amostras irradiadas com doses de $5 \mathrm{e}$ $10 \mathrm{kGy}$ apresentaram um menor escoamento e maior inchamento que a amostra não irradiada.

As amostras irradiadas com doses de 5 e $10 \mathrm{kGy}$ apesar de fundir, o valor de IF é menor do que o PELBD ${ }_{i}$ não irradiado. Supõe-se que a radiação fragmentou as cadeias poliméricas e reticulou em pequena proporção mudando sua conformação dificultando o deslizamento ao longo do cilindro.

Na FIG. 28 está apresentado o IF do PELBD, resina, injetado e irradiado em função da dose de irradiação. Observa-se na FIG. 28 que o IF diminuiu à medida que se aumenta a dose de radiação indicando o aumento de ligações cruzadas em relação à cisão. $\mathrm{O} P E L B D_{i}$ não irradiado possui um IF inferior à resina de PELBD que é 0,8 g.10 $\mathrm{min}^{-1}{ }^{(79)}$ devido a formação das duplas ligações no processo de injeção.

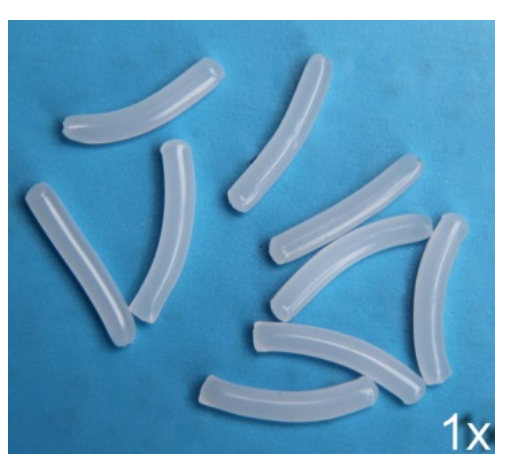

(a)

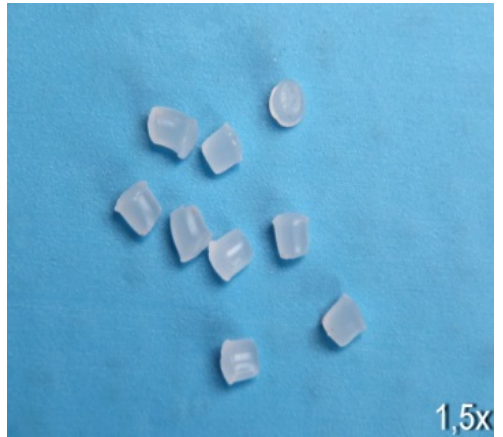

(b)

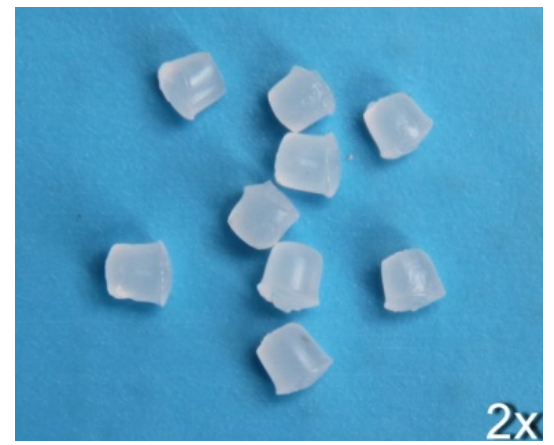

(c)

FIGURA 27 - Amostras obtidas no processo de análise de índice de fluidez do PELBD ${ }_{\text {. }}$ (a) 0 kGy. (b) 5 kGy. (c) 10 kGy.

O processo de reticulação foi mais intenso nas amostras irradiadas com doses de 20, 50 ou 100 kGy pois a radiação rompeu as ligações da cadeia principal e obteve radicais livres que se uniram em ligações cruzadas aumentando 
a dificuldade do material em fundir e fluir, justificando-se assim a ausência de valores de índice de fluidez ${ }^{(80)}$.

Quando o fundido sai da matriz, as macromoléculas tendem a voltar às suas conformações caóticas de equilíbrio. Isso produz um encolhimento longitudinal e uma expansão lateral ${ }^{(72)}$, aumentando o inchamento.

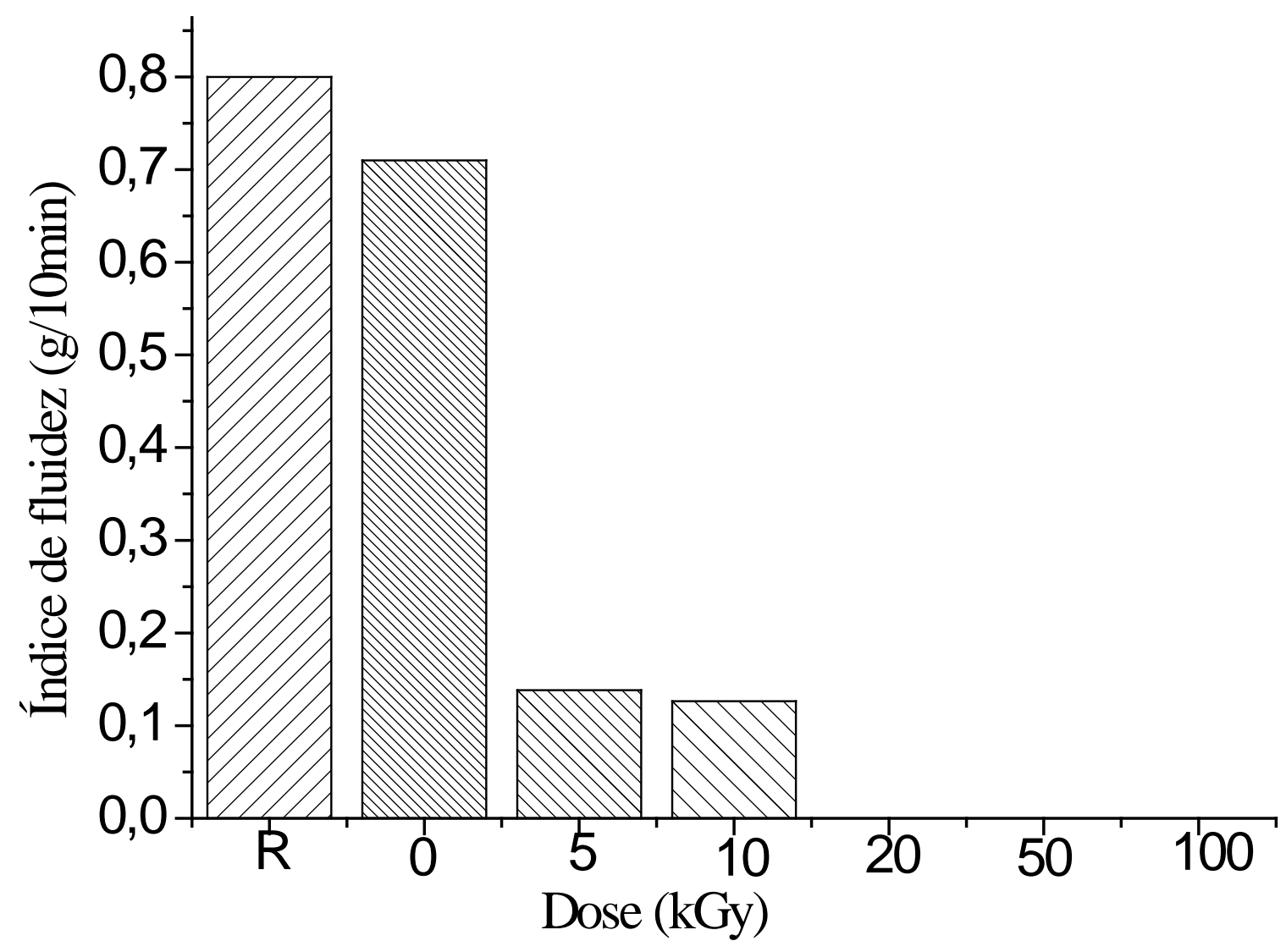

FIGURA 28 - Índice de fluidez do PELBD, resina, injetado e irradiado em função da dose de radiação.

O tamanho da cadeia lateral do $P E L B D_{i}$ não irradiado, por ser curto não irá causar qualquer emaranhamento das moléculas, apesar de suas cadeias apresentarem formação de duplas ligações seu inchamento foi maior ao da resina de PELBD ${ }^{(81)}$. Quanto aos PELBD $i$ irradiados temos aumento do inchamento pois suas cadeias poliméricas apresentam os efeitos cisão e reticulação do processo via radiação gama que deixa a estrutura da cadeia mais caótica. Supõe-se que as mudanças no material via radiação sejam mais intensas que o surgimento das duplas ligações no processo de injeção. O PELBD ${ }_{i}$ irradiado ao passar pela matriz 
tende a adquirir seu estado de equilíbrio de cadeias desordenadas aumentando o inchamento, FIG. 29.

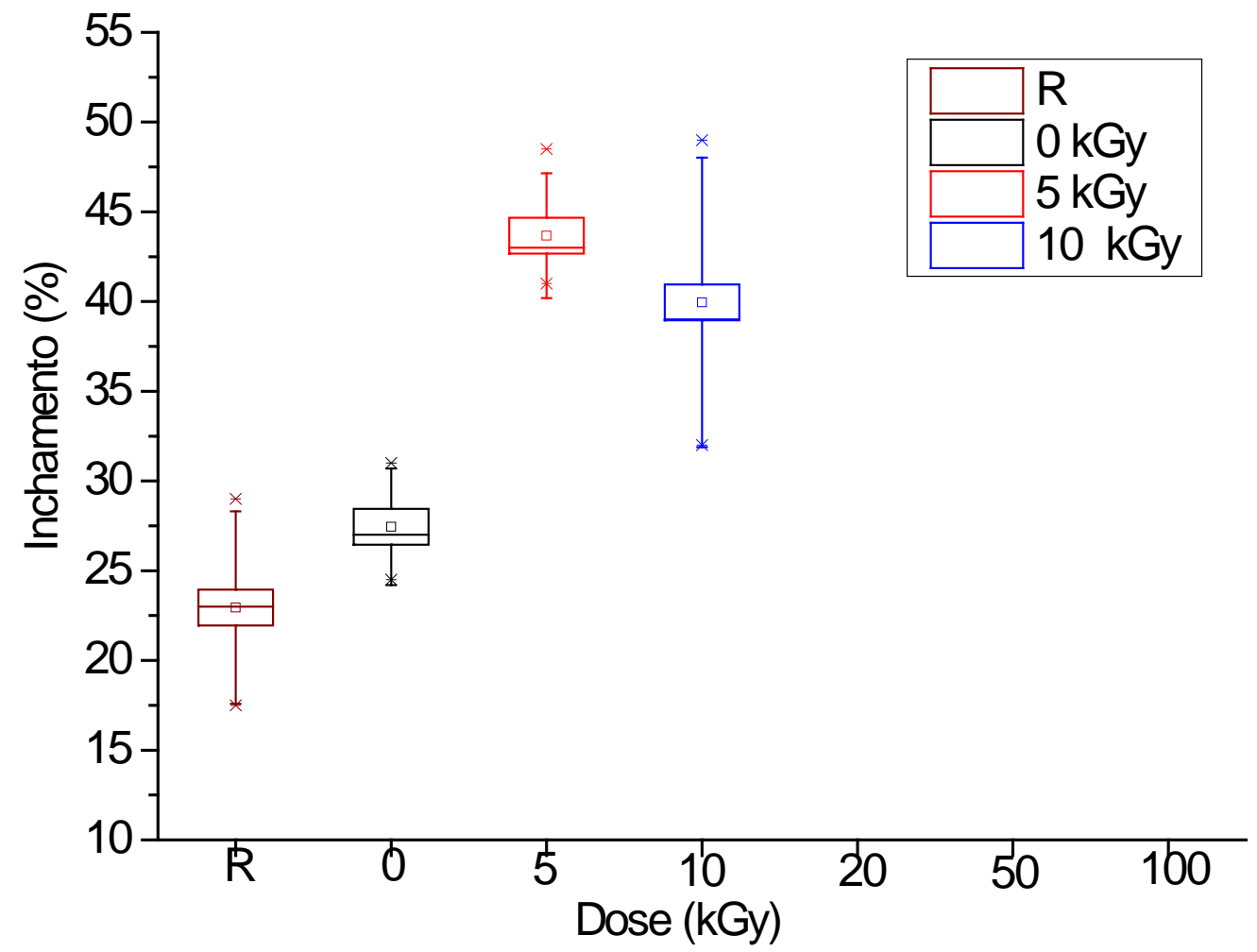

FIGURA 29 - Porcentagem de inchamento do PELBD, resina, injetado e irradiado em função da dose de radiação.

\subsubsection{Fração gel}

A fração gel determina a fração insolúvel por meio de extração com solvente, que para o PELBD é usado o xileno ${ }^{\left({ }^{(2)} \text {. }\right.}$

Na FIG. 30 apresentam-se as massas insolúveis das amostras irradiadas com doses de 50 e 100 kGy decorrentes das reticulações geradas. Em doses inferiores não foi possível obter as imagens, pois o material insolúvel resultante é pequeno ficando preso na malha de aço. 


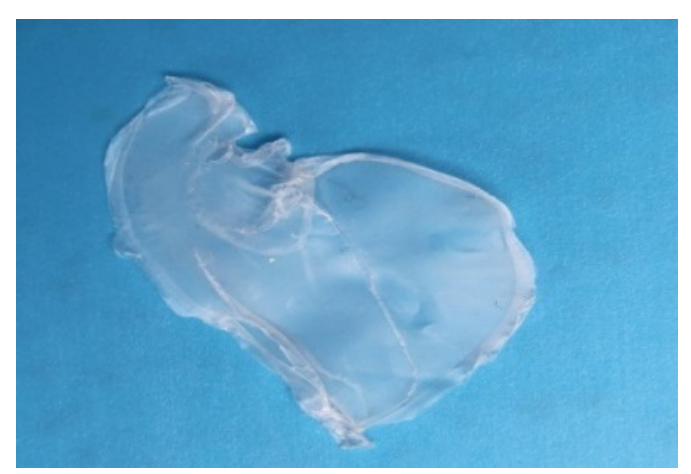

(a)

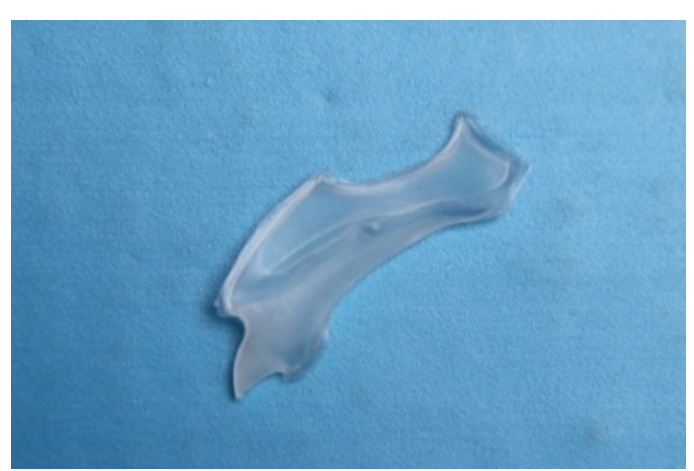

(b)

FIGURA 30 - Aspecto do gel da análise de fração gel do PELBDi. (a) 50 kGy (b) $100 \mathrm{kGy}$.

Observa-se na FIG. 31 o aumento na porcentagem de gel em função do aumento da dose de radiação. $O$ aumento de gel é um indicador de reticulação do material e, portanto, tem variação inversa ao índice de fluidez. Na preparação das amostras por injeção houve a formação de duplas ligações provocando um aumento de ligações químicas na cadeia polimérica e com isso aumento de fração gel quando comparado a fração gel do PELBD resina que é $4,6 \%$ de gel ${ }^{(82)}$.

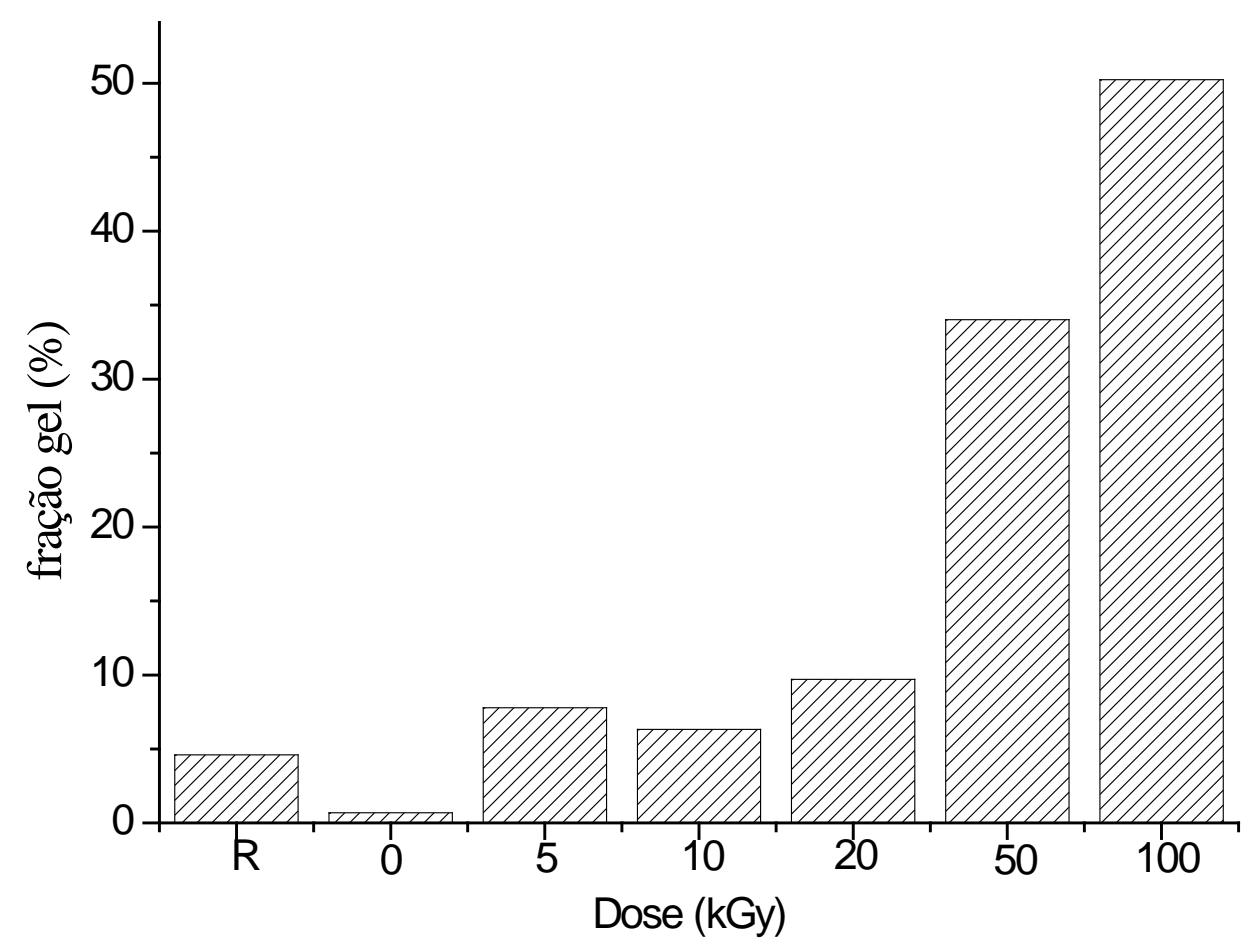

FIGURA 31 - Fração gel do PELBD, resina, injetado e irradiado em função da dose de radiação. 


\subsubsection{Análise no Infravermelho por Transformada de Fourier (FTIR)}

Durante o processo de injeção do PELBD ocorreu à formação de instaurações $-\mathrm{C}=\mathrm{C}$ - observada em número de onda $1654 \mathrm{~cm}^{-1}$ para o $P E L B D_{i}$ (FIG. 34 a). Nota-se a ausência desta absorção no espectro da resina de PELBD apresentada nas FIG. 32 e FIG. 34 b.

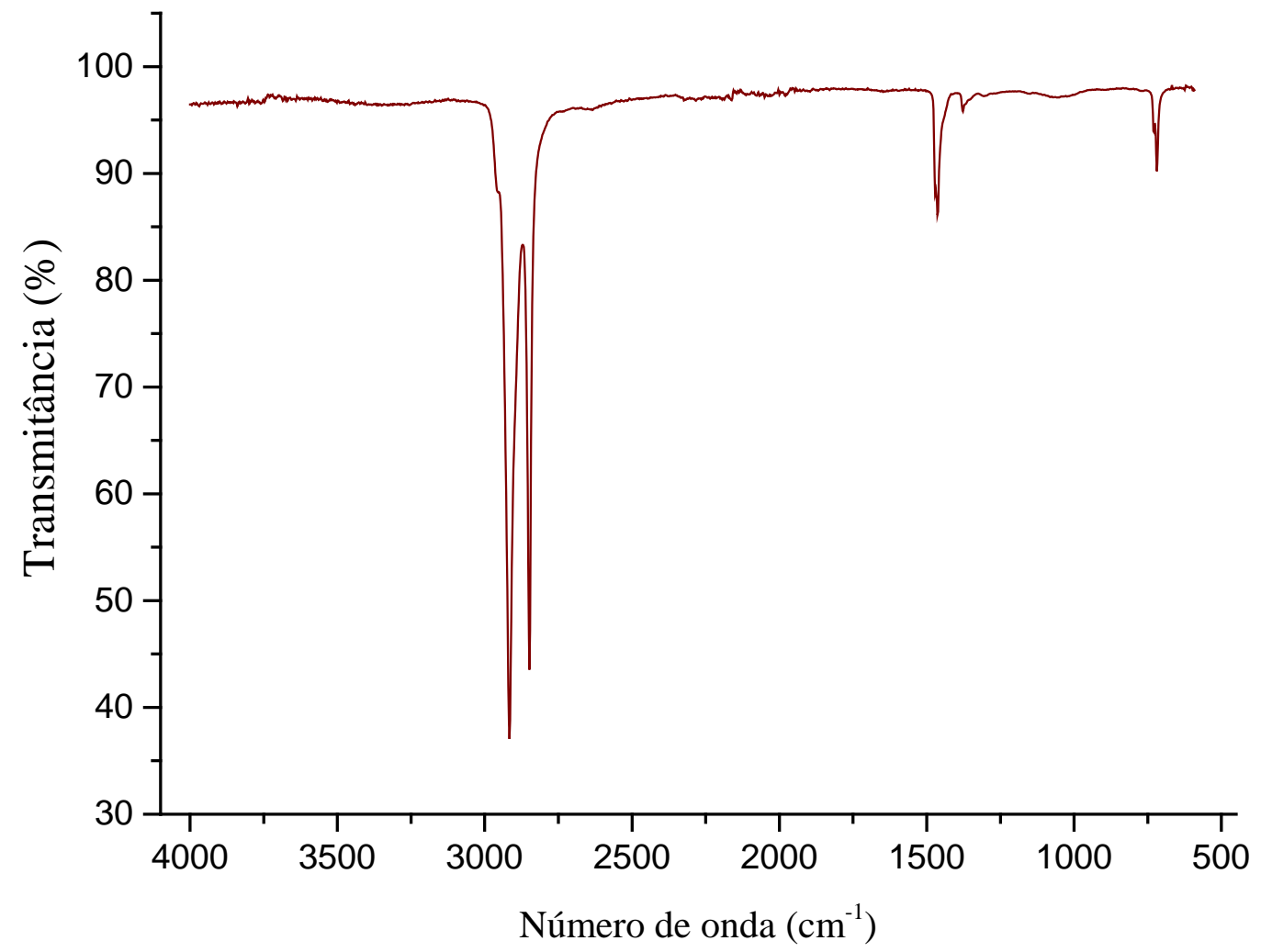

FIGURA 32 - Espectros FT-IR da resina PELBD entre 500 e $4000 \mathrm{~cm}^{-1}$.

Na FIG. 33 estão apresentadas as bandas mais relevantes da estrutura do PELBD $D_{i}$ nos números de onda 2918, 2850, 1473 e $1463 \mathrm{~cm}^{-1}$ (-CH-) referente ao estiramento do $-\mathrm{CH}_{2}$ e $716 \mathrm{~cm}^{-1}$ para $\left(\mathrm{CH}_{2}\right) \mathrm{n}>4$. 


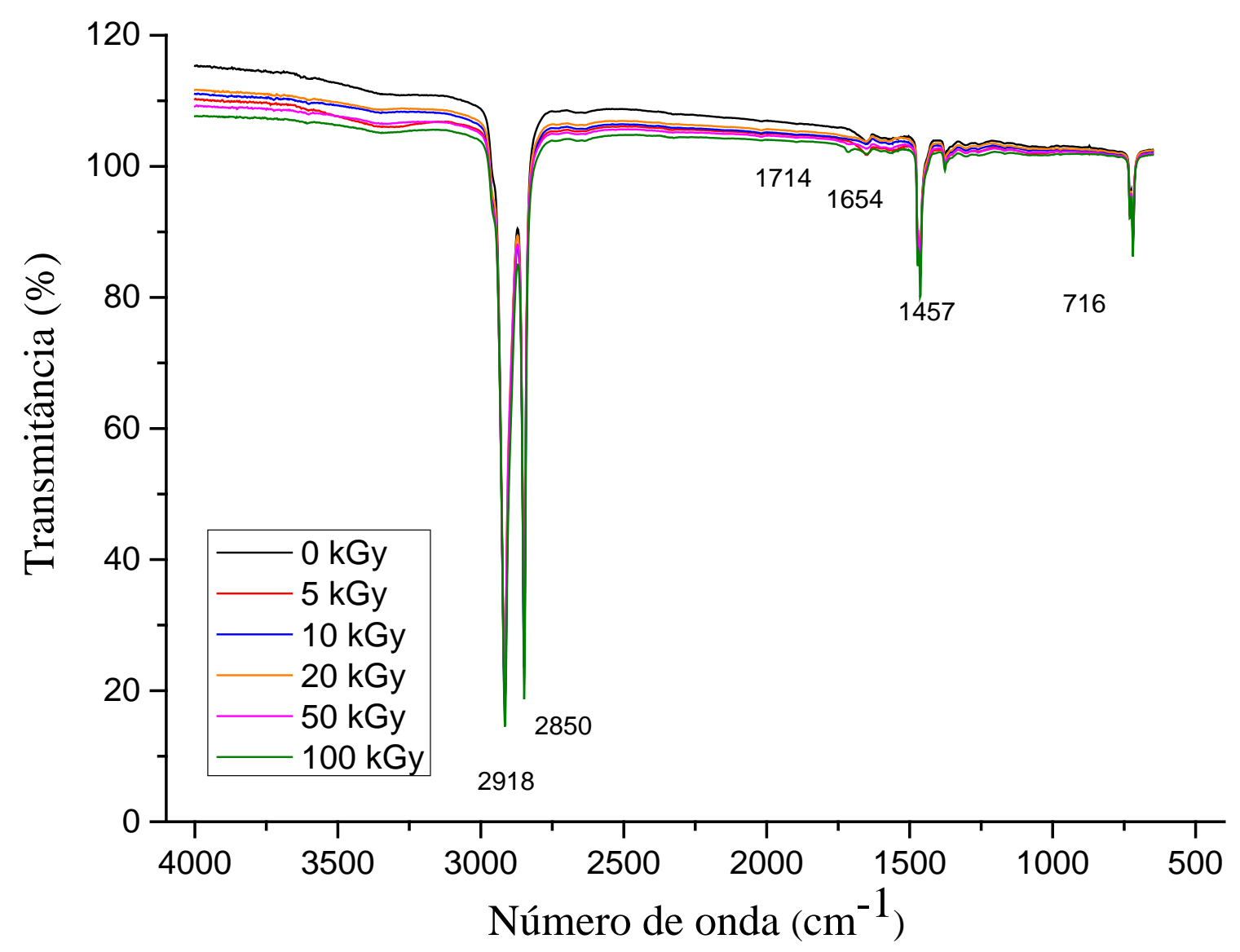

FIGURA 33- Espectros FTIR do PELBD ${ }_{i}$ irradiado com doses de 0, 5, 10, 20, 50 ou 100 kGy entre 500 e $4000 \mathrm{~cm}^{-1}$.

A técnica foi eficiente para identificar os efeitos de irradiação no $P E L B D_{i}$ à medida que a dose aumenta. As alterações na cadeia polimérica devido às reações de degradação oxidativa no processo de irradiação do $P E L B D_{i}$, foram mais evidentes nas doses de 50 e 100 kGy, onde a absorção a 1714 cm$^{-1}$ atribuída a estiramento da ligação $-\mathrm{C}=\mathrm{O}$ aparece sutilmente, indicando uma maior degradação em relação às outras doses ${ }^{(77)}$. Formam-se também radicais livres pelo efeito da cisão dando origem a insaturações de $-\mathrm{C}=\mathrm{C}-$, número de onda $1650 \mathrm{~cm}^{-1}$. 


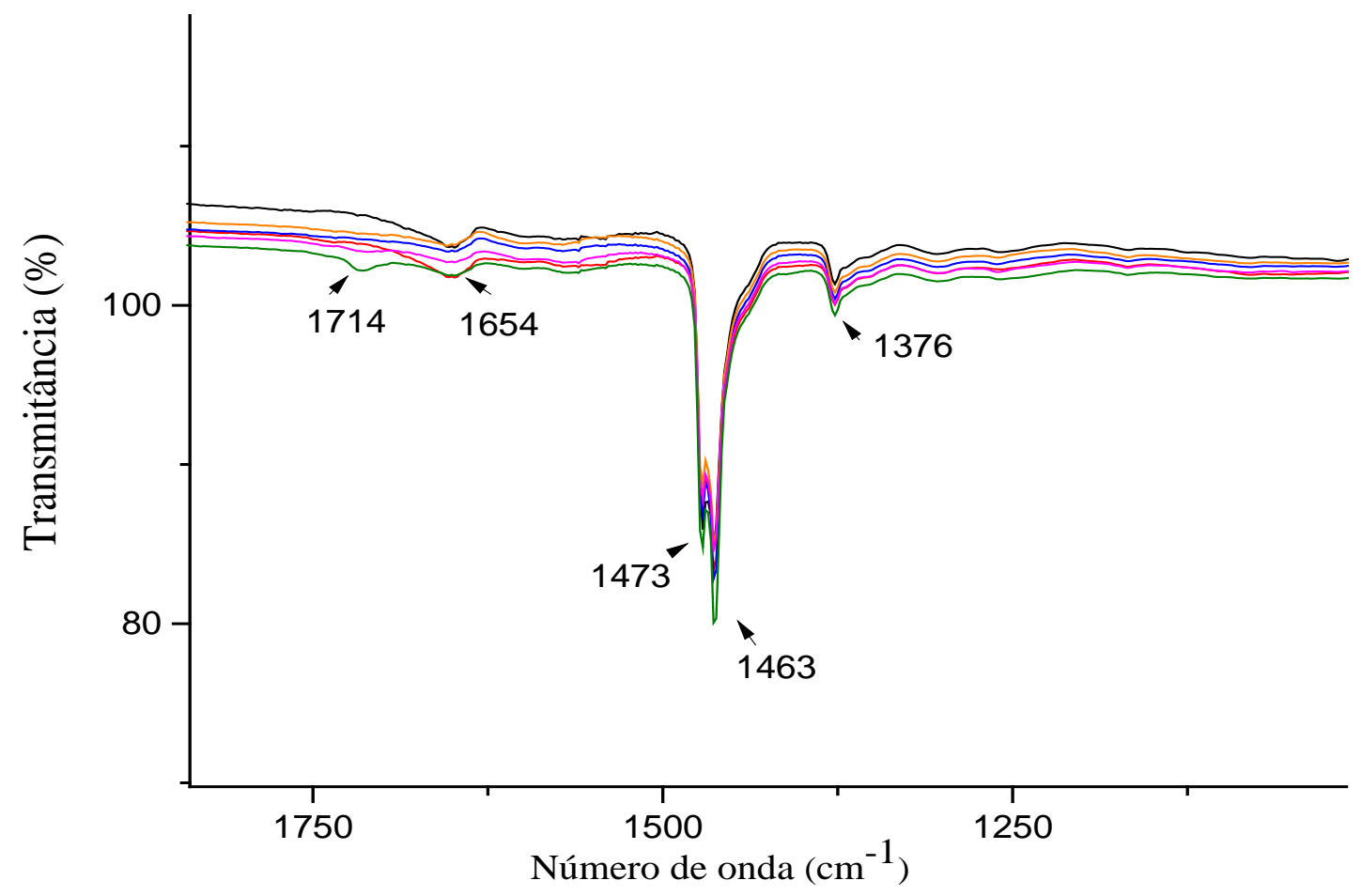

(a)

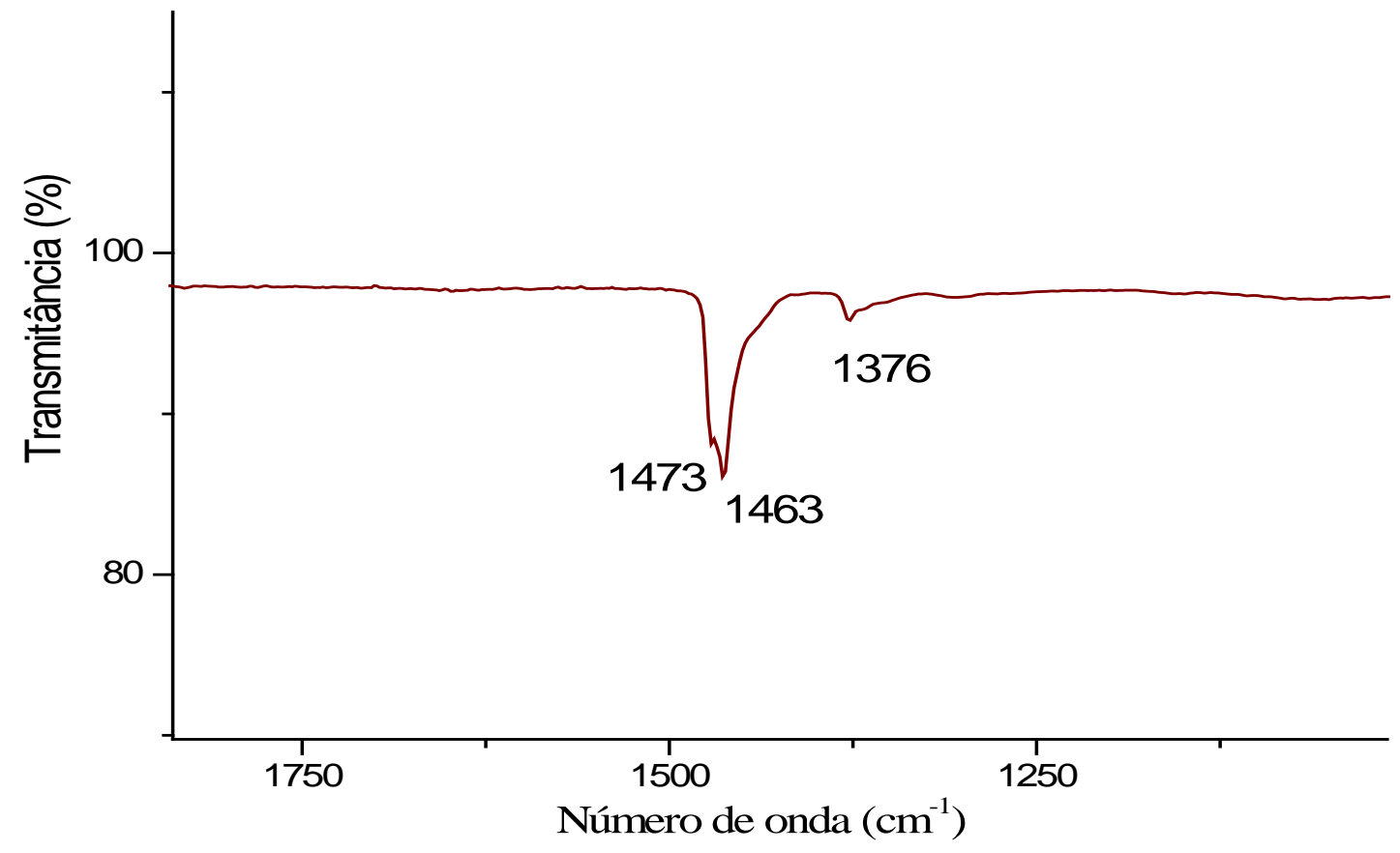

(b)

FIGURA 34 - Detalhe no intervalo de 1250 a $1750 \mathrm{~cm}^{-1}$ dos Espectros FT-IR do PELBD $_{i}$ (a) e da resina (b). 


\subsubsection{Análises por Calorimetria exploratória diferencial (DSC)}

Na TAB. 11 ao comparar a cristalinidade da resina de PELBD com o $P E L B D_{i}$ não irradiado confirma-se a degradação do material injetado pois diminui o grau de cristalinidade do PELBD . $_{\text {. }}$

Acredita-se que as longas cadeias lineares do $P E L B D_{i}$ tenham impedido as tensões, particularmente na superfície do molde de alinharem as cadeias do polímero na direção do fluxo durante o processo de injeção.

Apresentam-se na TAB. 11 os efeitos da degradação oxidativa e os efeitos da radiação no material injetado. Comparado o $P E L B D_{i}$ não irradiado com o $\operatorname{PELBD}_{i}$ irradiado à medida que se aumentou a dose de radiação houve uma pequena variação no grau de cristalinidade, na entalpia e na temperatura de fusão, mas quando se compara com a resina temos variações significativas.

TABELA 11 - Valores de temperatura de fusão, entalpia de fusão e cristalinidade obtidos por (DSC).

\begin{tabular}{llll}
\hline Doses $(k G y)$ & $\mathrm{T}_{\mathrm{f}}\left({ }^{\circ} \mathrm{C}\right)$ & $\Delta \mathrm{H}_{\mathrm{f}}(\mathrm{J} / \mathrm{g})$ & $\mathrm{X}_{\mathrm{c}}(\%)$ \\
\hline resina PELBD $(83)$ & 127,7 & 102,5 & 43,9 \\
PELBD $_{i} 0$ & 132,6 & 95,9 & 34,4 \\
PELBD $_{5}$ & 133,0 & 92,3 & 33,1 \\
PELBD $_{1} 10$ & 133,9 & 99,4 & 35,6 \\
PELBD $_{i} 20$ & 135,5 & 95,1 & 34,1 \\
PELBD $_{i} 50$ & 135,4 & 95,6 & 34,3 \\
PELBD $_{i} 100$ & 132,4 & 87,4 & 31,3 \\
\hline
\end{tabular}

\subsubsection{Difração de Raios X (DRX)}

As curvas de Difração de Raios X apresentam a contribuição de duas fases, cristalina e amorfa. Para o cálculo da fração cristalina dividiu-se a área dos picos pela soma das áreas correspondentes ao espalhamento amorfo e cristalino. Determinou-se o ajuste das curvas gaussianas geradas à base dos picos de difração, de forma a estimar o espalhamento amorfo e cristalino. Estes ajustes 
foram realizados no software Origin $8.0^{\circledR}$, como apresentado na FIG. 35, para todas as doses de radiação ${ }^{(84)}$.

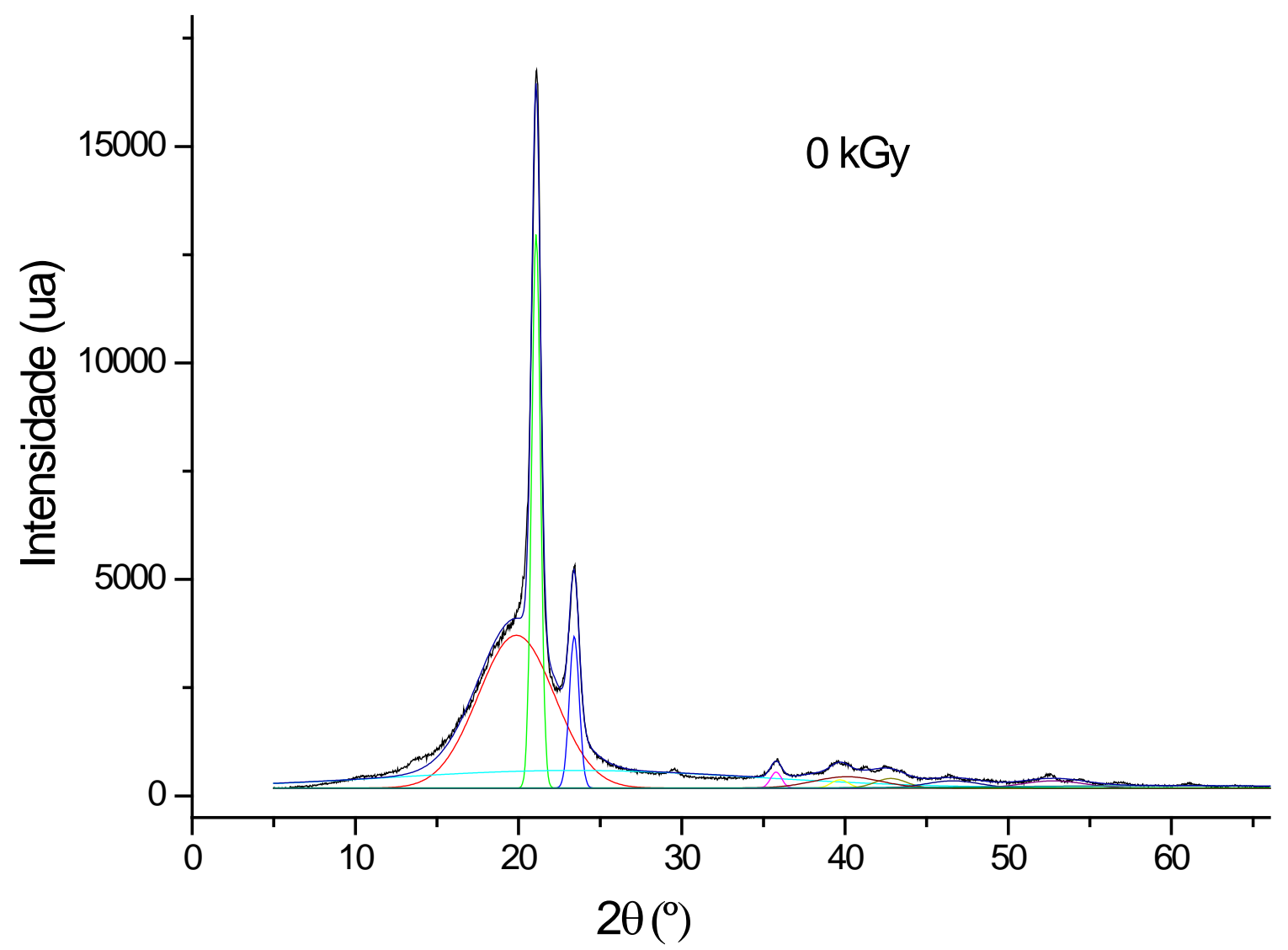

FIGURA 35 - Ensaio controle do $\mathrm{PELBD}_{\mathrm{i}}$ não irradiado na análise de DRX.

O valor do grau de cristalização pela técnica DRX é apresentado na FIG. 36 por três análises para cada dose de radiação (apêndice A, B e C). Ao comparar o grau de cristalinidade por meio de duas técnicas somente no valor para $P E L B D_{i}$ irradiado com 100 kGy houve uma variação significativa, amostra que sofreu maior efeito da irradiação, como observado por fração gel.

Análise de DRX tem como base de seus cálculos as difrações dos raios $x$ que colidem com os cristais. Considerando-se que a amostra não possui os cristais uniformemente distribuídos e, dependendo da região que o feixe passe irá identificar quantidades diferentes de cristais. 
As modificações no PELBD $_{i}$ por radiação gama são apresentadas pela técnica de DRX como um valor da cristalinidade mais acentuado em relação aos valores da técnica de DSC. Supõe-se que essa diferença tenha acontecido no processo de injeção do corpo de prova, pois a peça moldada resfria-se primeiro a superfície e em seguida o seu interior. Logo na superfície tem-se uma maior orientação nos cristais em relação ao interior do corpo de prova. Já a análise de DSC utiliza como base de cálculo a variação das entalpias, as análises obtiveram valores dentro da margem de erro aceitável.

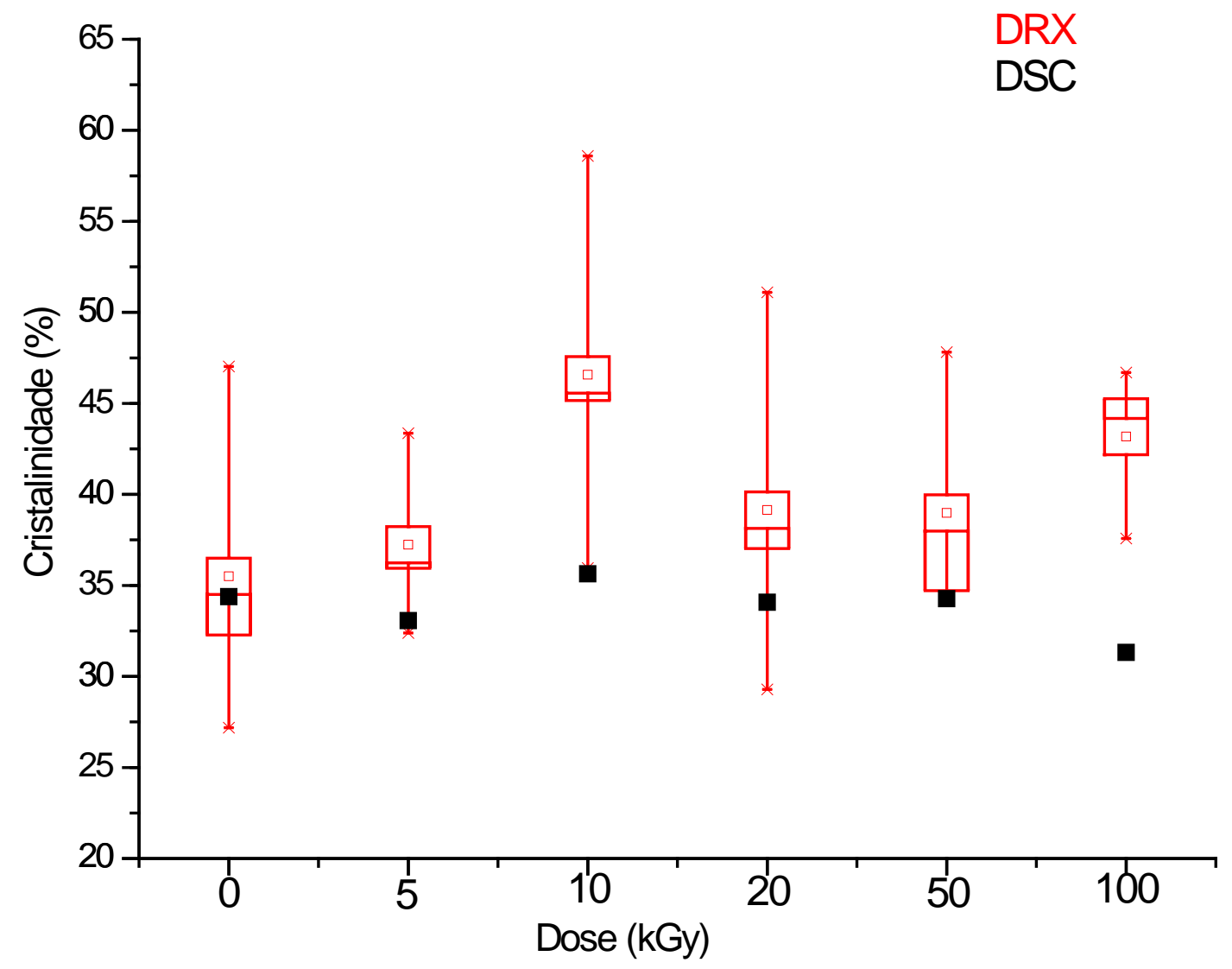

FIGURA 36 - Porcentagem de cristalinidade por DRX e DSC do PELBD não irradiado e irradiado com diferentes doses.

\subsubsection{Análise de termogravimetria (TG)}

O polietileno linear de baixa densidade injetado não irradiado quando aquecido apresenta dois eventos de perda de variações de massa significativos 
(FIG. 37). No primeiro intervalo de temperatura de 230 a $310{ }^{\circ} \mathrm{C}$ acontece a decomposição de ligações das cadeias curtas. Já no intervalo de temperatura de 320 a $460{ }^{\circ} \mathrm{C}$ houve decomposição de ligações das cadeias mais longas. Observa-se que as curvas são idênticas à da resina PELBD.

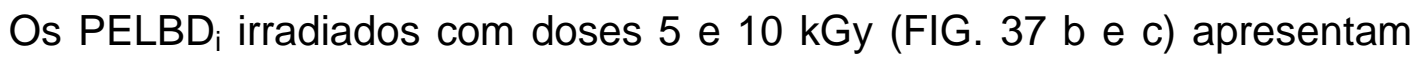
uma redução em sua temperatura de decomposição e o deslocamento dos picos 380 e $420^{\circ} \mathrm{C}\left(\mathrm{PELBD}_{\mathrm{i}}\right)$ para temperaturas mais baixas. Pode-se supor que nestas amostras tenha ocorrido a predominância da cisão na cadeia polimérica. Essa fragmentação da cadeia permitiu reduzir a quantidade de energia necessária para processar a degradação térmica.

Os dois estágios, cisão e reticulação, ficam mais evidentes no $P E L B D_{i}$ irradiado com dose de 20 kGy (FIG. 37 d). Aproximadamente $60 \%$ de sua decomposição acontecem a cerca de $410{ }^{\circ} \mathrm{C}$ e o restante da massa a cerca de $500^{\circ} \mathrm{C}$.

Quando o PELBD i é irradiado com doses de 50 ou 100 kGy (FIG. 37 e, f) a temperatura de decomposição aumenta e os picos 380 e $420{ }^{\circ} \mathrm{C}\left(P E L B D_{i}\right)$ se deslocam em direção a temperaturas mais altas se comparado ao $P E L B D_{i}$ não irradiado. Neste caso evidencia-se a reticulação corroborando com os resultados de índice de fluidez e fração gel. 

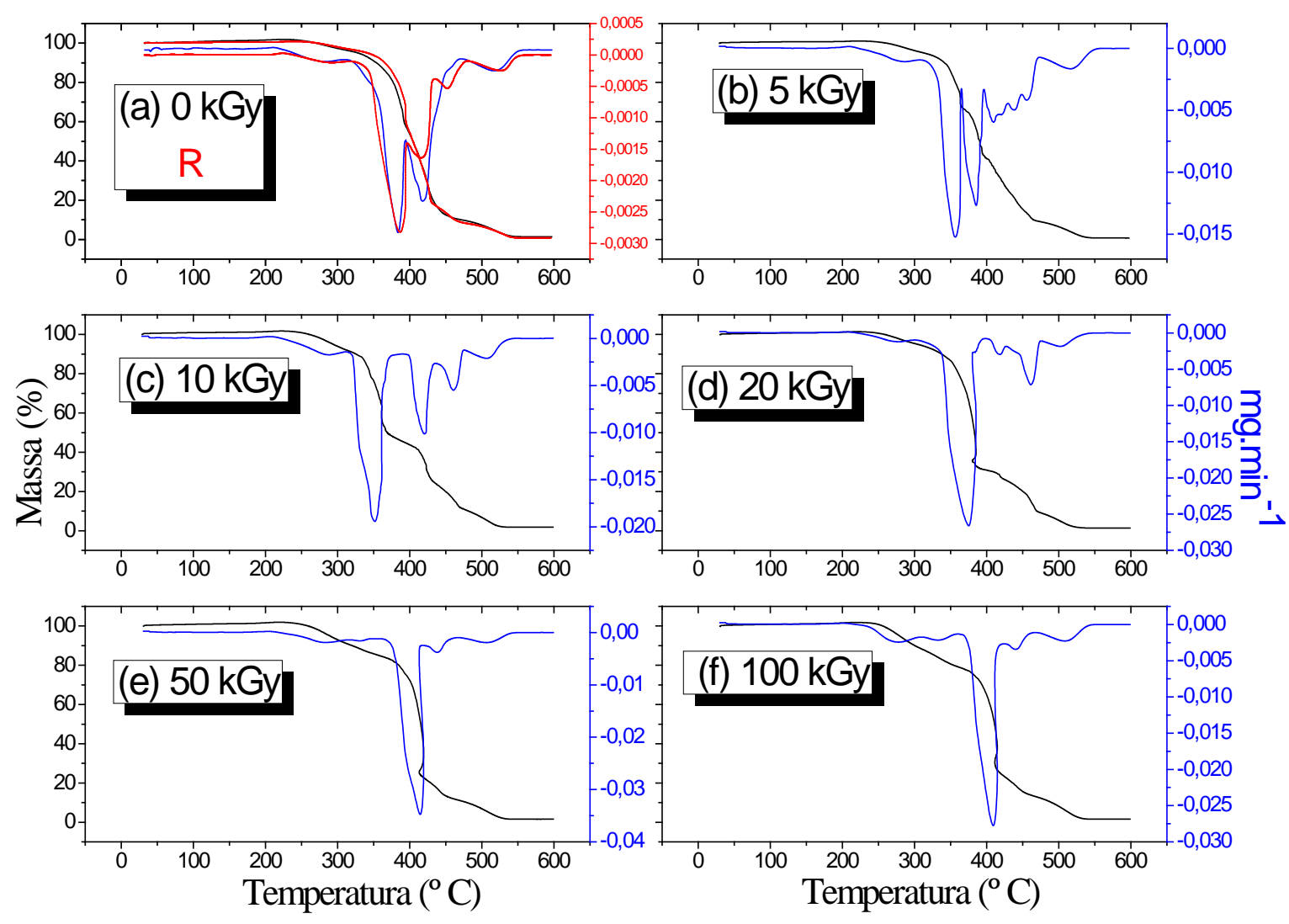

FIGURA 37 - TG-DTG em função da temperatura do PELBD obtido com doses de 0 kGy e resina (R) (a), 5 kGy (b), 10 kGy (c), 20 kGy (d), 50 kGy (e) e 100 kGy (f).

Na FIG. 38 está apresentada a decomposição do PELBD resina, injetado e irradiado em função da temperatura. Observa-se que a decomposição inicia-se igualmente a $100{ }^{\circ} \mathrm{C}$ mantendo-se até $300^{\circ} \mathrm{C}$ em todos os PELBD ${ }_{i}$ analisados. A partir de $310^{\circ} \mathrm{C}$ os $\mathrm{PELBD}_{\mathrm{i}}$ irradiados com doses de 5, 10 ou $20 \mathrm{kGy}$ começam a ter uma perda de massa mais intensa até $420^{\circ} \mathrm{C}$ e um segundo estágio de perda de massa ao redor de $480{ }^{\circ} \mathrm{C}$. Inversamente os $P E L B D_{i}$ irradiados com dose de 50 ou 100 kGy apresentam a ter uma porcentagem menor de decomposição à temperatura em torno $420{ }^{\circ} \mathrm{C}$ e maior decomposição a temperatura em torno de

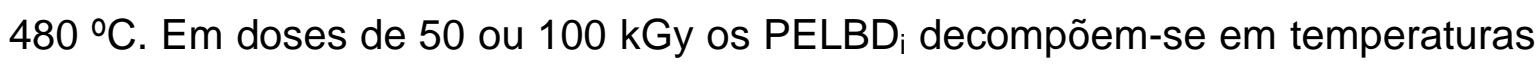
relativamente mais elevadas comparando-se aos $P E L B D_{i}$ irradiados em doses mais baixas, pois, como apresentamos anteriormente, nestas doses temos predominância de reticulação ${ }^{(71)}$. 


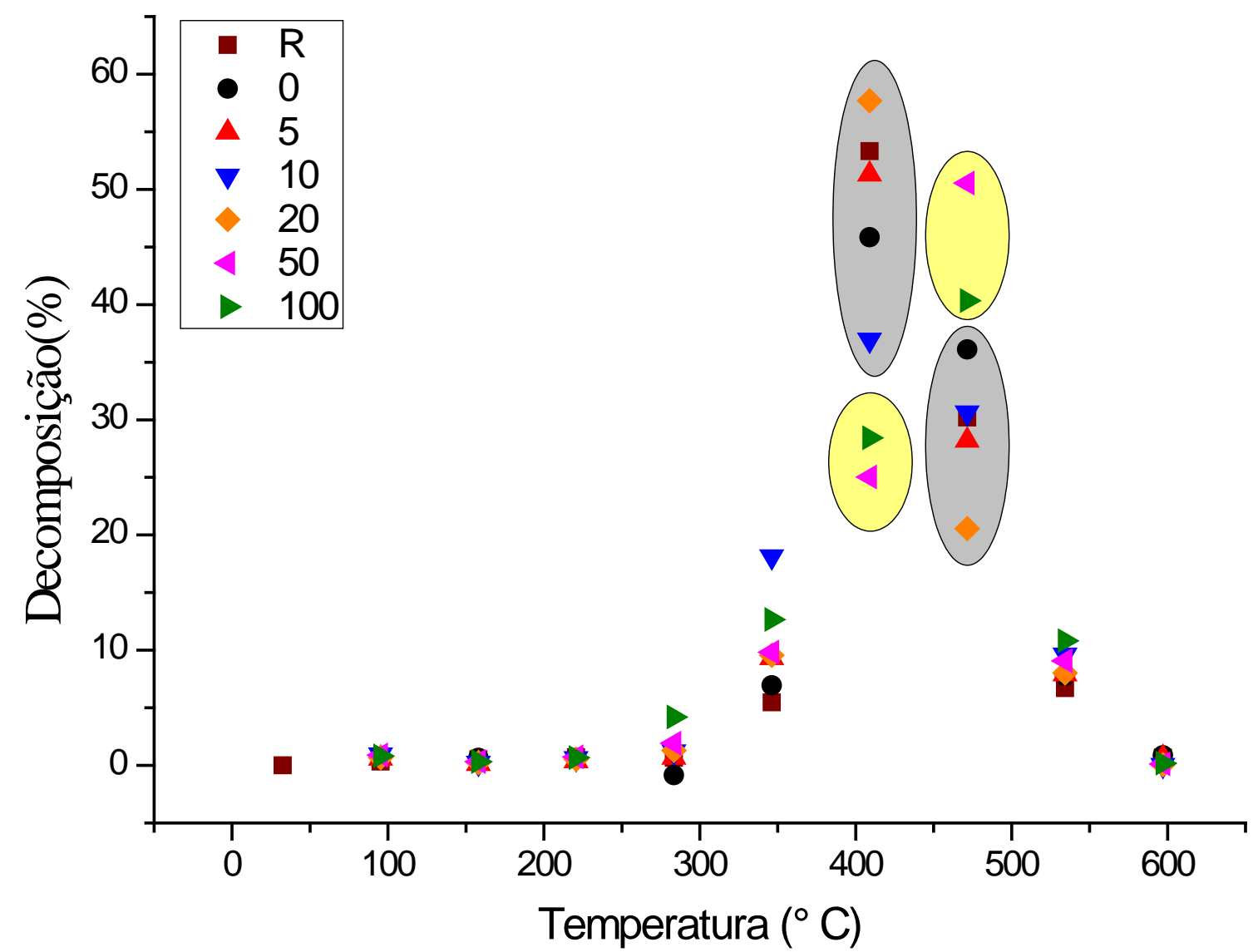

FIGURA 38 - Porcentagem de decomposição do PELBD resina, injetado e irradiado em função da temperatura.

\subsubsection{Análise termodinâmico-mecânica (DMA)}

A relaxação $\beta$ normalmente é encontrada quando o polímero apresenta ramificações e em polietilenos lineares, sendo atribuída ao movimento das ramificações na fase amorfa ou cisalhamento podendo ser intensificado com o aumento das interligações lamelares geradas pelas ramificações, e relacionada com transição vítrea na fase amorfa ${ }^{(85)(86)(87) .}$

Na FIG. 39 apresentam-se as curvas do módulo de perda em função da temperatura o aumento de intensidade dos picos de relaxação em doses de 5 , 10, 20, 50 ou $100 \mathrm{kGy}$, doses em que o material tem maior tendência de reticulação. Essa elevação de intensidade confirma o aumento de interligações na fase amorfa e consequentemente aumento do peso molecular. 


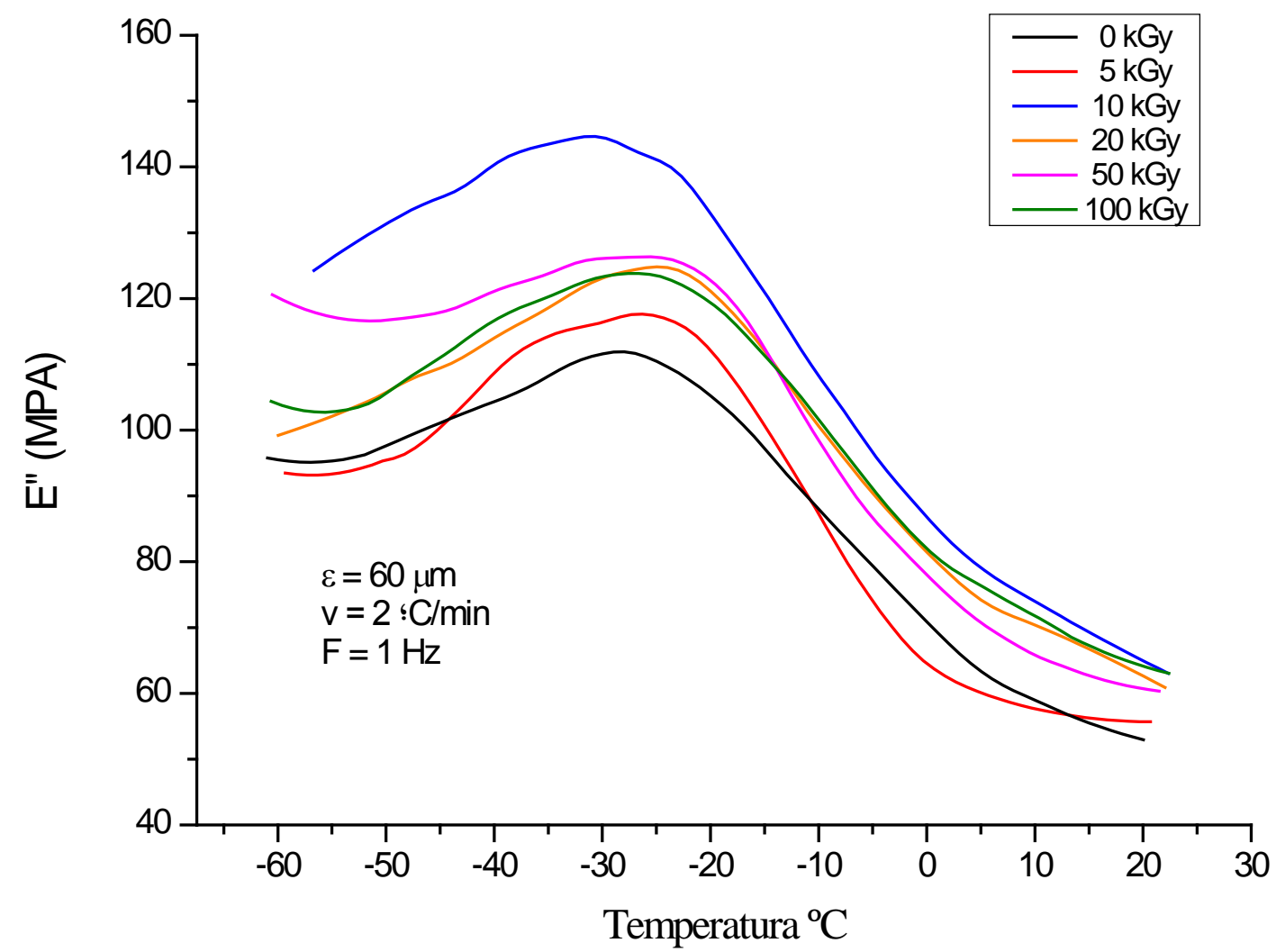

FIGURA 39 - Curvas de módulo de perda (E") em função da temperatura.

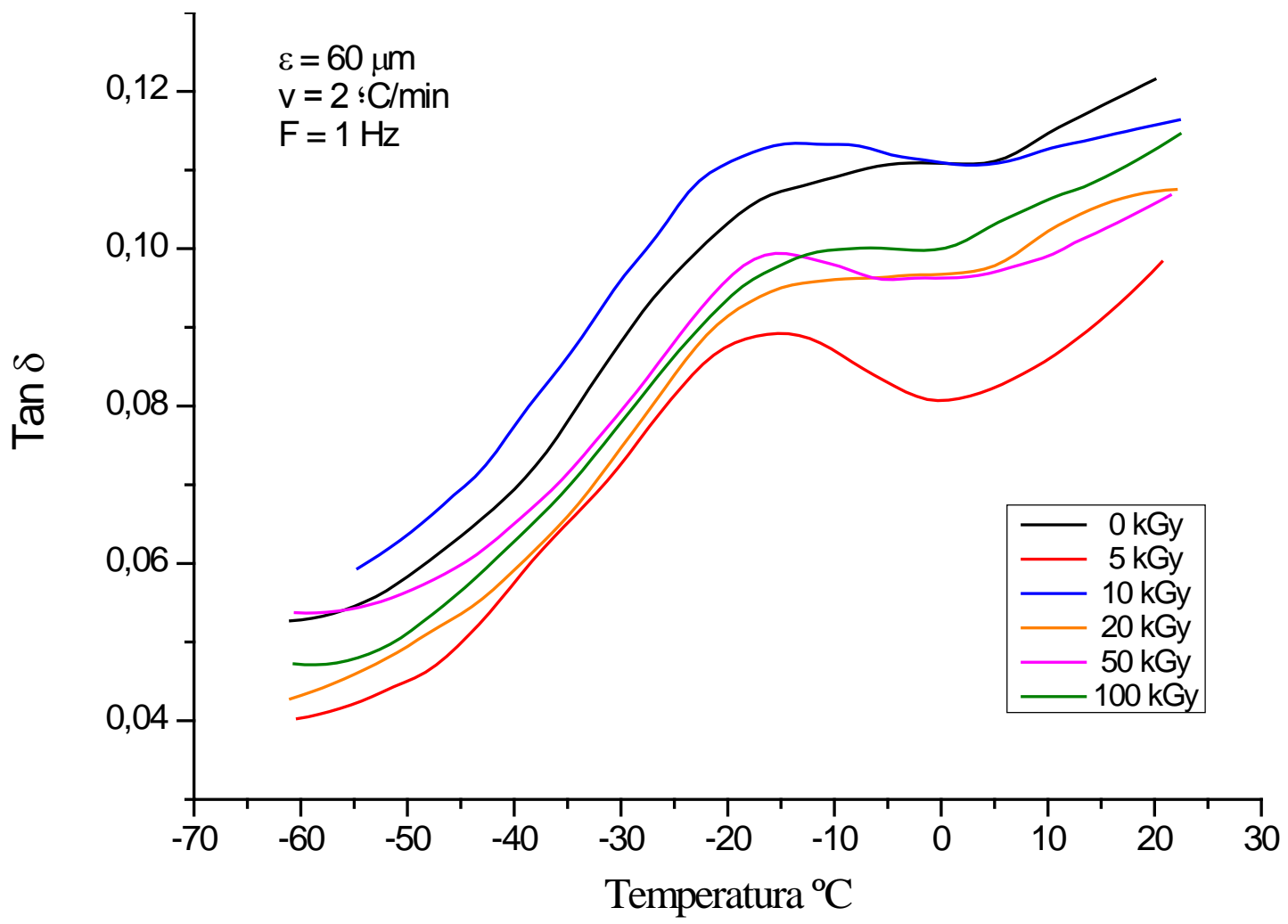

FIGURA 40 - Dissipação de energia (Tan $\delta$ ) em função da temperatura. 


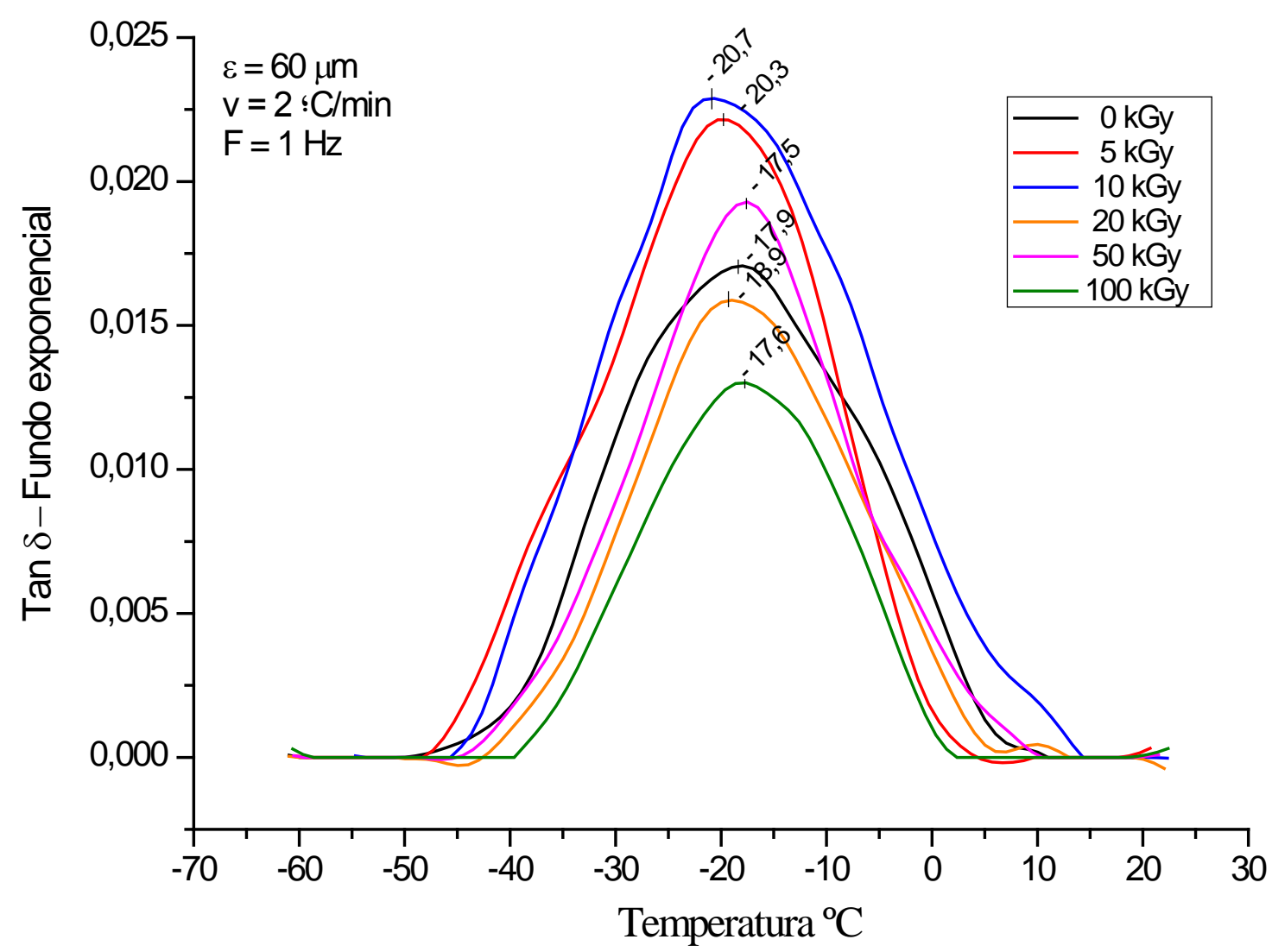

FIGURA 41 - Análise termodinâmico-mecânica (DMA) do PELBD ião irradiado e irradiado.

As curvas de DMA de módulo de perda (E") (FIG. 39) e dissipação de energia (tan $\delta$ ) (FIG. 40), em função da temperatura, apresentaram um pico largo próximo à temperatura $-23{ }^{\circ} \mathrm{C}$ correspondendo à relaxação $\beta$, ou seja a transição vítrea ${ }^{(88)}$. O máximo dos picos que corresponde à $T_{g}$ foi -17,9, -20,3, -20,7, -18,9, $-17,5,-17,6^{\circ} \mathrm{C}$, respectivamente, para doses 0 (não irradiado), 5, 10, 20, 50 e 100 kGy (FIG. 41).

Na FIG. 42 o pico formado é devido à relaxação das cadeias moleculares. Para baixas doses (5 e 10 kGy) há uma cisão de cadeias o que facilita a sua movimentação (menor Tp) apresentada na FIG. 43 aumentando o número de cadeias participando da relaxação (aumento da altura do pico). Para a dose de 20 kGy há um equilíbrio entre a cisão e a reticulação. Já para as doses altas 50 e 100 kGy predomina a reticulação dificultando a movimentação das cadeias (maior Tp) e, como a amplitude de medida se mantem, o pico diminui pois um número menor de cadeias responde à tensão aplicada. 


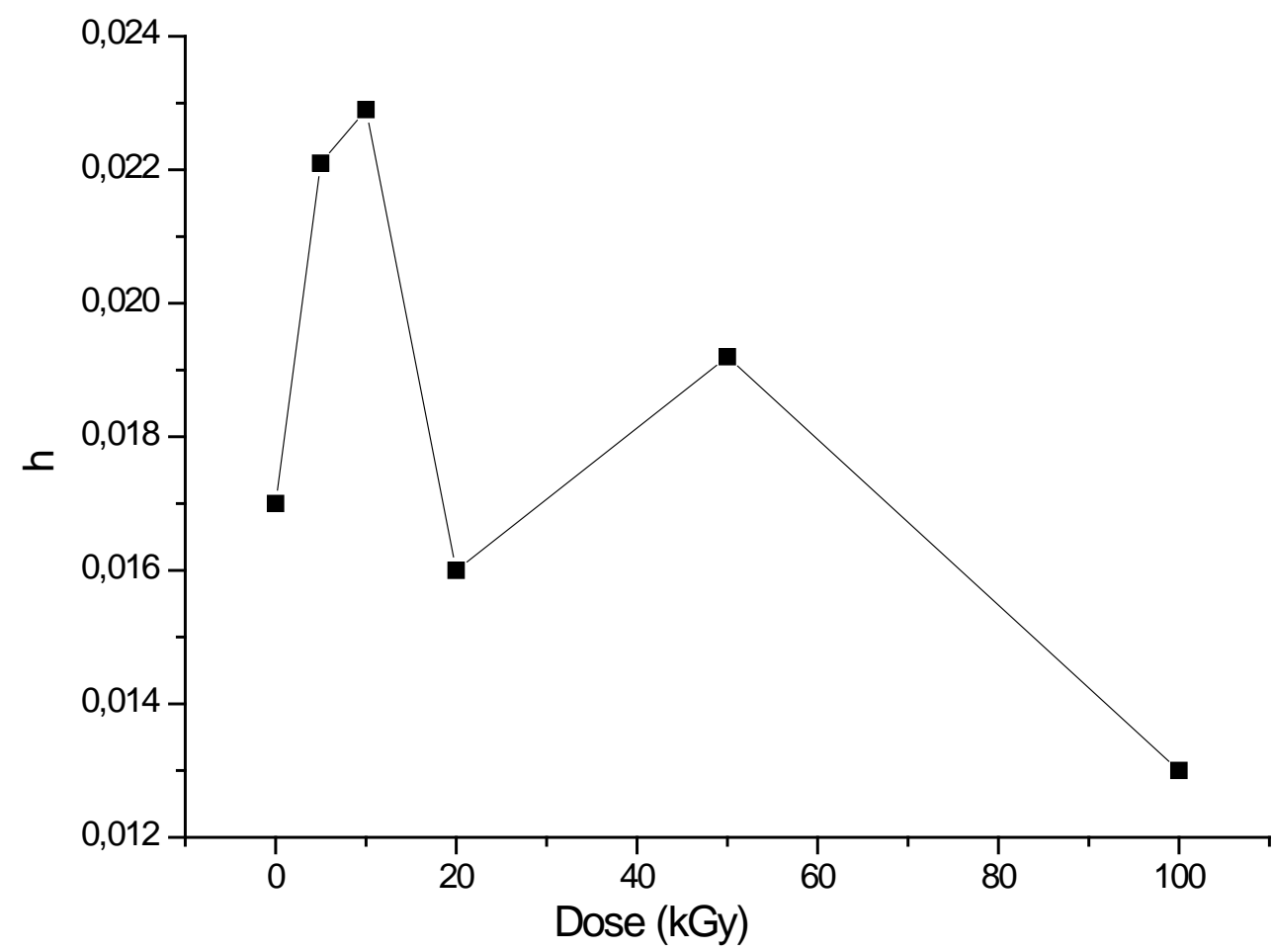

FIGURA 42 - Altura do pico (Tan $\delta$ - fundo exponencial) em função da dose de irradiação.

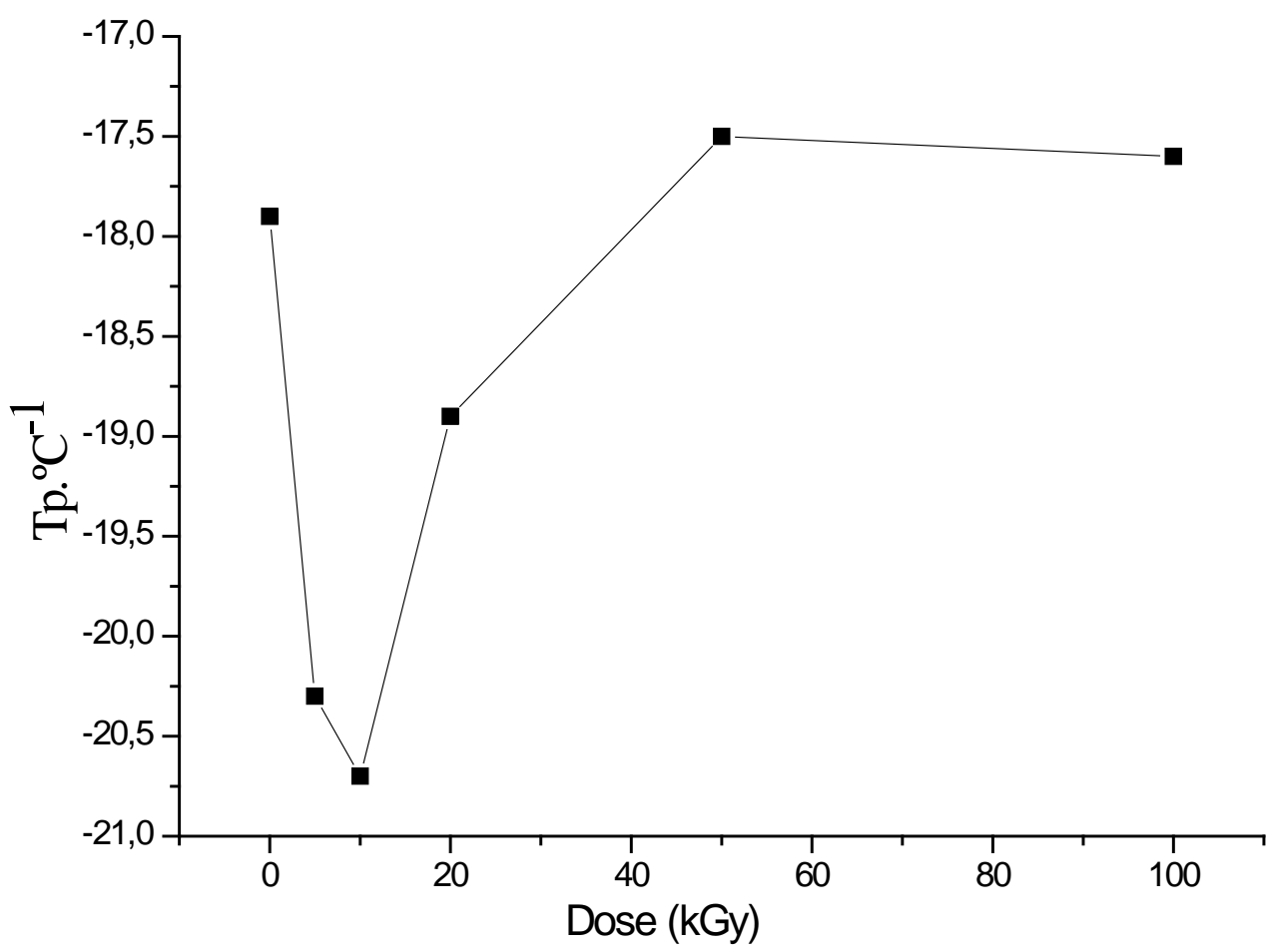

FIGURA 43 - Temperatura do pico (Tan $\delta$ - fundo exponencial) em função da dose de irradiação. 


\subsubsection{Reometria de placas paralelas}

A reometria rotacional permite identificar as propriedades viscoelásticas dos polímeros relacionando-se a suas estruturas.

Nos ensaios de reologia as amostras de $P E L B D_{i}$, não irradiadas e irradiadas com doses de $5,10,20,50$ e $100 \mathrm{kGy}$, fundem entre as placas paralelas e retiram-se os excessos de material após o aquecimento. As com doses de 50 e 100 kGy apresentaram uma aparência e consistência de "borracha" impedindo a retirada do excesso de material (FIG. 44). Estas amostras também escorregaram (FIG. 46) durante os ensaios e por isso, não foi possível obter as curvas de G', G" e $\left|\eta^{*}\right|$ nas doses de 50 e 100 kGy (FIG. 45) ${ }^{(89) .}$

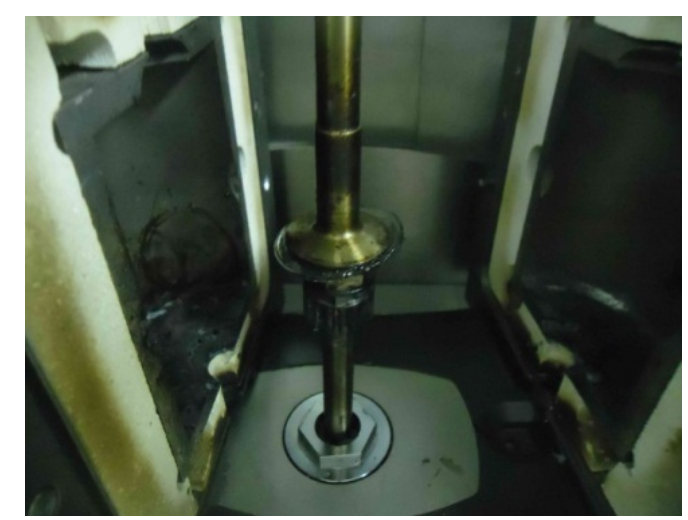

(a)

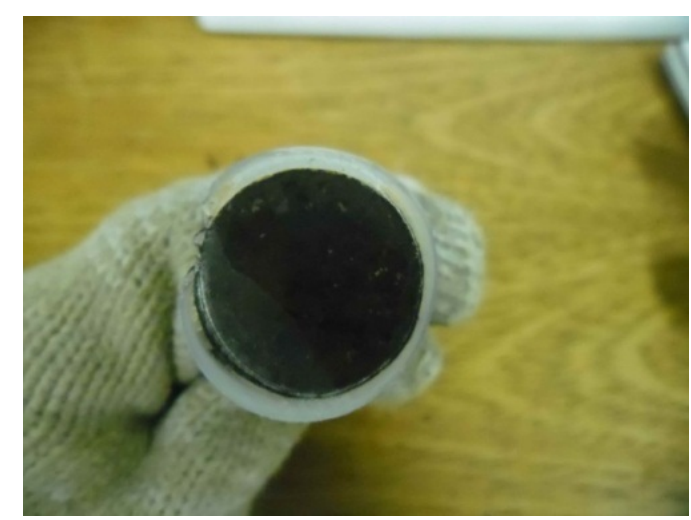

(b)

FIGURA 44 - PELBD 50 kGy na análise de reologia.

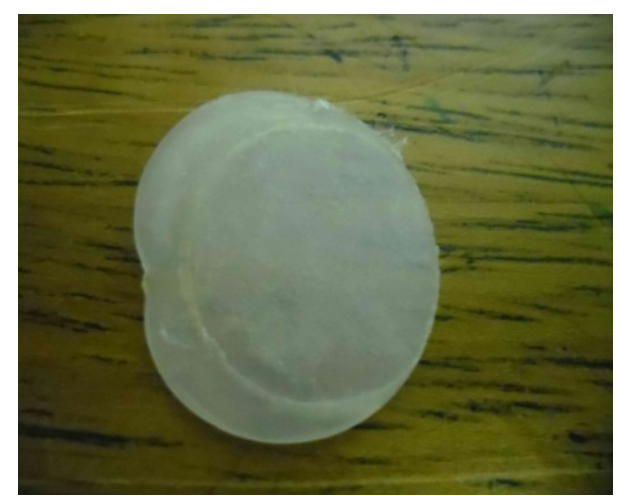

(a)

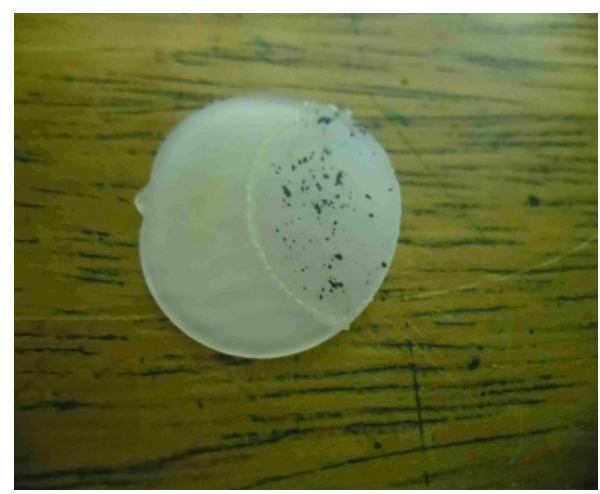

(b)

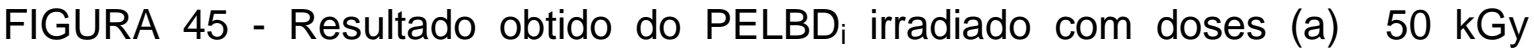
(b) 100 kGy após término da análise de reologia. 


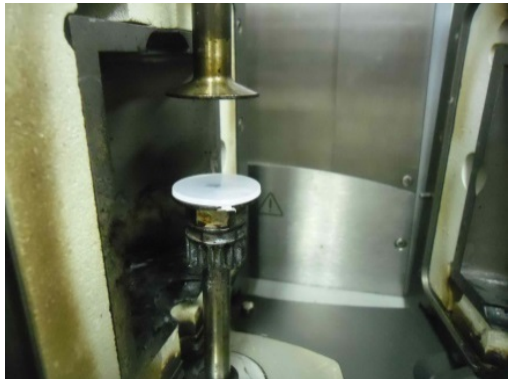

(a)

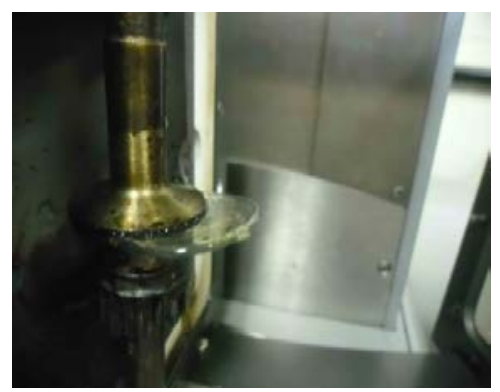

(b)

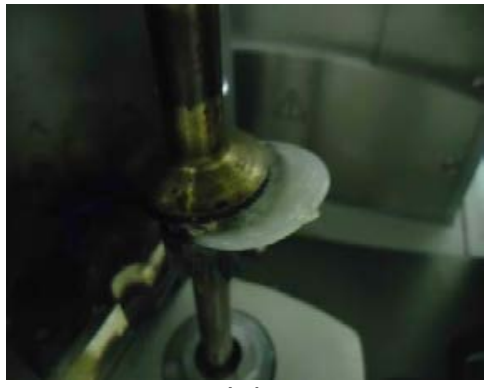

(c)

FIGURA 46 - Análise de reologia do PELBD obtido com dose de 100 kGy.

Quando o polímero é submetido a uma deformação cíclica em cisalhamento (oscilatória), surgirá uma viscosidade complexa com duas componentes, sendo a parte real correspondente à contribuição elástica e a imaginária à contribuição viscosa

Nos ensaios de varredura de deformação determinou-se a deformação de cisalhamento corresponde a região de viscoelasticidade linear de $10 \%$ para todas as amostras. O fato do módulo de armazenamento G' ser menor que o módulo de perda G" indica uma menor deformação elástica e maior deformação viscosa ${ }^{(90)}$

Logo na FIG. 47, os PELBD i irradiados apresentam tendência de material viscoso. Nas propriedades viscoelásticas no estado fundido, pode-se observar que o G' e G" também variam com o peso molecular e com a DPM. Na FIG. 47 está identificado o comportamento do peso molecular (PM) e a sua distribuição de peso molecular (DPM) por meio do cruzamento entre as curvas G' e G" (72). Sempre tem que se ter em mente que na irradiação temos os processos de cisão e reticulação ocorrendo simultaneamente 

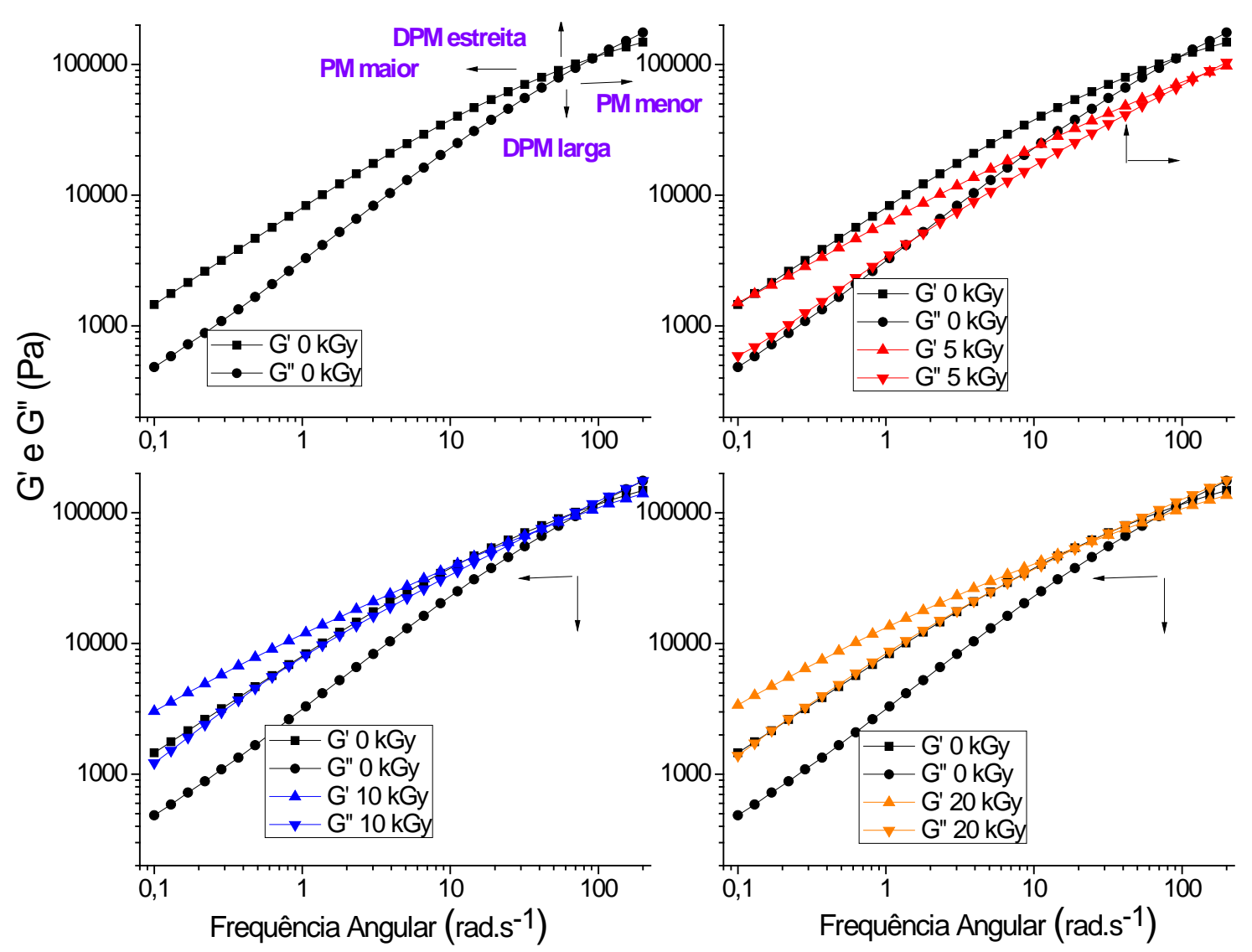

FIGURA 47 - Módulos de cisalhamento (G 'e G") em função da frequência.

Considerando os $P E L B D_{i}$ com razão entre as curvas $G^{\prime} / G^{\prime \prime}$ igual a 1 , obtiveram-se como resultados as frequências angulares de G'/G" nas diversas doses apresentadas na FIG. 48. O PELBD $i$ irradiado com dose de 5 kGy, teve uma frequência angular superior à frequência do $P E L B D_{i}$ não irradiado indicando menor PM (peso molecular) e DPM (distribuição do peso molecular) mais estreita. Enquanto que nas amostras irradiadas com doses de 10 e 20 kGy obtiveram-se frequências angulares menores que a do $P E L B D_{i}$ não irradiado indicando maior PM e DPM mais larga (FIG. 47 e FIG. 48). 


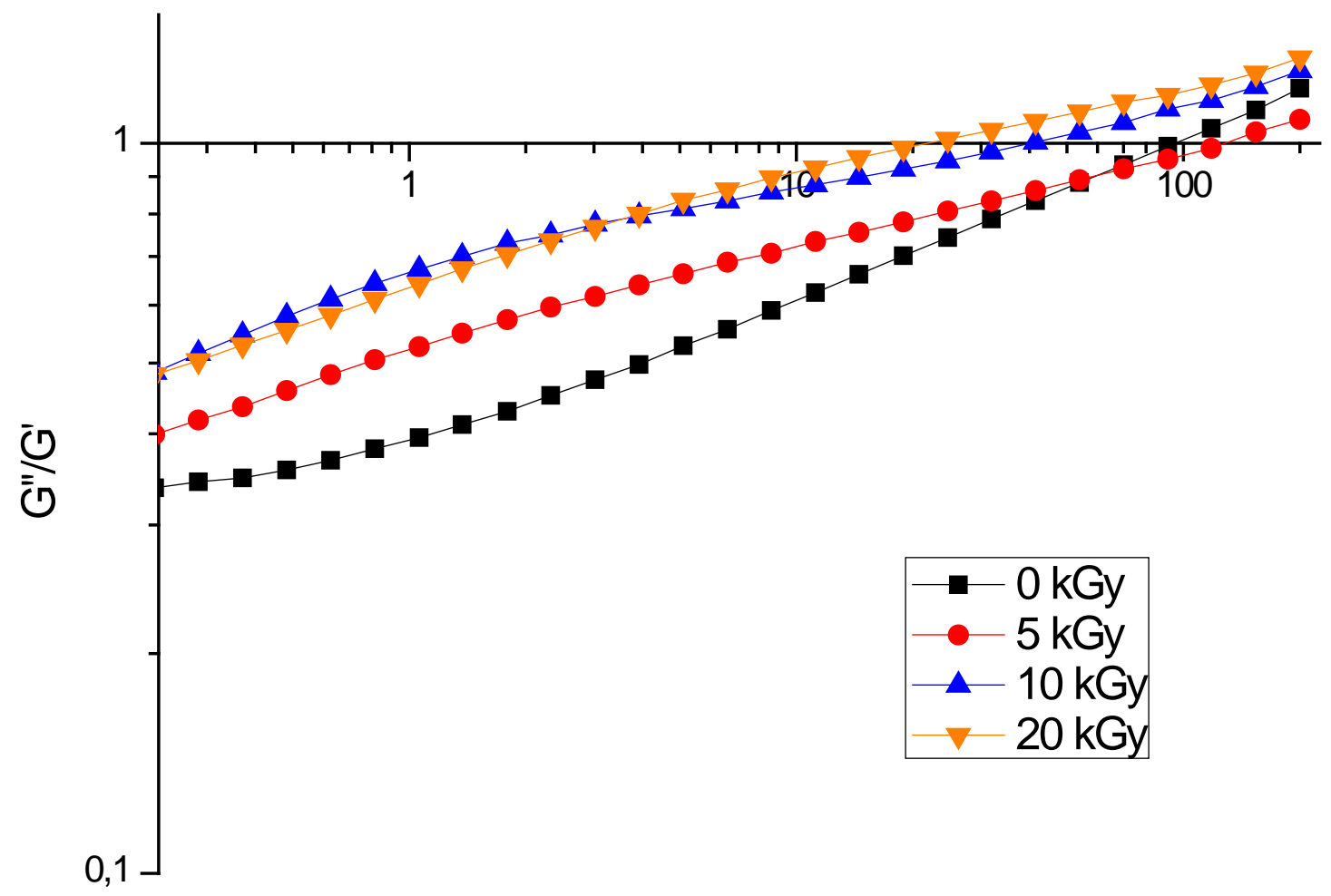

FIGURA 48 - Gráfico da Razão entre as curvas G" e G'.

Em seguida calculou-se a variação da frequência angular (FIG. 49) onde percebe-se que em doses acima de $10 \mathrm{kGy}$ os $P E L B D_{i}$ apresentam maior tendência a reticulação. 


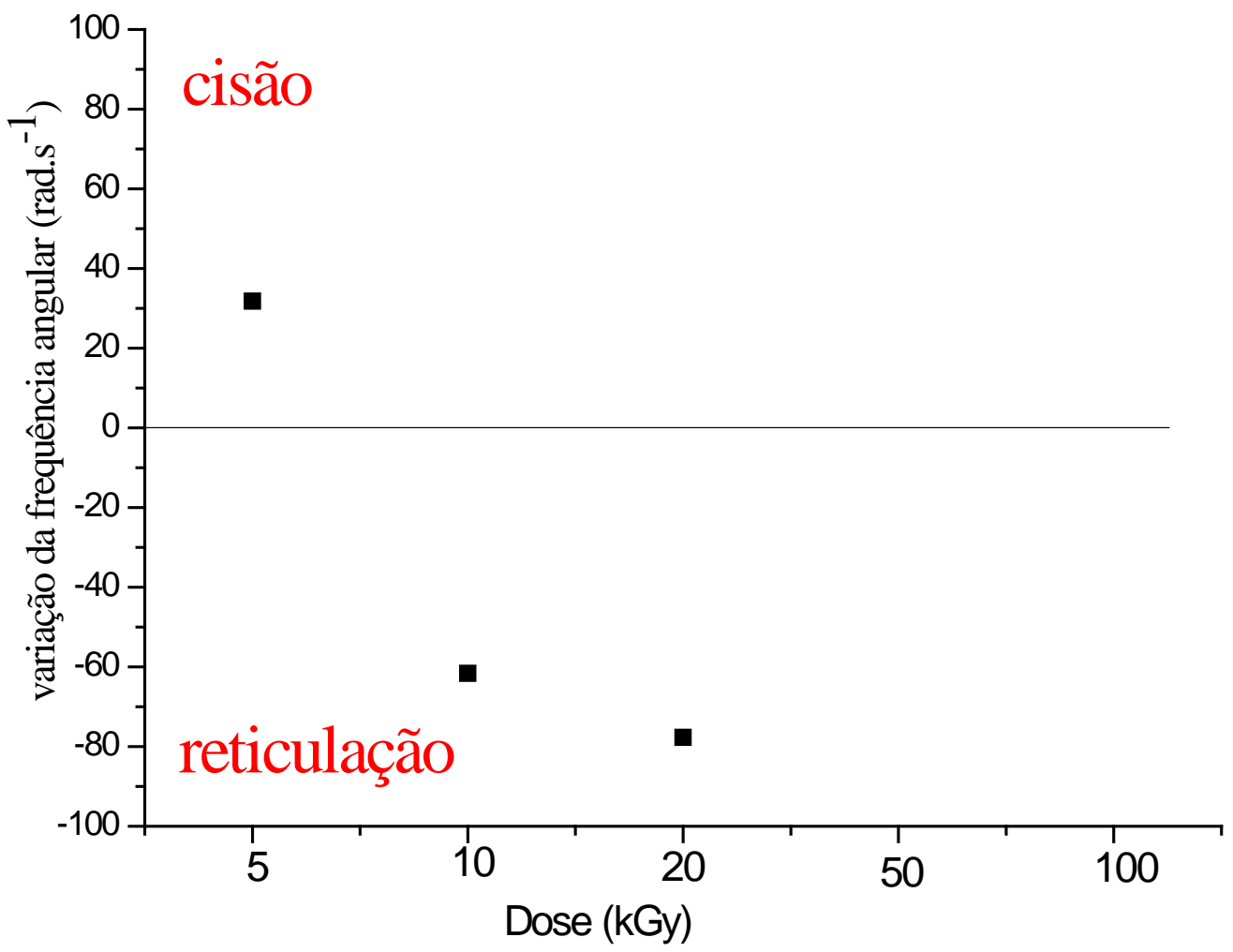

FIGURA 49 - Variação da frequência angular em função da dose de radiação.

Quando o $P E L B D_{i}$ é irradiado na presença de ar aumenta-se a viscosidade complexa (FIG. 50) em relação ao $P E L B D_{i}$, sendo este um comportamento reológico em regime permanente. Observa-se que o $\left|\eta^{*}\right|$ em função da taxa de cisalhamento aumenta com o aumento de doses de radiação. 


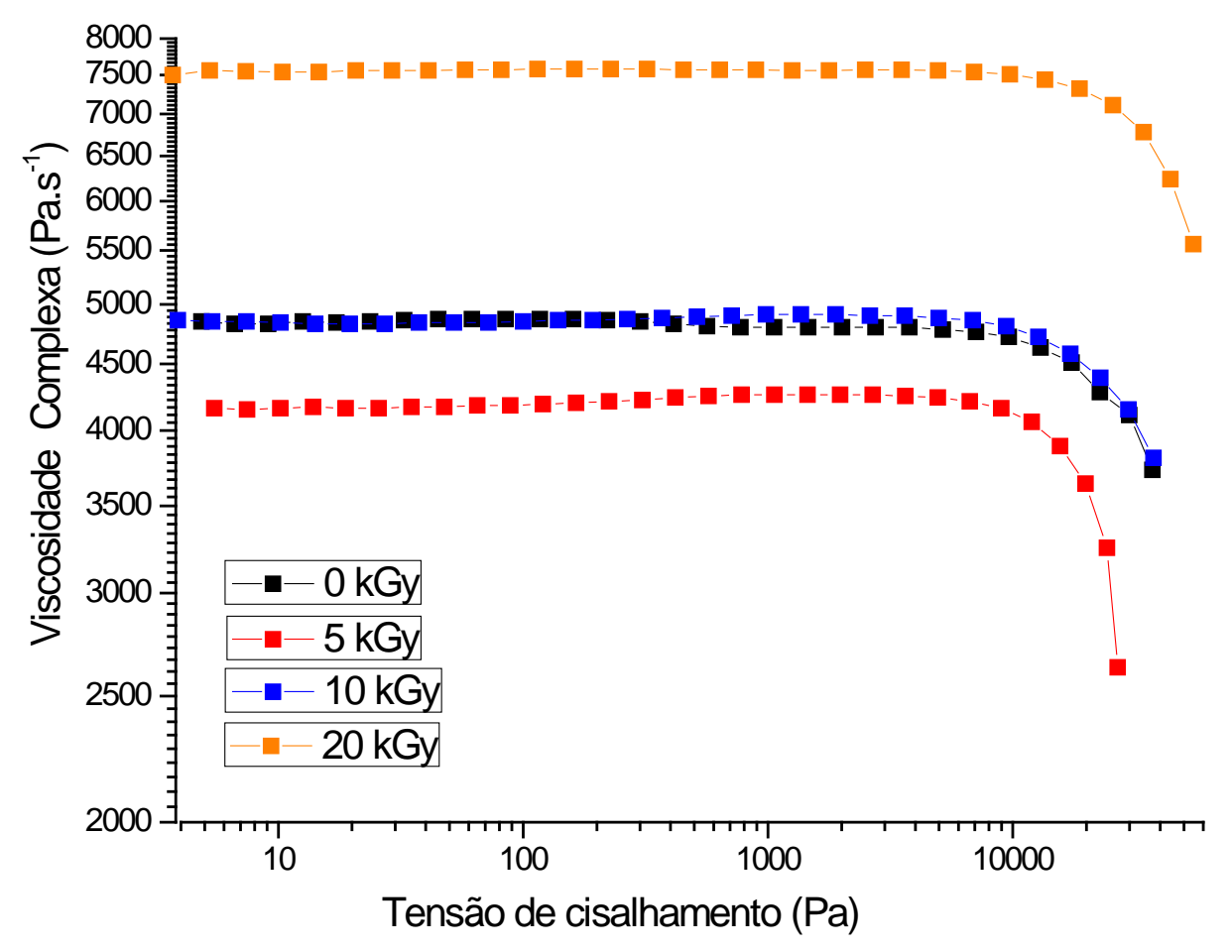

FIGURA 50 - Viscosidade complexa em função da tensão de cisalhamento.

As curvas da FIG. 51 indicam o comportamento reológico em regime oscilatório. À medida que aumenta a dose de radiação há uma tendência a um aumento no valor da viscosidade complexa a baixas frequências. Entretanto, a partir da frequência de 10 rad. $\mathrm{s}^{-1}$ é possível verificar que para todos os sistemas a viscosidade complexa diminui com o aumento da frequência e se aproxima do $\mathrm{PELBD}_{i}$ não irradiado em frequências elevadas.

Considera-se que esses valores de viscosidade complexa estão relacionados com os valores de IF que são determinados por um balanço entre as massas moleculares, distribuição de massa molecular e ramificações.

Apesar do $\mathrm{PELBD}_{\mathrm{i}}$ irradiado com $20 \mathrm{kGy}$ possuir maior massa molecular e menor valor de IF em relação ao $\mathrm{PELBD}_{i}$ não irradiado, ambos tiveram valores intermediários de viscosidade complexa comparativamente aos outros. Postula-se que essa proximidade de valores tenha sido ocasionado pelos efeitos da estrutura molecular. 


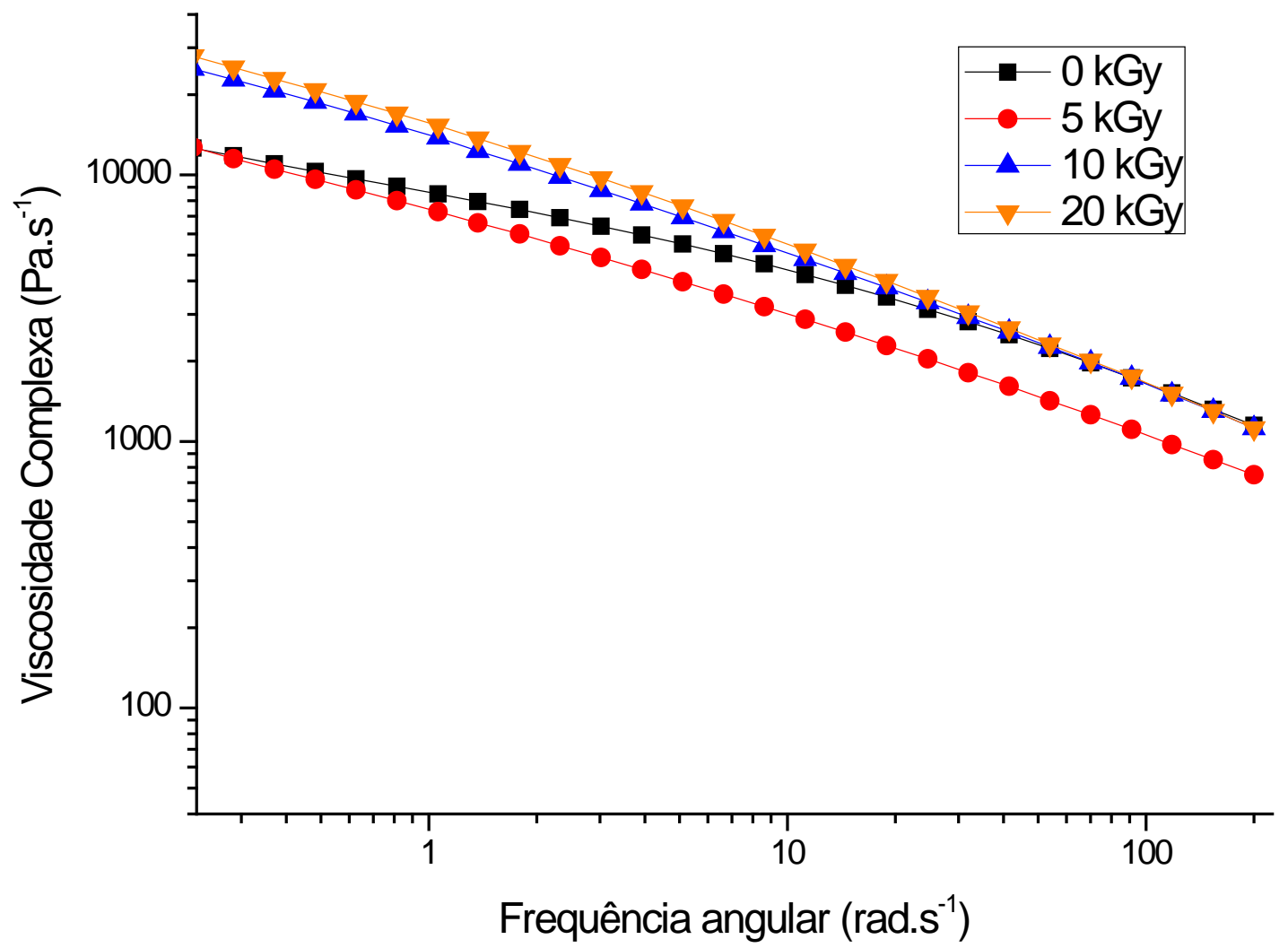

FIGURA 51 - Viscosidade complexa em função da frequência do $P E L B D_{i}$ não irradiado e irradiado. 


\subsubsection{Ensaios mecânicos}

A FIG. 52 apresenta as curvas de tensão (MPa) versus deformação (\%) dos 10 corpos de prova utilizados para cada dose de radiação.
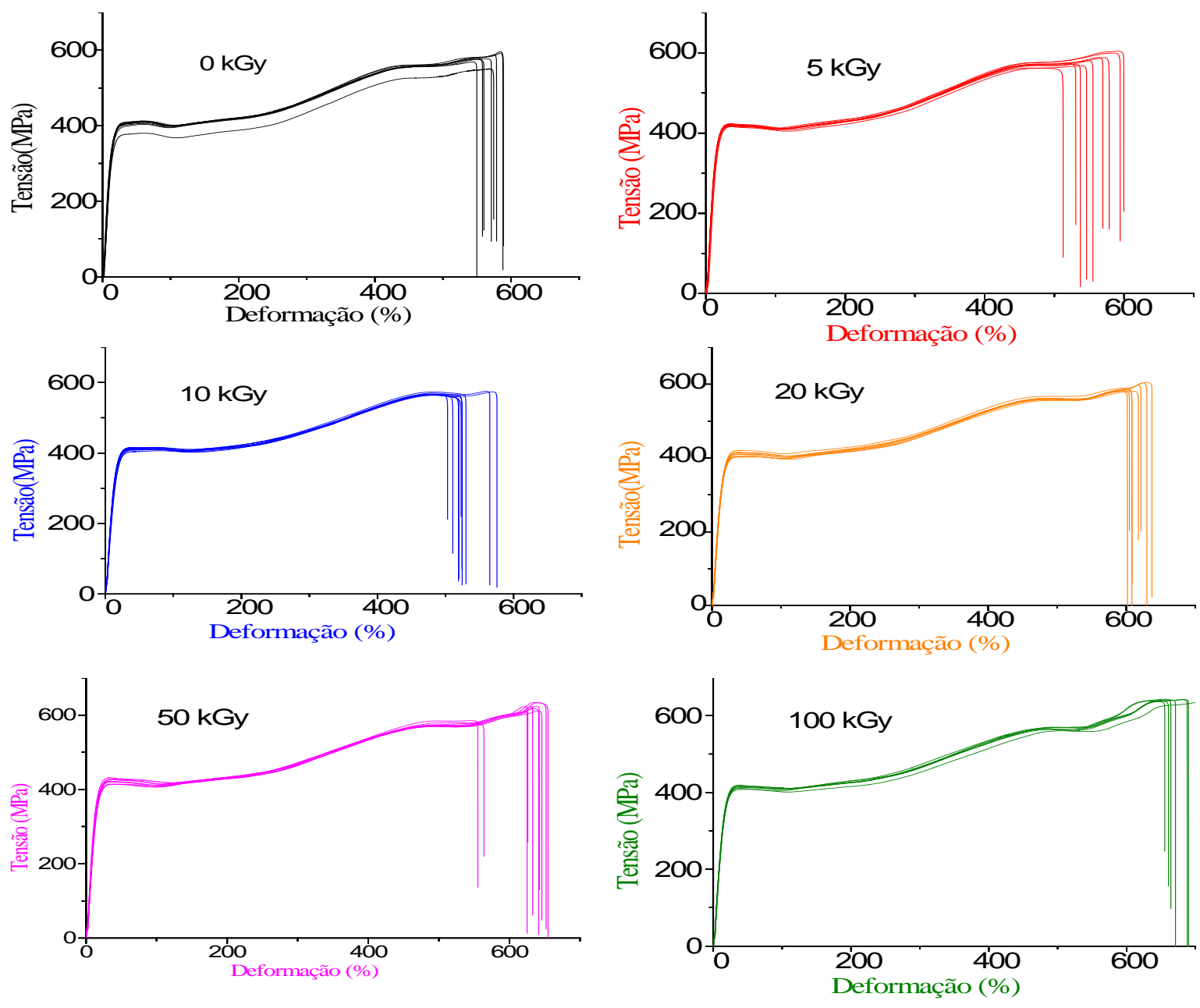

FIGURA 52- Resultado de teste de tração, força em função do tempo para $P E L B D_{i}$ não irradiado e irradiado.

Na FIG. 53 (a) observa-se que não há variações acentuadas na tensão de ruptura entre o $P E L B D_{i}$ não irradiado e os $P E L B D_{i}$ irradiados com baixas doses de radiação, mas com o aumento da dose para 50 e 100 kGy verifica-se aumento da tensão o que indica maior reticulação. Por menor que seja a sua concentração, as ligações cruzadas inibem o escoamento das moléculas. Assim como o grau de cristalinidade, os emaranhamentos restringem a movimentação molecular. 
Entretanto na FIG. 53 (b) observa-se que houve uma diminuição da deformação do material irradiado se comparado com $P E L B D_{i}$ não irradiado, 0 $P E L B D_{i}$ irradiado está mais rígido.

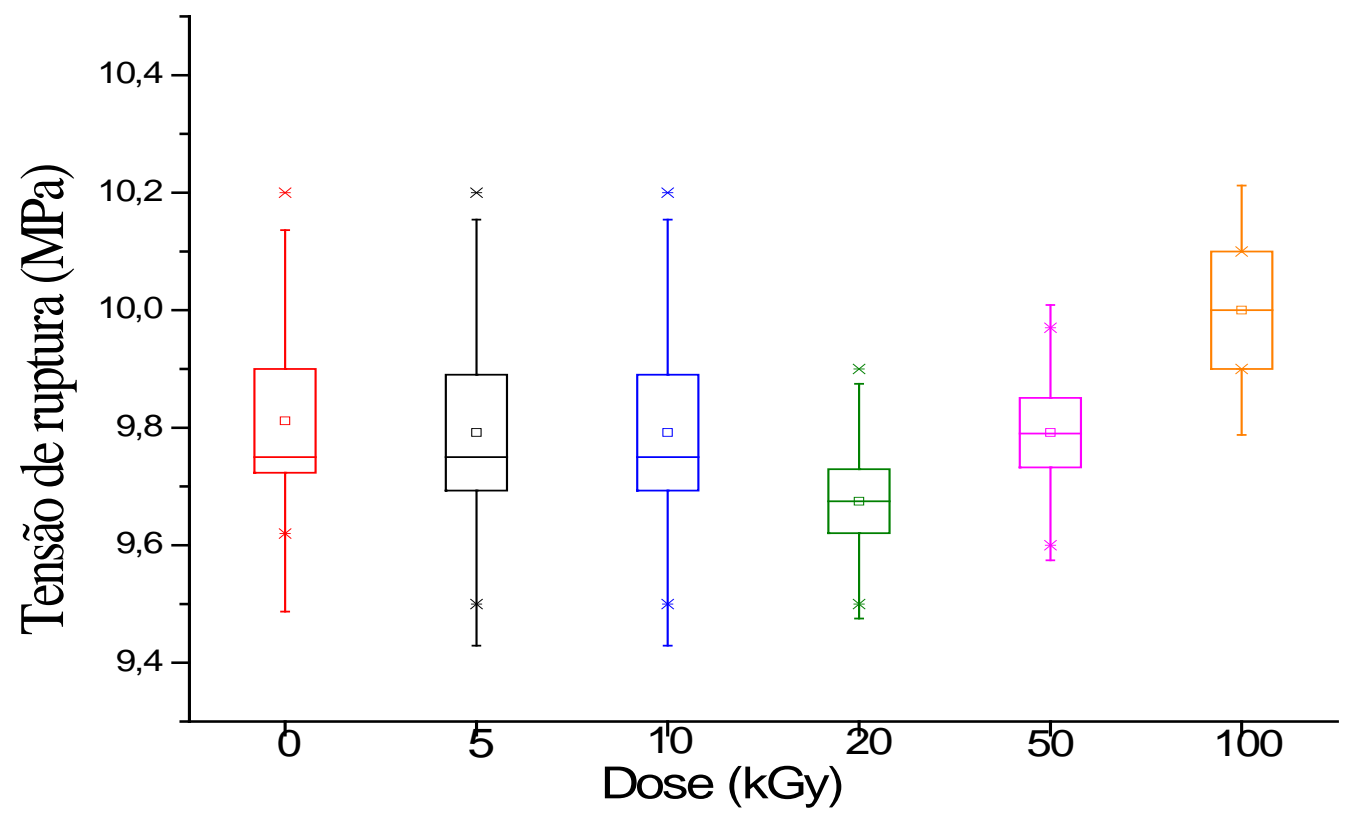

(a)

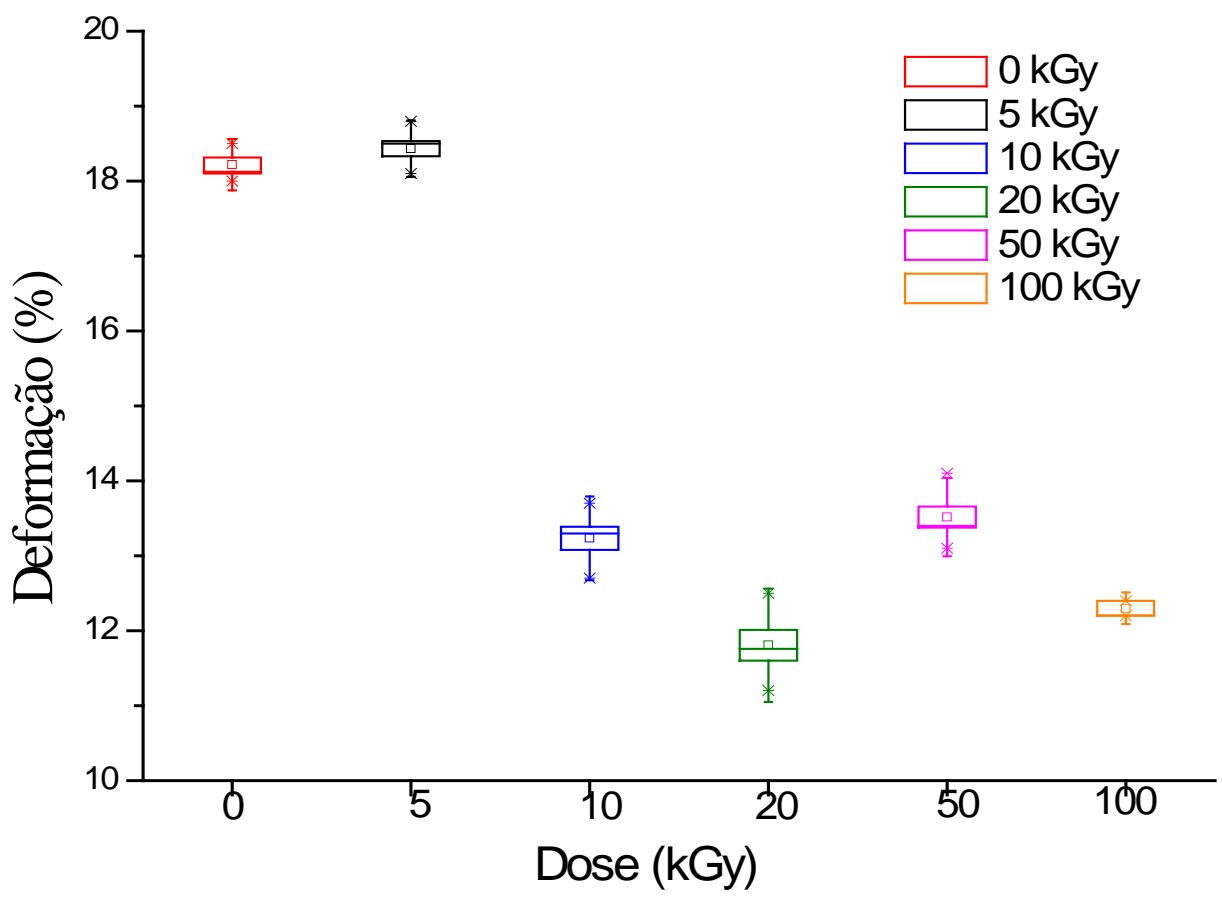

(b)

FIGURA 53 - Tensão de ruptura e Deformação do $P E L B D_{i}$ não irradiado e irradiado em função das doses de radiação. 


\section{CONCLUSÃO}

Os efeitos da irradiação como cisão e reticulação citados na literatura foram comprovados experimentalmente. Esses resultados indicaram que houve mudanças nas propriedades desse material para todas as doses de irradiação.

Os ensaios indicaram preferencialmente a ocorrência de cisão nas doses de 5 e 10 kGy identificado pelo índice de fluidez e baixa formação de gel.

Por meio do FTIR detectou-se a presença de duplas ligações em amostras injetadas. E a presença de carbonila nas amostras irradiadas com doses de 50 e 100 kGy.

DSC e DRX identificou-se uma diminuição do grau de cristalinidade obtendo como resultado valores compatíveis entre si, menos para a dose de 100 kGy.

As amostras irradiadas com doses de 5 e 10 kGy se decompõem em temperaturas mais baixas em relação ao $P E L B D_{i}$ (tendência a cisão). As irradiadas com doses de 50 e 100 kGy se decompõem em temperaturas mais elevadas em relação ao $\mathrm{PELBD}_{\mathrm{i}}$ (tendência a reticular).

Nos testes de reometria de placas paralelas confirmou-se a dificuldade do polímero irradiado em fundir e fluir, ao indicar um aumento da viscosidade à medida que se aumenta a dose de radiação. Foram evidentes os efeitos de reticulação na aparência da amostra a partir da dose de 20 kGy.

Nos testes de reometria de placas paralelas indicaram aumento da viscosidade à medida que se aumenta a dose de radiação, aumento do peso molecular e diminuição da DPM na dose de 10, 20 kGy. 
Constatou-se nos ensaios mecânicos que o PELBD ${ }_{i}$ irradiado tornou-se mais fragilizado.

As indústrias de esterilizações e transformações podem ter um conhecimento prévio dos possíveis efeitos da radiação gama no $\operatorname{PELBD}_{i}$ e assim escolher o que melhor atende a seus critérios de produção. 


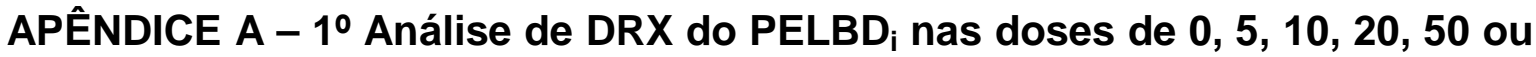
100 kGy.

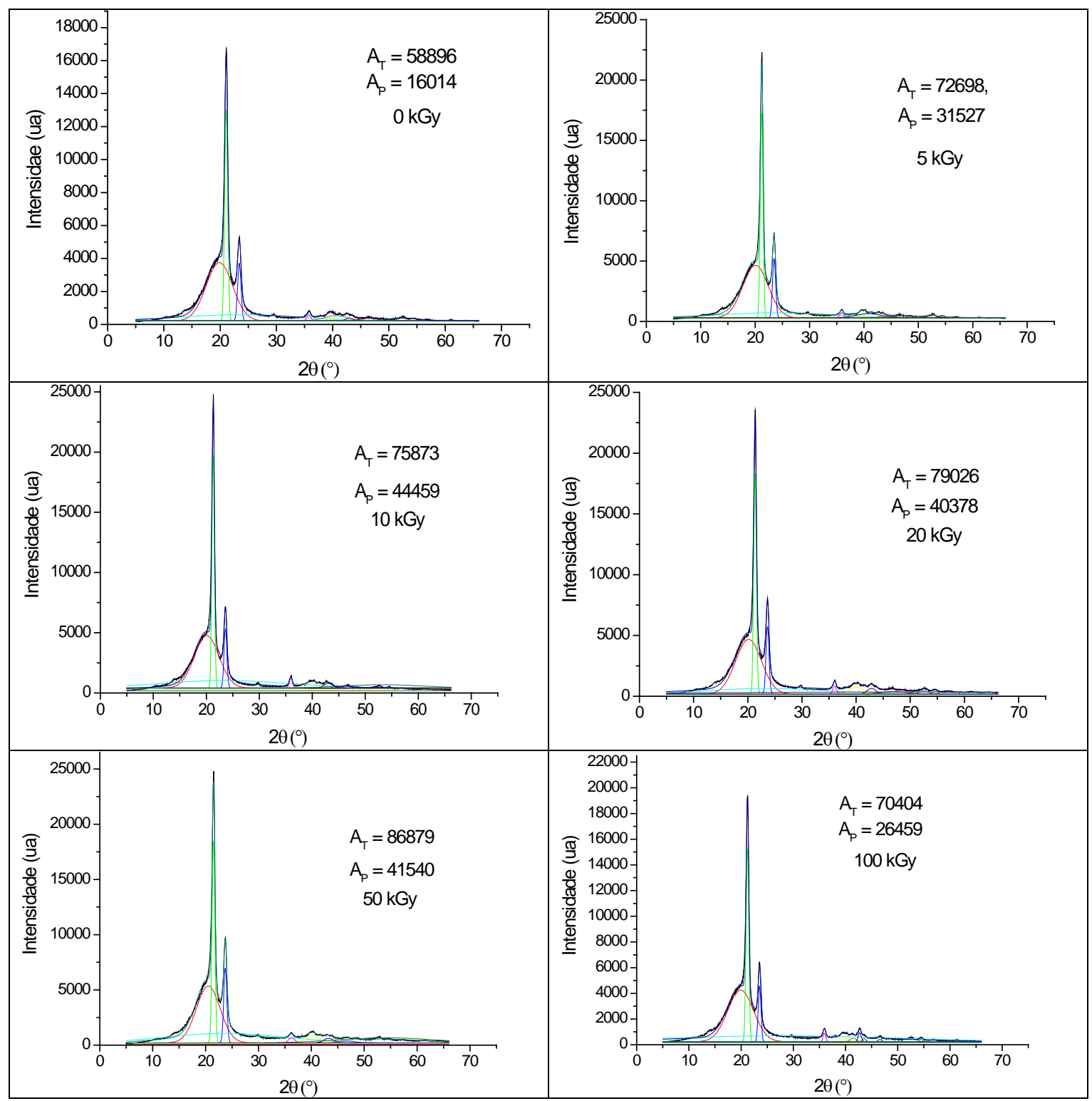


APÊNDICE B - $2^{\circ}$ Análise de DRX do PELBD $_{i}$ nas doses de $0,5,10,20,50$ ou 100 kGy.

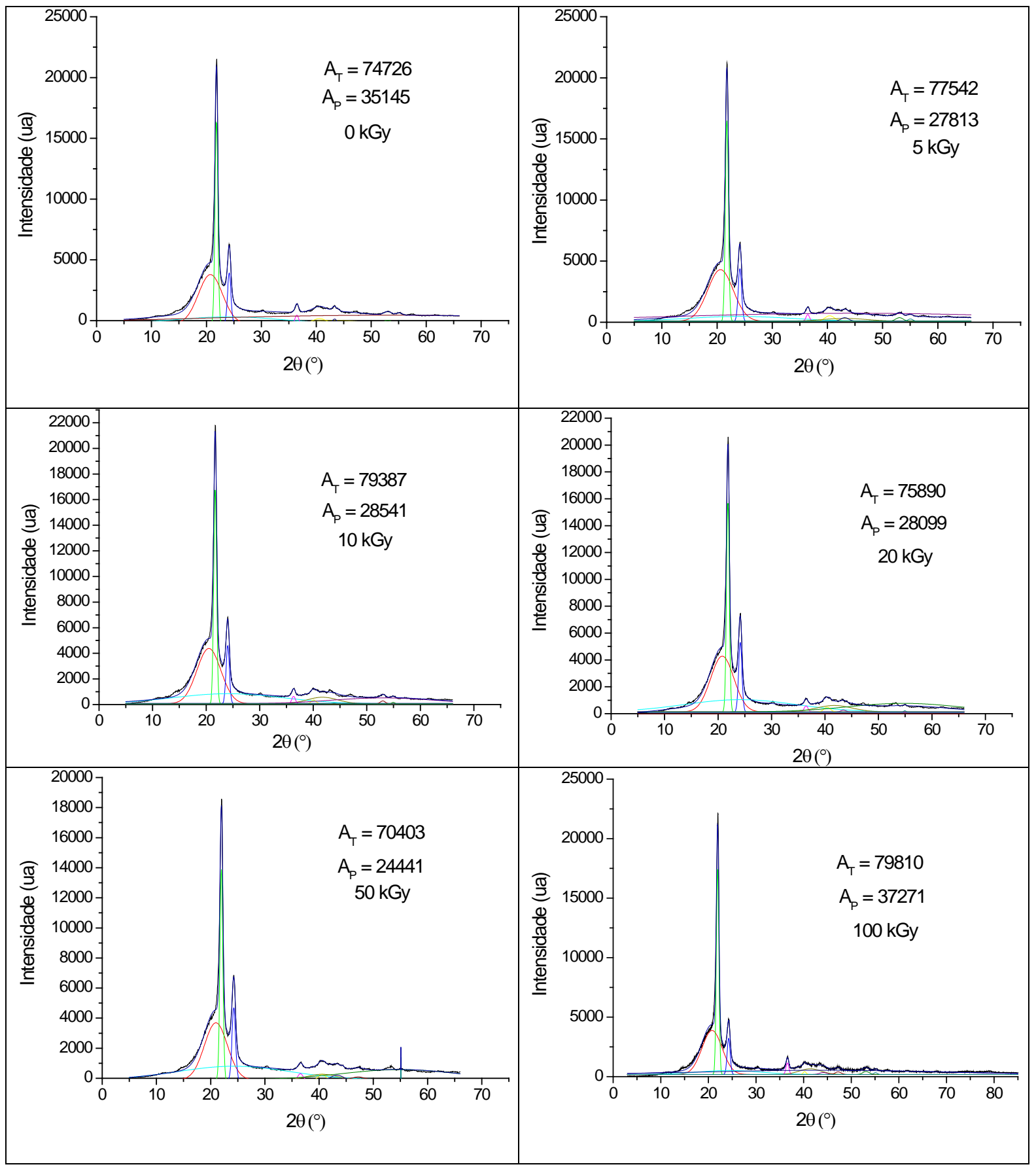


APÊNDICE C - $3^{\circ}$ Análise de DRX do PELBD ${ }_{i}$ nas doses de $0,5,10,20,50$ ou 100 kGy.

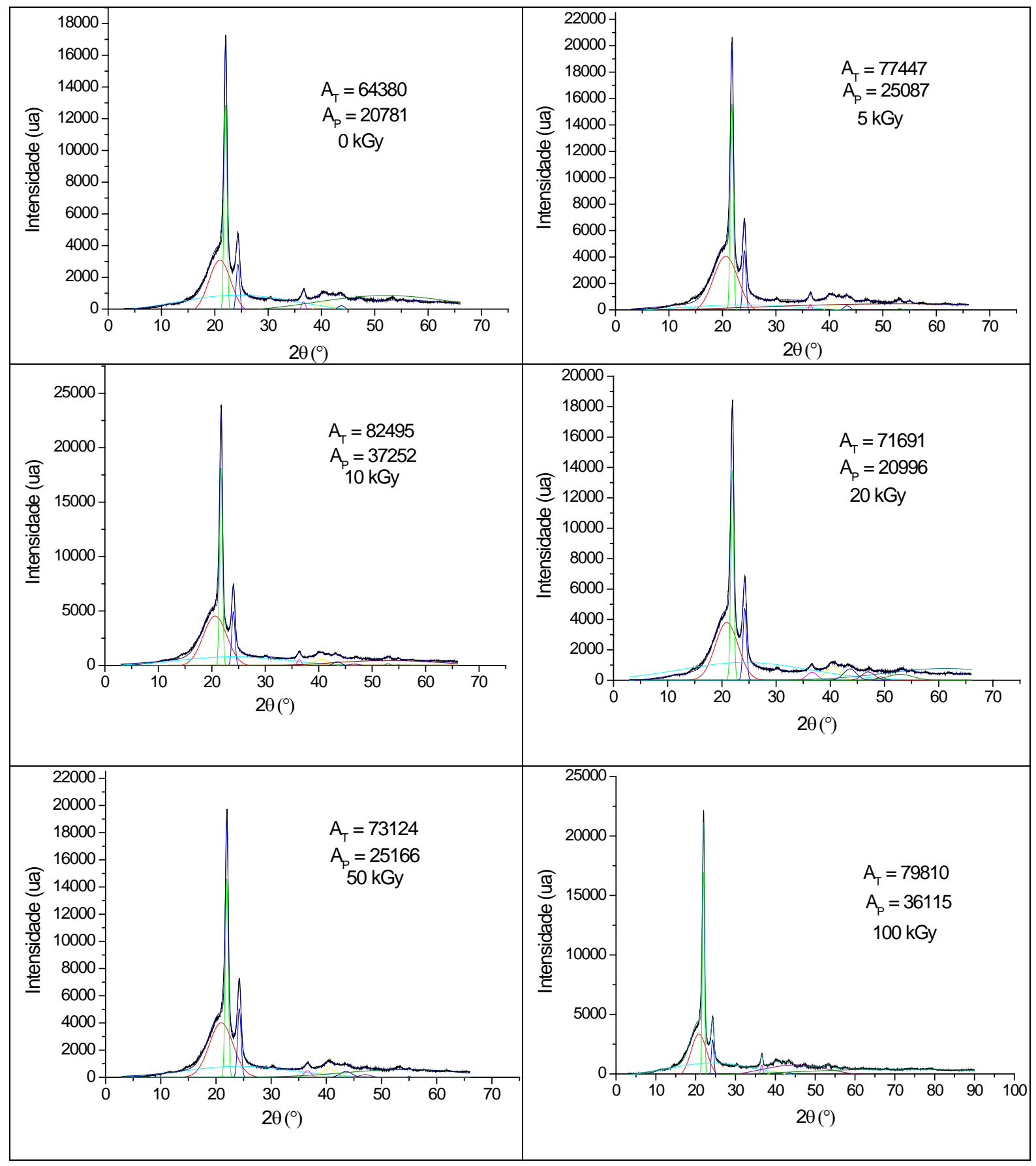




\section{REFERÊNCIAS BIBLIOGRÁFICAS}

1. CANEVAROLO, S, V. Ciência dos polímeros. Um texto básico para tecnólogos e engenheiros. São Paulo, S.P. : Artliber, 2002.

2. MICHAELI, W.; GREIF, H.; KAUFMANN, H.; VOSSEBURGER, F. J. Tecnologia dos plásticos. São Paulo, S.P. : Edgard Blucher LTDA, 2010.

3. LUCAS, E. F., SOARES, B. G.; MONTEIRO, E. E. C. Caracterização de polímeros: determinação de peso molecular e análise térmica. Rio de Janeiro, R.J.: Editora e-papers Serviços Editoriais Ltda, 2001.

4. COUTINHO, F. M. B.; MELLO, I. L.; SANTA MARIA, L. C. Polietileno: principais tipos, propriedades e aplicações. Polímeros: Ciência e Tecnologia, v. 13, n.1, p. 1-13,2003.

5. HARADA, J. Moldes para injeção de termoplásticos projetos e princípios básicos, São Paulo, S.P. : Artilber, 2004.

6. QUENTAL, A. C.; HANAMOTO, L. S.; FELISBERTI, M. I. Caracterização de polietilenos lineares de baixa densidade II. Fracionamento por cristalização isotérmica a partir do estado fundido. Polímeros: Ciência e tecnologia, v.15, n. 4, p. 281-288, 2005.

7. FERREIRA, L. M. Preparação de suportes poliméricos com aplicação prática na indústria, utilizando a técnica de copolimerização de enxerto por radiação gama. 1994. Tese (Doutorado) - faculdade de ciências, Lisboa.

8. CLEGG, D. W.; COLLYER, A. A. Irradiation Effects on Polymers. New York, N.Y. : Ed, 1991.

9. CHAPIRO, A. Radiation chemistry of polymeric systems. New York, N.Y. : Mark, H. and Marvell, C. S. (Eds), 1962.

10. SKIENS, W. E. Sterilizing radiation effects on selected polymers. Radiat. Phys. Chem, v. 15, p. 47-57, 1980.

11. CBE/EMBRARAD,

1978.

Disponível em: <http://www.cbesa.com.br/?gclid=CO_emuTRurkCFUkS7Aodg3EAHA>. Acesso em 06 de dezembro de 2013.

12. HAJI-SAEID, M.; SAMPA, M. H. O.; CHMIELEWSKI, A. G. Radiation treatment for sterilization of packaging materials. Radiat. Phys. Chem, v.76, p. 1535-1541, 2007. 
13. PEACOCK, A. J. Handbook of polyethylene structures, properties and applications. New York, N.Y. : Copyrighted Material, 2000.

14. NOOIJEN, G. A. H. Ziegler/Natta catalysts in particle from ethylene polymerization: the effect of polymerization start-up on catalyst activity and morphology of the produced polymer. Catalysis Today, v.11, p.35-46, 1991.

15. NOOIJEN, G. A. H.; McMILLAN, F. M. The chain straighteners. London. : Macmillan Press, 1979.

16. AKCELRUD, LENI. Fundamentos da ciência dos polímeros. Barueri, S.P. : Manole, 2007.

17. SPERLING, L. H. Introduction to Physical Polymer Science. New York, N.Y. : Wiley, 1992.

18. SCIPIONI, R. B.; MAULER, R. S.; GALLAND, G. B.; QUIJADA, R. Obtenção de polietileno linear de baixa densidade utilizando catalisadores Ziegler-Natta Homogêneos e 1-hexeno como comonômero. Polímeros: Ciência e tecnologia-out/dez, p.33-39, 1994.

19. FORTE, M. C.; MIRANDA, M. S. L. ; DUPONT, J. Novas resinas produzidas com catalisadores metalocênicos. Polímeros: Ciência e Tecnologia. p. 49-60, 1996.

20. WANG, Q.; WENG, J.; FAN, Z.; FENG, L. Study on polimerization of ethylene with $\mathrm{Cp} 2 \mathrm{ZrCl} 2 /$ aluminoxanes. European Polymer Journal, v.36, p.1265-1270, 2000.

21. DOW QUÍMICA - Evolução dos polietilenos para as resinas de tecnologia insite, PE. Disponível em:<http://www.dow.com/brasil/>.Acesso em 02 de fevereiro de 2013.

22. JOHNSON, L. K.; KILLIAN, C. M.; BROOKHART, M.; New Pb (II) and Ni II) Based Catalysts for Polymerization of Ethylene and alfa-Olefins. Journal of American Chemical Society, v.117, 1995.

23.BRASKEM - Disponível em:<http://www.braskem.com.br/site.aspx/Comoe-Produzido>. Acesso em 04 de maio de 2012.

24. BUTLER, T. I. WAGNER J. R. Multilayer Flexible Packaging. 2009.

25.SMITH, W. F.; HASHEMI, J. Fundamentos de Engenharia e Ciências dos Materiais. São Paulo, S.P. : Mc Graw Hill, 2010. 
26. CONSTANTINO, M. G. Química Orgânica - Curso Básico Universitário. São Paulo, S.P. : LTC, 2005.

27. YOUNG, R. E., LOVELLI, P. A Introduction to Polymers. London : CRC Press, 1991.

28. L'ANNUNZIATA, M. F. Handbook of Radioactivity Analysis. USA, 2012.

29. L'ANNUNZIATA, M. F. Radioactivity introduction and history. Amsterdam : Elsevier, 2007.

30. MAKUUCHI, K.; CHENG, S. Radiation processing of polymer materials and its industrial aplications. Canada :JOHN WILEY SONS INC, 2012.

31. SPINKS, J. W. T. WOODS, R. J. An introduction to radiation chemistry. New York, N. Y. : John Wiley Sons, 1990.

32. O'DONNELL, L. H.; SANGSTER, D. F. Principles of radiation chemistry. London. : GBR Edward Arnold, 1970.

33. Mc LAUGHLIN, W. L.; BOYD, A. W. CHADWICK, K. H.; Mc DONALD, J. C.; MILLER, A. Dosimetry for Radiation Processing. London : Taylor and Francis, 1989.

34. FIRESTONE, R.B.; SHIRLEY, V. S. Table of Isotopes. New York, N.Y. : John Wiley and Sons, Inc, 1996.

35. LEDERER, C. M.; SHIRLEY, V. S. Table of Isotopes. New York, N.Y. : John Wiley and Sons, Inc., 1978.

36. Polymer Cross-Linking Information . 2003. http://www.r-scc.com/pdf/techelectronics.pdf.

37.RIMDUSIT, S.; SOMSAENG, K.; KEWSUWAN, P.; JUBSILP, C.; TIPTIPAKORN, S. Comparison of gamma radiation crosslinking and chemical crosslinking on properties of methylcellulose hydrogel. Engineering Journal, vol. 16, p.15-28, 2012.

38. PESSANHA, A. B.; ROCHA, M. C. G. Introdução de ligações cruzadas no LLDPE através de processo de extrusão reativa de graftização do viniltrimetóxi-silano (VTMS) na cadeia polimérica: efeito das condições de processamento e do sistema reacional. Polímero, v.21, n.1 , p.53-58, 2011.

39. LACHTERMACHER, M. G. e RUDIN, A. Processo reativo do polietileno linear de baixa densidade na extrusora de dupla rosca I Efeito do tratamento de peróxdo na extrutura molecular. Polímeros: Ciencia e Tecnologia, v.4, n.1, p.32-40, 1994. 
40.SUAREZ, J. C. M.; MONTEIRO, E. E. C.; MANO, E. B. Study of the effect of gamma irradiation on polyolefins- low-density polyethylene. Polymer Degradation and Stability, v.75, n.1, p.143-151, 2002.

41. CLOUGH, R. L.; GILLEN, K. T.; MALONE, G. M.; WALLACE, J. S. Color formation in irradiated polymers. Radiat. Phys. Chem, v.48, n.5 , p.583594, 1996.

42. WONG S. H.; SUNSHINE, I. Handbook of Analytical Therapeutic drug monitoring and toxicology. Boca Raton, New York, London, Tokyo : CRC Press, 1997.

43. WERF. Disinfection Comparison of UV Irradiation to Chlorination: Guidance for Achieving Optimal UV Performance. EUA : Project 91-WWD-1, 1995.

44. MUKHERJEE, R. N. Radiation : a means of sterilization. IAEA Bulletin, v.17, p. 28-37, 1975.

45. FILHO, T. L.; TEIXEIRA, L. J. Q.; ROCHA, C. T.; FERREIRA, G. A. M.; SOUZA, M. C. Energia ionizante na conservação de alimentos: revisão. B.CEPPA, v. 30, n.2, p.243-254, 2012.

46. HERNANDES, N. K.; VITAL, H. C.; SABAA SRUR, A. U. O. Irradiação de alimentos: vantagens e limitações. Boletim SBCTA, v.37, n.2, p.154-159, 2003.

47. Disinfection and sterilization infection control guidelines, CHRISP, 2006.

48. GORESLINE, H. E. Training manual on food irradiation technology and techniques. Rome, Italy : International atomic energy agency, 1997.

49. ORGANIZATION, WORLD HEALTH, AGENCY, INTERNATIONAL ATOMIC ENERGY AND NATIONS, FOOD AND AGRICULTURE ORGANIZATION OF THE UNITED. High-dose irradiation: wholesomeness of food irradiation with doses above $10 \mathrm{kGy}$. Geneva : Report of a Joint FAO/IAEAMHO Expert Committee. World Health Organization, 1999.

50. FDA 21 CFR 179, 45 (USFDA, 2001) e norma 21 CFR 179,45 d.

51. TETRA PAK. Disponível em:<http://www.tetrapak.com/br/reciclagem/ciclode-vida-da-embalagem/matéria-prima> Acesso em 03 de dezembro de 2012.

52. SOLUPACK. Sistemas de embalagens. Disponível em:<http://www.solupack.com.br/SolufilmX.aspx> Acesso em 02 de janeiro de 2013. 
53. ROBERTSON, G. L. Food Packaging Principles and Practice. 3 ed. United States, U.S. : CRC Press, 2013.

54.BRASIL, Ministério da Saúde. Manual de processamento de artigos e superfícies em estabelecimentos de saúde. Brasília, 1994.

55. CBE, Esterilização por radiação gama em embalagens farmacêuticas, veterinárias e cosméticas, Revista controle de contaminação, 2012.

56. KURTZ, S. M. UHMWPE Biomaterials Handbook. USA, 2009.

57. BRASIL, Ministério da Saúde. Orientações gerais para central de esterilização. Coordenação Geral das Unidades Hospitalares Próprias do Rio de Janeiro, 2001.

58. WINPAK. Products. Health Care Packaging. Medical Packaging. Disponível em: <http://www.wipak.com/medical/index.html> Acesso em 05 de janeiro de 2013.

59. BUENO, P. H. S. Efeito da radiação gama e do tipo de embalagem sobre as características microbiológicas, físico-químicas e sensoriais de peito de frango refrigerado. 2008. Dissertação (Mestrado) Universidade Federal de Minas Gerais, Belo Horizonte.

60. ALEXANDRE, F. A.; FARIA, A. F.; CARDOSO, C. F. Avaliação da eficiência da radiação ultravioleta na esterilização de embalagens plásticas. Ciênc. agrotec., v.32, n.5, p.1524-1530, 2008.

61.ROCHA, M. C. G.; COUTINHO, F. M. B.; BALKE, S. Índice de Fluidez: Uma Variável de Controle de Processos de Degradação Controlada. de Polipropileno por Extrusão Reativa, Polímeros: Ciencia e Tecnologiajul/set, p.33-37,1994.

62. ASTM D1238-04 - Standard Test for Melt Flow Rates of Thermoplastics by Extrusion Plastometer. (37)

63. RENFREW, A.; MORGAN, P. Polythene The technology and uses of ethylene polymers. London. : I Liffe e Sons limited, 1957.

64. ASTM D2765-01 - Standard test methods for determination of gel content and swell ratio of crosslinked ethylene plastics.

65. SMITH, B. C. Fundamentals of Fourier transform infrared spectroscopy, United States of America, U.S.A.: CRC Press, 1996.

66. HOBOKEN, N.J. Caracterization and Analysis of Polymers. : A John Wiley, INC, Publication- Willy- Interscience, 2008. 
67. HUMMEL, D. O. Atlas of Polymer and Plastics Analysis.: $3^{\text {rd }}$ ed., v.1, 1996.

68. ASTM D3418-08 - Standard Test Method for Transition Temperatures and Enthalpies of Fusion and Crystallization of Polymers by Differential Scanning Calorimetry.

69. PADILHA, A. F. Materiais de engenharia microestrutura e propriedades. Curitiba P.R. : MCT Produções Gráficas, 2000.

70. ASTM D 6370-99 - Standard Test Method for Rubber - Compositional Analysis by Thermogravimetry (TGA), (2009).

71. CANEVAROLO, S. V. Técnicas de caracterização de polímeros, São Paulo, S.P. : Artliber, 2003.

72. BRETAS, R. E. S.; D`AVILA, M. A. Reologia de polímeros fundidos. São Carlos, S.P. : Editora da UFSCar FAPESP, 2000.

73. BASSO, G. M.; PAULIN, P. I.; BRETAS, R. E. S.; BERNARDI, A. Correlação entre propriedades reológicas e ópticas de filmes tubulares de polietileno linear de baixa densidade com diferentes distribuições de ramificações curtas. Polímeros: Ciência e Tecnologia, v.16, n.2, 2006.

74. GUERRINI, L. M.; PAULIN, P. I.; BRETAS, R. E. S, BERNANDI. A. Correlação entre as propriedades reológicas, óticas e a morfologia de filmes soprados de LLDPE/LDPE. Polímeros: Ciência e Tecnologia, v.14, n.1, 2004.

75. ASTM D 638-03 - Standard Test Method for Tensile Properties of Plastics ${ }^{1}$.

76. PAZ, R. A.; LEITE; D., A. M.; ARAUJO, E.M.; MELO, T.J.A.; PESSAN, L.A. Avaliação do comportamento térmico por DSC na região da pele e do núcleo de amostras injetadas de nanocompositos de poliamida 6/argila organofilica. Polímeros, v.20, n.4, p. 258-263, 2010.

77.DE PAOLI, M. A.; Degradação e Estabilização de Polímeros.: Chemkeys, 2008.

78. KRISTON, I. Some aspects of the degradation and stabilization of Phillips type polyethylene. Budapest.: Ph. D. Thesis, University of Technology and Economics, 2010.

79.BRASKEM - Boletins Técnicos: Disponível em: <http://www.braskem.com.br/>. Acesso em 05 de março de 2013.

80.SAWYER, L. C., GRUBB, D. T.; MEYERS, G. F. Polymers Microscopy. : Springer, 2008. 
81.WONG, A. C. -Y. Factors affecting extrudate swell and melt flow rate. Journal of Materials Processing Technology, v.79, p.163-169,1998.

82. FERRETO, H. F. R. ; OLIVEIRA, A. C. F. ; LIMA, L. F. C. P ; PARRA, D. F.; LUGÃO. A. B. . Thermal, tensile and rheological properties of linear low density polyethylene (LLDPE) irradiated by gamma-ray in different atmospheres. Radiat. Phys. Chem., v.81, n.8, p.958-961, 2012.

83. FERRETO, H. F. R. ; OLIVEIRA, A. C. F. ; LIMA, L. F. C. P ; PARRA, D. F.; LUGÃO. A. B. . Structural Changes in Linear Low-density Polyethylene (LLDPE) Irradiated in different atmospheres. The Polymer Processing Society, 2010, Banff Canada. Proceedings of the polymer, 2010.

84. MURTHY, N. S.; MINOR, H. General procedure for evaluating amorphous scattering and crystallinity from x-ray diffraction scans of semicrystalline polymers. Polymer Papers, v.31, p.996-1002, 1990.

85. NITTA, K.-H., TANAKA, A. Dynamic mechanical properties of metallocene catalyzed linear polyethylenes. Polymer. v.42, n.3, p.1219-1226, 2001.

86. KOLESOV, I. S., ANDROSCH, R., RADUSCH, H.-J. Effect of crystal morphology and crystallinity on the mechanical $\alpha$-and $\beta$-relaxation processes of short-chain branched polyethylene. Macromolecules, v.38, n.2, p.445-453, 2005.

87.DANCH, A., OSOBA, W., STELZER, F. On the a relaxation of the constrained amorphous phase in poly(ethylene). European Polymer Journal, v.39, n.10, p.2051-2058, 2003.

88. FERRETO, H. F. R.; Estudo da síntese de copolímero olefínico à base de politetrafluoroetileno (PTFE) por meio da enxertia induzida por radiação gama. 2006. Tese (Doutorado)- Instituto de Pesquisas Energéticas e Nucleares, São Paulo.

89. KIM, K.J., OK, Y.S e KIM, B.K. Crosslinking of polyethylene with peroxide and multifunctional monomers during extrusion. Eur. Polym. J., v.28, n.12, p.1487-1491, 1992.

90. BECKER, M. R., FORTE, M. M. C. e NETO, R. B. Preparação e avaliação térmica e reológica de misturas de PEBD/PELBD. Polímeros: Ciência e Tecnologia, v.12, n.2, p. 102-108, 2002. 